\title{
ABU GHRAIB AND THE COMMEMORATIVE VIOLENCE OF WAR TROPHY PHOTOGRAPHY
}

\author{
by \\ Joey Brooke Jakob \\ Master of Arts, University of Manitoba, Manitoba, Canada, 2008 \\ Bachelor of Arts, University of Winnipeg, Winnipeg, Canada, 2004
}

A Dissertation presented to Ryerson University and York University

in partial fulfilment of the requirements for the degree of

Doctor of Philosophy

in the joint program in

Communication and Culture

Toronto, Ontario, Canada, 2017

(CJoey Brooke Jakob 2017 


\section{AUTHOR'S DECLARATION}

\section{AUTHOR'S DECLARATION FOR ELECTRONIC SUBMISSION OF A DISSERTATION}

I hereby declare that I am the sole author of this dissertation. This is a true copy of the dissertation, including any required final revisions, as accepted by my examiners.

I authorize Ryerson University to lend this dissertation to other institutions or individuals for the purpose of scholarly research.

I further authorize Ryerson University to reproduce this dissertation by photocopying or by other means, in total or in part, at the request of other institutions or individuals for the purpose of scholarly research.

I understand that my dissertation may be made electronically available to the public. 


\section{ABSTRACT \\ ABU GHRAIB AND THE COMMEMORATIVE VIOLENCE OF WAR TROPHY PHOTOGRAPHY}

\section{Joey Brooke Jakob}

\section{Doctor of Philosophy}

\section{Communication and Culture}

\section{Ryerson University and York University, 2017}

The photographs from the Abu Ghraib scandal are horrific, but they are also understandable. Simply put, the Abu Ghraib photos are purposeful compositions that highlight victory over the enemy Other in war. The photos illustrate sexual and racial violence, founded upon postcolonial narratives, but this is only a starting point for their significance. I address how meaning is made for the U.S. military personnel who took photographs of naked Iraqi detainees at Abu Ghraib, by looking backward to soldiers' photography from WWI and II, and by considering soldiers' online sharing of photographs in the present, examining roughly fifty photos total. The relationships between photographic materiality, emotional and gestural communication, and the production of cultural memory, disseminated via networked circulation, all shape how soldiers' wartime photographs come to be regarded. Employing an interdisciplinary approach, this research draws upon war photography; visual culture and communication; sociology of groups and ritual; sociology of emotion; combat histories; memory studies; and online photo sharing practices. In so considering, the Abu Ghraib photos are not unique, and are instead grouped within the greater concept of the "war trophy." I expand on this concept by defining "war trophy photography" as the entwined practices of war photography and trophy collection, rooted in ritual and group solidification. Staged to depict the violent conquering of the enemy, I argue that war trophy photography recognizes war efforts through the construction of a visual record, one that 
reproduces relations of dominance and submission. I call this representation "commemorative violence," a central concept I develop to define the war trophy photograph. In addition to grounding the Abu Ghraib photos historically, I review their visual semiotic, cultural significance, such as with the "Doing a Lynndie" meme, which features civilians gesturing in thumbs-up toward a downtrodden individual, copying the same gesture as often used in the images from Abu Ghraib, and the now defunct site "Now That's Fucked Up," which briefly allowed soldiers in 2005 to trade gruesome war trophy pictures for pornography. The conclusion reflects on war trophy photography with the topical consideration of drones, ultimately suggesting that drone warfare photos are expressionless because of the overt absence of people. 


\section{ACKNOWLEDGEMENTS}

I would first and foremost like to thank my advisor, Dr. Paul S. Moore, for his continued support. There were many times I found myself stuck and his guidance and direction enabled me to not only move forward, but also to do so with enthusiasm. Thank you to my other committee members, Dr. Kevin Dowler and Dr. Stéphanie Walsh Matthews, for the conversations that helped to shed light on some challenging ideas. Additional thanks go to Dr. Sarah Parsons and Dr. Karen Engle, for rounding out the committee, and shedding light on some things requiring further thought.

The very early stages of this project emerged in a Postcolonial Affects course, taught by Dr. Nima Naghibi, who understood why I just could not stop thinking about Abu Ghraib. Thank you to Julie Tomiak, Patricia Mazepa, Carl Benn, and Daniel Kreiss, for helping me along the way. Thank you also to Jo Ann Mackie for being an administrative angel.

My loved ones also need to be thanked, for all the weird hours I have kept, and all those phone calls and emails that went unreturned. Debbie and Kurt Jakob, Mum and Dad, thank you for understanding that I had to move away, and thanks to my extended family for helping to keep them well and entertained in my absence.

I owe a great debt to my colleagues and friends: Joe Turcotte, Erin McCurdy, Steph Rogerson, Samantha Hogg, Zorianna Zurba, Natalya Androsova, Eryk Martin, Douglas Spielman, Chris Powell, and Jeremy Mathers. Thank you to my chosen family Robyn Webb, Maria Sword, Jon Benson, Patrick Skene, Cory Bellhouse, Mathew Gagne, and Ryann Giorgi. 


\section{DEDICATION}

To Barry Bernstein, a kind and encouraging person. I miss you all the time.

And, to my Baba, Edith Yager, for sitting with me that morning of September 11, 2001, a day that opened my eyes like never before to war and enemy Otherness. 


\section{TABLE OF CONTENTS}

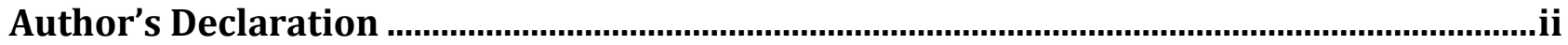

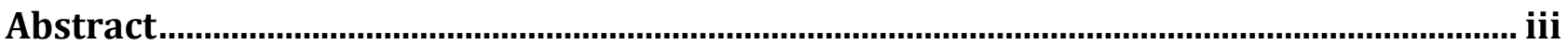

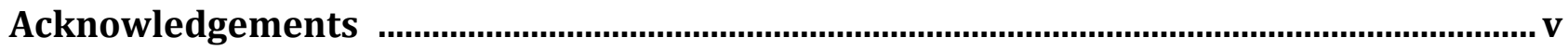

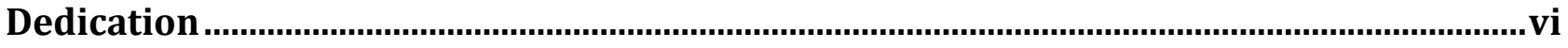

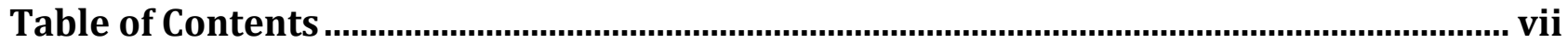

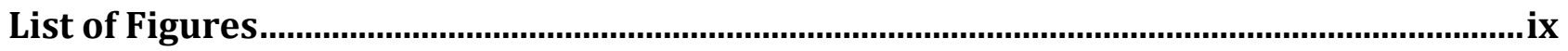

Abu Ghraib and War Trophy Photography ……..........................................................1

Horror and Outrage Over the Photos .................................................................................. 2

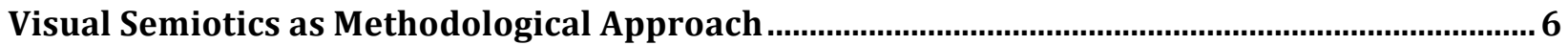

"Behind," "in," and "With" the War Trophy Photograph ................................................................. 11

Chapter 1-The Camera at War-In, With, and Behind the Photograph: The Visual Semiotics of

the War Trophy Photograph ....................................................................................................................... 11

Chapter 2-"Behind" The War Trophy Photographs-Commemorative Violence in Historic

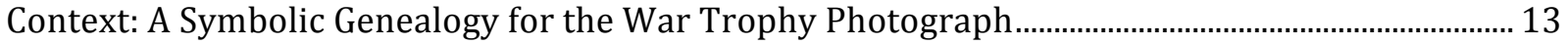

Chapter 3-"In" The War Trophy Photograph-Gesture, Emotional Expression, and Camp

Humour: The Case of "Doing a Lynndie" ..................................................................................................... 14

Chapter 4- "With" the War Trophy Photograph - Images, Narrative, and Cultural Memory:

Circulation of the War Trophy Photograph ……………………….........................................................15

Conclusions-Reflecting on "A Few Bad Apples" and Looking Forward: Are Drone War

Photographs Objects of Commemorative Violence? ……………………………………………………. 17

Chapter 1-The Camera at War...................................................................................... 18

In, With, and Behind the Photograph: The Visual Semiotics of the War Trophy Photograph. 18

Background to the Abu Ghraib Photos....................................................................................................... 18

Official U.S. Responses to the Abu Ghraib Photos .................................................................................... 20

Historical Relation of War Photography and the War Trophy ……………………………….... 21

The Commemorative Violence of War Trophy Photographs....................................................... 28

Interpretation and "Like-Minded Community": Contexts of Abu Ghraib Photographs....................... 37

A Shared History and Practice: Photography Meets War in Example ............................................. 41

Chapter 2-“Behind" the War Trophy Photograph............................................................ 45

Commemorative Violence in Historic Context: A Symbolic Genealogy for the War Trophy

Photograph .......................................................................................................................... 45

Power and Photographic Visuality: Tracing Historical War Trophy Photographs..................... 51

A Symbolic Genealogy of War Trophy Photographs .........................................................................63

Soldiers' Scrapbooks from the Art Gallery of Ontario Photo Collection.....................................................6 63

Prisoner of War Photos from the U.S. National Archives.................................................................................... 67

Types of Photography and Photographic Practices.......................................................................... 71

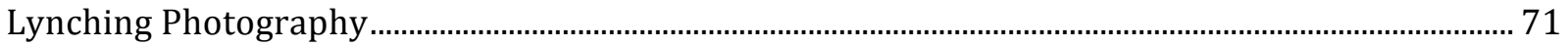

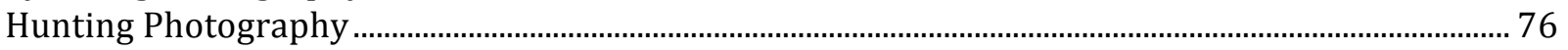

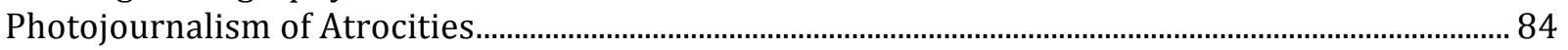

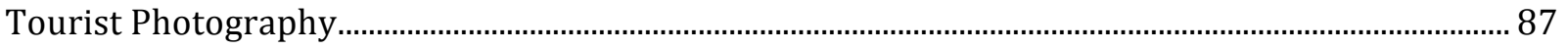

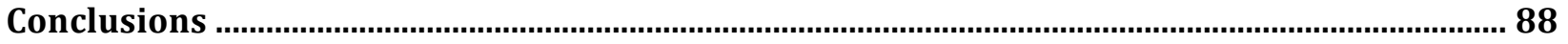

Chapter 3-“In" The War Trophy Photograph .................................................................. 91

Gesture, Emotional Expression, and Camp Humour: The Case of 'Doing a Lynndie'.................. 91

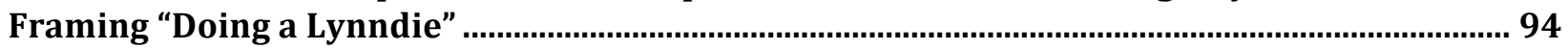


Meme Circulations of "Doing a Lynndie" and Other Related Photos

Using Gesture: Histories and Theories of the Thumbs-Up and Index Finger Pointing ............ 101

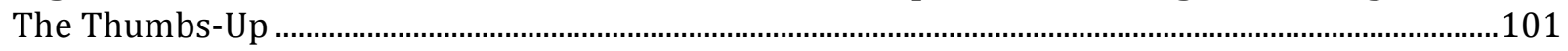

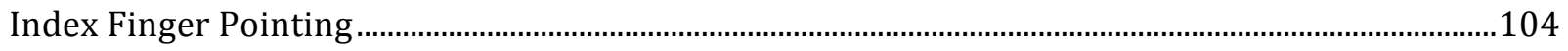

Gestural "Pointing” in Photography ……................................................................................................

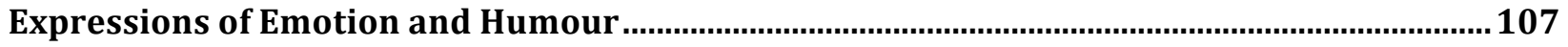

"Doing a Lynndie" and Camp Humour .................................................................................................

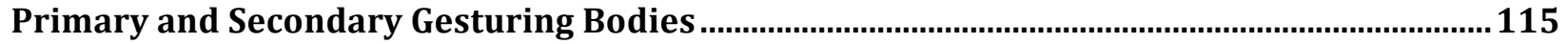

Gesture as a Component of Commemorative Violence......................................................................115

Lynndie England: Feminist Hero or Targeted Scapegoat? .......................................................................117

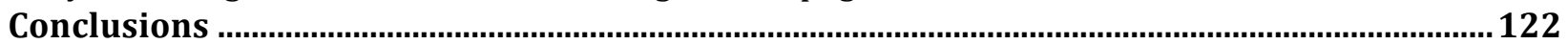

Chapter 4-“With" The War Trophy Photograph ...............................................................124

Images, Narrative, and Cultural Memory: Circulation of the War Trophy Photograph ..........124

Assigning Cultural Memory..............................................................................................................135

History and Origin of "Group" Components to Cultural Memory ……...............................................137

Authority, Social Order, and the Production of Cultural Memory............................................................139

Working with Jan Assmann's Definition of Cultural Memory..................................................................140

Analog and Digital Photography: Private Durability and Public Impermanence ....................143

Uses of Online Forums: Now That's Fucked Up (NTFU), undermars.com, and LiveLeak ........ 154

The Age of Digital Photography: Networked Circulation Meets Cultural Memory ....................162

Violence communicated through photography: Analog and Digital convergence................... 167

Conclusions..............................................................................................................171

Reflecting on "A Few Bad Apples" and Looking Forward: Are Drone War Photographs Objects

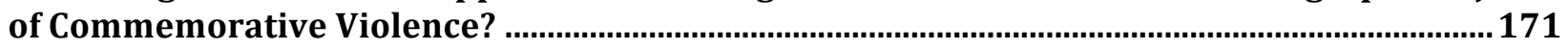

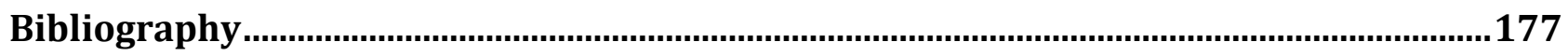




\section{LIST OF FIGURES}

Figure 4.1 The Range OF Cultural Memory Potential for Analog and Digital PhotograPhS ....................................1130 


\section{ABU GHRAIB AND WAR TROPHY PHOTOGRAPHY}

"If there were no photographs, there'd be no Abu Ghraib. There would have been no investigation. It would have been 'oh, ok, whatever. Everybody go home.",

Jarval Davis, Military Police Sergeant, Ghosts of Abu Ghraib (01:12:15).

"There's a big sign: No Photography. Besides, photographing something like that is just stupid."

Roman Krol, Military Intelligence Interrogator, Standard Operating Procedure (00:34:05).

"It's not so much that you're there committing these acts of abuse. If you were in the pictures while this stuff was going on, you were going to be in trouble."

Brent Pack, Army Special Agent, Criminal Investigation Division, Standard Operating Procedure (01:16:00).

"He would have never had me standing next to Gus if the camera wasn't there."

Lynndie England, Private First Class, Military Police, Standard Operating Procedure (00:14:05).

An image made to commemorate violence. United States Private First Class, Lynndie England stands over a leashed Iraqi detainee at Abu Ghraib prison, at the bottom right of the frame. When the picture was passed around and circulated, he was given the moniker "Gus". Naked, he faces the camera. His eyes appear closed, his head slack and near resting on the floor. His right knee is bent toward his torso; he assumes the foetal position. Overall his body seems limp, vulnerable, and defeated. This physicality, oddly, seems to be echoed in the slouched body of Lynndie England. Standing beside "Gus," England gazes downward toward him. Though she holds a near-taut leash that connects to his neck, symbolic of command and authority, she does not appear jovial or powerful as she often does in other photos. Beyond these attributes is the chaotic scenery of the hallway, like a tornado had just blown through: the many doors open, strewn-about paper on the floor and posted on the walls, and sheets that haphazardly hang in the doorways. This image widely circulated in April 2004, contradicting the purpose of bringing "freedom" through a "War on Terror" (Bush 2003) and "civility" to Iraq in the early days of the U.S. occupation (Ehrenreich 
2005, 131); a leashed "Gus" at the hands of a U.S. soldier ironically does not proclaim freedom nor civility.

\section{HORROR AND OUtRAGE OVER THE PHOTOS}

It's the photographs from Abu Ghraib, not what appeared therein, that are the problem. In the testimony and explanations of those who were directly involved, the camera and its images are what brought the events to light, and why they got in trouble. In the quotations above, from interviews in the documentary Standard Operating Procedure (Morris 2008), Military Intelligence Interrogator Roman Krol indicates that a sign appeared in the prison with a simple instruction: "No Photography." Private First Class Lynndie England-who appears in many of the photos with a thumbs-up, for whom the popular meme "Doing a Lynndie" is named—identifies that the camera is what precipitated one of the infamous images, this one where she appears to be holding a leash attached to a naked detainee crawling on the floor. Even Criminal Investigator Brent Pack specifies that appearing in the photos is the issue, not the acts of abuse depicted therein. Interviewed in another documentary, Ghosts of Abu Ghraib (Kennedy 2007), another member of the Military Police, Jarval Davis, blatantly says that there would have been no investigation without the images, tacitly outlining that the behaviour was not the problem; rather, it was the fact that the acts were photographed.

By all accounts, the scandal at Abu Ghraib would never have happened without the photos. The photos and the depicted acts are often conflated when proclaiming shock and disappointment, and yet, many U.S. military officials declared that the main issue rests specifically in the existence of the photos. After all, the abuses would only be alleged if not for the photos, which offer visual evidence and the proof of wrongdoing. Many individuals directly or indirectly related to the events have publicly noted their "disgust" for these photos. The rhetoric used in media accounts bears mention of this, especially because they were cited as being horrified by the Abu Ghraib scandal; 
however, it is not altogether clear whether the incredulity is over the actions at Abu Ghraib or the photos taken. International Committee of the Red Cross spokesperson Dorothea Krimitsas claims shock and dismay "at the mistreatment and abuse displayed in these images" (Red Cross 2005; emphasis mine). Thus, one could assume that the problem is not with the torture per se, but instead rests with the visual proof of this act. Still employed by the U.S. Army, Brent Pack was hired in 2004 to assess if and what criminality occurred at Abu Ghraib, echoes similar sentiments. He too insists that being framed within the image is what caused the deep questioning, and not the acts of abuse themselves (Morris 2008, 01:16:00). Meghan Ambuhl, a military police member who participated in what occurred, also suggests: "Nothing would have happened to anybody if the photographs wouldn't have been out" (Kennedy 2007, 01:12:08). Finally, taking a stance on the acts depicted, journalist Robert Jay Lifton outlines in his article, "Conditions of Atrocity," that the circumstances at Abu Ghraib produced the situation now described in the visual record, and compares Abu Ghraib to what occurred at Mỹ Lai (2004). ${ }^{1}$ While Lifton fails to address the photos themselves as problematic objects, the editorial team at Al Jazeera English directly point toward the images: "the scandal over detainee abuse broke last week with the release of photographs," (2004) further solidifying that it is the photos that caused the outrage, and hearsay changed to fact.

The fact that U.S. military participated in the acts depicted in the photos is not the problem. The problem is the photos. Seymor Hersh, the journalist who broke the Abu Ghraib story in 2004, notes that these pictures are not entirely uncommon: in his day, during Vietnam, "everybody had some kind of photograph that they hid behind the sock in the drawer" (Goodman and Hersh 2004). But Hersh is quick to note a difference between then and this incident, because of how these photos

\footnotetext{
${ }^{1}$ The Mỹ Lai Massacre was "the most shocking episode of the Vietnam War" (Greiner 2009, 519), a mass killing of roughly 350-500 unarmed civilians in South Vietnam on March 16, 1968, under the command of U.S. Army Lieutenant William Calley. Military photographers' images and other stories of the events were stifled, until a military press release on September 5, 1969 mentioned the prospect of charges against Calley (Belknap 2002, 118). From that point, news outlets garnered interest in the story, and much like Abu Ghraib, notions of a cover-up grew.
} 
are passed around in our media era, digital and not analog. These photos are not private; they are instead publicly shared.

I propose that Abu Ghraib cannot be discussed without making the role of photography central. Abu Ghraib demonstrates how soldiers' personal photographs from wartime can act as trophies because these visuals commemorate their violent actions. The connection between violence, commemoration, and the soldier's war photograph as trophy is my problem, seeking to understand Abu Ghraib in historic context as visual communication. Prominent scholars of visual culture have highlighted the links between these photographs and violent affect (Puar 2004; Sontag 2001; Butler 2009), while others have linked the case more specifically to depictions of suffering (Andén-Papadopoulos 2008; Apel 2005; Razack 2008), yet others as representations of victory (Tucker and Triantafyllos 2008; McClintock 2009; Limon 2007). I bind these three approaches to simultaneously consider the images from Abu Ghraib as communicating a victorious celebration of the affect of inflicting suffering upon an enemy. I call this "commemorative violence" and the Abu Ghraib images as war trophies emerge as a performance, circulation, and witness to pictorial violence. War trophy photographs capture something worth remembering for the soldiers who take them; the images are themselves the trophies. Like other types of trophies, this object is emblematic of the efforts it took to achieve a desired result, which when captured, is reflected by the framed image itself. The war trophy photograph, then, is imbued with shared memory and commemoration, which are powerful reminders of the struggles and successes soldiers have made together.

My object is the relationship between war photography, visual semiotics, and violencebased commemoration. As a result, I define Abu Ghraib through the field of visual communication. Primarily rooted in theories of photography, my research considers the image in relation to those who see it, and how they use it. Others have analysed Abu Ghraib from the perspective of social psychology (Zimbardo 2007), criminology (Hamm 2007), feminist critique (Zurbriggen 2008), anti- 
racist discourse analysis (Limon 2007), aesthetics and art history (Eisenman 2007), postcolonial critique (Philipose 2007), and gender (Holland 2009). Instead, my disciplinary approach of visual communication leads me to define the Abu Ghraib images first of all as war trophy photography, whose commemorative violence exists in continuity across many historical war zones. My analysis begins with the ambiguity opened by the gap between the visible discomfort of the Iraqi detainees and the U.S. military members' indifference to this discomfort. First, I examine how the reception of mediated suffering has long been situated as a problem for visual communication, in that engagement with violence can be both felt and limited by the "distant suffering" that the medium of photography allows (Boltanski 1999). Next, I consider the contents depicted within the frame at work in processing this suffering. With the Abu Ghraib photographs, posed, purposeful gesture and embodiment are key elements. Both posing and interpreting gestures require a shared understanding, knowable by social convention (Kendon 2004). Finally, I turn to the constitution of these shared ways of understanding, or "cultural memory," in which common themes are imagined by those who share the same space, time, or have access to the same objects (Assmann 2008).

The history of photography and visuality are complicated by the power dynamics attributed to the act of looking, whereby some have the authority to see and judge while others do not (Crary 1990; Mirzoeff 2011). Layered in here are the ways in which these dynamics produce visual culture as something that deeply affects the ways people relate to one another (Mitchell 2002, 170). What follows is a discussion of the concept, visual reproduction, which is comprised of questions concerning the veracity and authenticity of the visual (Benjamin 1968). Following this logic, the image might become "spectacular" with the emergence of reproduction, causing viewers to first be enthralled, and then duped, by what they see (Debord 1994). This, however, might greatly limit the agency of the viewer. To engage with the image, especially if intolerable, like those depicting distant suffering, is to struggle against it, and this might cause the viewer to vacillate between 
passivity and activity (Rancière 2009). The result, continuing with this reasoning, is neither to be duped nor to be oblivious; instead the focus moves toward what people do with what they see. Here, two possibilities emerge: an image of this kind is capable of challenging and even changing one's political beliefs (Butler 2009), or the image can only provide a cursory understanding, not change one's mind (Sontag 2001). The commemorative violence of war trophy photographs is transmitted over time, at a distance, but in distinct ways from the witness of distant suffering (Boltanski 1999). The mediated transmission of framed anguish serves a commemorative function of inculcation, rather than distanced witness. The photo as reminding object possesses the quality of the moment commemorated, engraved with shared memories, which are solidified by the formation of representation and subsequent movement of this object (George 1996). This transmission of violence, however, can occur beyond the instantiation of the object, and is comprised of the affective tones that exude from the image (Butler 2009). Finally, this is the point at which violence is transmitted; moving along with and through an object, violence is communicated (Girard 1979; Butler 2009; Virilio 1989). One form of this transmission is commemoration, and that is especially at play in the use of photographs of posed victory taken by soldiers as trophies of wartime.

\section{Visual Semiotics as Methodological Approach}

Defining Abu Ghraib as an example of the commemorative violence of war trophy photography, my analysis of the images as mediated suffering, gesture, and collective memory gains coherence by centering on visual semiotics as methodology for a critical interpretation. I employ a combined historical and comparative approach to study the relationship between society and its texts. My research illustrates that combat photographs offer a way to highlight group formations, whereby discriminatory cultural notions of "us" and "them" - or Othering ${ }^{2}$ — are solidified. I argue that

\footnotetext{
${ }^{2}$ The capital "O" has come to describe a social subject who experiences racialized, gendered, cultural, economic, sexual, and/or political marginality. This word developed from analyses of the effects of social
} 
soldiers' war photography relies upon symbolic communication, which renders the image as a trophy for the "us" group. Community results from the communication of symbols among a group of people that understand and interpret with commonality (Tardini and Cantoni 2005, 372). Symbols, to clarify, rely upon social convention for consistent and consensual—or at the very least, commonly understood-meaning-generation that is specific to the circumstances of that particular moment (Peirce CP 2.410) These symbols, whether of violence or other resonant images, bring people together in the creation of rifts between different groups who see the images in different ways (Hodge et al. 1988, 153). Some may see the photos from Abu Ghraib and find them funny, with little objection over their composition and what they depict, while others see them as representations of abuse, if not torture. The different interpretations and meanings made by those who see the photos differently constitute a person's location within a social group. Disagreement over meaning is what coheres each group internally and what distinguishes them from other groups and marks them as separate. In brief, a Peircean approach ${ }^{3}$ to visual semiotics is used to study the representational meaning of images throughout the dissertation, although I will not often employ its formal terminology. Though some terms will be used, visual semiotics here is only my method, and not my disciplinary place. I draw upon visual semiotics as a foundation, using its language and

\footnotetext{
inequalities that are at once socially constructed and having real effects (Collins 1993). The Other is established in colonial, globalized, and multicultural practices, where some are defined as inherently different as a means to situate and confirm the norm in power (Ahmed 2000). Racial differences are not only cited, but are produced, in these contexts (Goldie 1993; Jan Mohamed 1985).

${ }^{3}$ My choice in using Peircean semiotics for visual analysis, over that of Groupe $\mathrm{m}$, is centred upon Peirce's definition of the Iconic visual sign. Groupe $\mathrm{m}$ (which includes Hébert and Klinkenberg) distinguish between the "Iconic" and the "Plastic," in a manner not addressed by Peirce. The Iconic sign, as addressed by Peirce and also by Groupe $\mathrm{m}$, is intentional in the ways that it is culturally referential, thus being recognizable as the thing it purports to represent. To address the forced, non-figural qualities of a visual, Groupe $m$ added the concept of "Plastic," which is different because this type of representation requires interpretation of arbitrary, non-culturally specific aspects. For instance, a cloud might resemble a cat to one person, as an abstract reference, and would be considered plastic, whereas a visual of a cat would be "iconic" with its intentionality to resemble a cat. I have chosen to conduct a somewhat informal, empirical analyses for which the Peircean Iconic suffices, because applied only to culturally specific symbolism in photographs.
} 
practice alongside a more general approach of a cultural studies close reading, resembling a discourse analysis, common to my field of visual communication.

The cultural relevance and value of the photograph can be found in its meanings. Visual semiotic analysis enables the study of signs, which are composed of the elements contained within the photographic frame (Barthes 2010, 26; Moriarty 1996, 168). The field of possible meanings includes not only how people and things in the photo relate to one another, but also what these relations might mean when viewed. Although somewhat simplistic, the purpose of using this method is to chart this relationship: that what a photo contains reciprocally affects how a photograph can be read. In The Symbiotics of Semiotics and Visual Communication, Sandra Moriarty states that images are comprised of codes, and meaning from these codes are derived when the receiver understands these signs (2002, 20-21). Observing Peircean semiotics, Moriarty presents three types of signs: iconic, whereby mimetic representation occurs; indexical, whereby a physical connection is visually displayed, for instance with a footprint indicating that someone has stepped there; and symbolic, which is the only one of these three employed here throughout, whereby the meaning of the visual is arbitrary and codified according to social convention and practice $(2002,21)$. I am considering the symbolic according to Moriarty's application of visual semiotics, for analysis of war trophy photos, because this sign type demands mutual or shared understanding of a visual object, for meaning to be attributed. As such, meanings are derived from what can be ascertained according to the relationships, between people and things, which are displayed within the image. With further consideration, I interpret the photos using "abduction": the breaking down of all parts within the frame, in order to understand the compositional whole (Moriarty 1996, 184). Abduction-which Peirce identifies as a process seeking theory, while induction is a process seeking facts (quoted in Sebeok and Umiker-Sebeok 1983, 24-25)—is iterative in scope (Moriarty 1996, 175). Moriarty discusses how understanding the image via 
interpretation of social convention is similar to a doctor accumulating symptoms prior to determining a diagnosis $(2002,25)$. A critical mass of content is reached whereby pictorial characteristics are compiled from the images, enabling the process of "inference chaining." This process, where one element of an image connotes a meaning through the placement of another element within or alongside the image, revealing context, fashions conjectures based on visual "clues" that holistically describe plausible, or known, conditions $^{4}(2002,24)$.

Regarding the process of inference chaining specifically, Peircian semiotics is triadic, and chains of codes unravel to become "interpretants" as aspects of the sign are read. This triadic model contains three elements: 1) the "representamen," known as the form of the sign; 2) the "interpretant," as the sense or interpretation made of the whole sign; and 3) the signalling thing or "object" to which the sign refers (Peirce CP 2.274). For Peirce, a sign only signifies something when it is interpreted. Such a reading might be arbitrary; however, as previously stated, the reading is entirely dependent on already established social convention and practice (Moriarty 2002, 21). Determinations of meaning from a representation, however interpretive, are nevertheless comprehensible, and reliable, if the associations or networks of relationships that led to the interpretation are exposed. Peirce's triadic model supports the following statement about Abu Ghraib photographs, which applies throughout this dissertation: the representamen are the digital photos; the signalling object can be found in the visible emotional and gestural communication; the interpretant is the cultural memory that solidifies group differences, between the U.S. military and the Iraqi detainees, in the making of these war trophy photographs.

The photographs I consider stem first from those of Abu Ghraib. Other photographs consulted are soldier's snapshot albums from the First and Second World Wars, from The Imperial

\footnotetext{
${ }^{4}$ The example Moriarty uses is an advertisement for a Jaguar car: a sleek, elegant car is parked in front of a high school, coupled with a signboard for a class reunion. Moriarty argues that such an ad signals desires for success and achievement, coupled with a competitive drive to boast when confronted by those we wish to impress.
} 
War Museum (London, England), and the Photography Collection of The Art Gallery of Ontario (Toronto, Ontario). Prisoner of war photos are from the U.S. National Archives (Washington, DC) are also considered. More broadly, and primarily via online image search, lynching, journalistic, and tourist types are also analysed. The hunting photography images are from on online search of Trophy Hunter Magazine and Hunting Illustrated. "Doing a Lynndie" meme images are found at Knowyourmeme.com. Other images come from the U.S. online archive, VetFriends.com, and Janina Struk's Private Pictures: Soldiers' Inside View of War, which provided an image from Nowthatsfuckedup.com, now redacted.

Visual semiotics allows me to focus on the interplay between specific depictions, implicit symbolism and the circulation of collective meaning. Unlike linguistic semiotics, which centres on definitions of words, visual semiotics centres on the pictorial as a determinant location for the attribution of meaning. The composition or juxtaposition of elements within given parameters like a photograph's frame then becomes a "sign" that indicates complex meanings in a truncated or simplified form (van Leeuwen 2004, 3). Methodologically, signs can be used to proceed with an interpretation of significance. Analyzing similar compositions or historical resonances allow links to aspects of the symbolic that are not necessarily intentional on the part of the maker of the image, but nonetheless can be defined as shaping the collective identity of the community interpreting the image (Hodge et al. 1988, 185). For instance, war trophy photographs as signs heightens their use to celebrate, indeed to commemorate, the perpetration of wartime violence among the soldiers who take and circulate them. Within this visual semiotic framework, each chapter begins with key examples and proceeds to build an interpretation inductively, iteratively incorporating relevant theoretical concepts in order to generalize across semiotic codes in generic types of images. 


\section{“Behind,” “In,” AND “With” the War TRophy Photograph}

After first charting a broad foundation for defining the commemorative violence of the War Trophy Photograph, I then proceed through a type of tripartite perspective by positioning a critique "behind," "in", and "with" the image, corresponding to chapters in turn. I take a step back to bring the context of what historically came earlier to light, and to see what enabled the composition of that framing to become visible; this is what occurs behind the image. I then consider an example from the photographs in and of itself: to imagine the contents is to see what is enclosed, or what exists in the frame. Finally, I examine what proceeds from an image, what happens with an image over time as it circulates and is seen. The analysis begins with the context behind the image, to allow connections to be made between the people and the objects beyond the frame. Only some of these connections appear in the photos, particularly regarding physical gestures, face-foreword body framing, and eye contact with the camera lens. From here, these formulations move beyond photographic capture; what happens with the image once created becomes central. People often share images that they find personally meaningful, for whatever reason in whatever format: analog with the person-to-person passing around of paper copies or digital online sharing via screens. Ideas and notions accompany these images, beyond and alongside whatever captions or descriptions someone might personally include with their sharing.

Chapter 1-The Camera at War-In, With, and Behind the Photograph: The Visual Semiotics of the War Trophy Photograph

Motivated by the photographs from the US-operated Iraqi prison Abu Ghraib, and looking backward, this argument is four-fold. I begin by asking Are the photographs from Abu Ghraib unique? To the contrary, I find them to be in continuity with soldier's war photography from WWI to the post-9/11 Iraq invasion, insofar as the photographs act as war trophies, as collected artefacts from the enemy. Chapter 1 begins by offering the contemporary context for the events and photos at 
Abu Ghraib, and the historical context of military conventions regulating war trophies. Here, I position the phenomenon of group photography in combat as one piece of a greater puzzle regarding a critical analysis of war and commemoration or remembrance. The images discussed are not simply war photographs, but are also "trophies," prizes awarded after successful hunt and capture. This first chapter situates the "camera eye" as a defining characteristic of war trophy photography because the technological capabilities afforded by the camera provide a tool for capture and technical exteriorization of memory.

The images from Abu Ghraib carry the memories invested in them by those who partook in the image making. Their circulation as digital objects initially existed within a like-minded community of those who took the photos, but also of those with whom the images were sharedfriends and family — in addition to those who simply find the photos amusing, or at the very least as nothing suspect. I problematize the boundaries of that community in terms of a number of interrelated factors: race; power and domination; rhetoric of "a few bad apples"; homophobia and sexual humiliation; and likeness to souvenir lynching photos and postcards. To more thoroughly understand these interpretations, visual semiotics is considered in the next section. Focusing on symbolism and meaning attribution, this section outlines the reliance on social convention for the accumulation and readability of meaning, specifically regarding relationships between people and objects. The full definition of war trophy photography as commemorative violence emerges. Staged as it is for the purpose of photographing the violent conquering of the enemy, I argue that war trophy photography recognizes war efforts through the construction and circulation of a visual record, and reaffirms the boundaries of each situated group while reproducing emotive and gestural relations of dominance and submission. The final component of Chapter 1 is a section called "A Shared History and Practice," where I discuss three examples of war trophy photography from 
different combat eras - the First World War, the Second World War - to illustrate how Abu Ghraib exists in continuity with other moments of commemorative violence in war trophy photographs.

Chapter 2- "Behind" The War Trophy Photographs-Commemorative Violence in Historic Context: A Symbolic Genealogy for the War Trophy Photograph

War trophy photos have a visual semiotics that can be charted in relation to contexts of other genres of snapshot photography. I thus ask, How do these photos compare and connect to other trophy photos? Here, a second facet of my argument demonstrates how the compositions are rooted in a shared set of visual signifiers and poses in various types of amateur photography. Chapter 2 discusses what exists behind the image and considers the codifying elements that shape early photography, chiefly by examining the technohistorical dimensions that are concealed within the image. The classification of war photographs, as trophies, draws upon photo types and photographic practices, in addition to the histories of photography and visuality. These combine to exhibit a lasting representation that solidifies group identity, specifically with the display of victory in combat.

Specifically regarding the images, the photographs are classified according to the elements featured within the frame, in addition to the events surrounding their capture. I present five types of photography and photographic practices shaping the commemorative violence of war trophy photography: a) lynching; b) hunting; c) atrocities, and also, more subtly, and d) tourism. I relate these types of images to the visual semiotics of Abu Ghraib and war trophy photographs through common features such as the posing of subjects and the positioning of objects within their frames, with a shared primary function being the communication of relationships defined by inequitable power dynamics. These photographic types collectively illustrate how the semiotics of compositional elements reinforce commemorative and violent properties specific to war trophy photos. 
Chapter 3-"In" The War Trophy Photograph-Gesture, Emotional Expression, and Camp Humour: The Case of "Doing a Lynndie"

In a case study of the social circulation of the infamous pose "doing a Lynndie," I ask What are the key visual themes and symbols contained within the photos? This component of the relation between the images from Abu Ghraib and those who celebrate them is the formation of group identities and social recognition. The images from Abu Ghraib highlight victory and teamwork, however horrific, of the U.S. military members, and Chapter 3 examines what is in the photographs, concentrating on what is expressed within the frame by the visual language of their gestures and expressed emotions. Adding to my analysis of the commemorative violence of war trophy photographs, this chapter focuses on the visible dynamics of belonging and exclusion, which results in camaraderie but also Othering. Said another way, gestures and emotions represent something because they are concerned with generating meaning. "What is normally called 'gesture' are those movements that partake of these features of manifest deliberate expressiveness to an obvious degree" (Kendon 2004, 14). This chapter specifically focuses on smiles, eye contact, thumbs-up, and index finger pointing. To this end, while nonverbal communication displays certainly are subjective, physical embodiments are symbolically understandable via visual semiotic analysis.

Specific features and sections of Chapter 3 revolve around a key photo from Abu Ghraib: the "Doing a Lynndie." This photo shows a smiling Lynndie England giving a thumbs-up on one hand, combined with index finger on the other hand, pointing toward detained naked Iraqi men formed into a human pyramid. The image illustrates England's power, and this power is reaffirmed and solidified by the viral meme, "Doing a Lynndie," in which the general public is encouraged to take and share snapshots showing the humiliation of another, sometimes but not always an Other. The power dynamics of this relationship are framed in terms of the "primary gesturing body" (the Lynndie figure) and the "secondary gesturing body" (the humiliated and Othered person), and are 
highlighted in an analysis of five of the most popular meme examples, further contextualized by histories of the meaning of the thumbs-up and index finger pointing. A discussion of these specific gestures would be incomplete without an analysis of the accompanying expressions of emotion and sense of humour, which are part of generic practices of snapshot photography. More to the point, "Doing a Lynndie" features camp humour, a "benign violation" (Warren and McGraw 2016, 407) that intends to disrupt norms of propriety with awkwardly funny, if not offensive, material. Aspects of commemorative violence emerge here, too: the secondary gesturing body is an extension of the primary gesturing body. In this way, a photograph of the Other's manipulation becomes the trophy, which continues to symbolize victory over the humiliated Other. Finally, the quoteability of Lynndie is reconsidered: even though she is one of, if not the key face of torture at Abu Ghraib, she also embodies a kind of power over men often not illustrated by women, in or out of war.

Chapter 4- "With" the War Trophy Photograph-Images, Narrative, and Cultural Memory: Circulation of the War Trophy Photograph

Finally, I consider the largely-redacted archive of online soldiers' war trophy photos since Abu Ghraib to ask How do these photos communicate as memory objects? The sharing of a war trophy photograph establishes and re-establishes shared cultural memory via networked circulation, nowadays online. Chapter 4 outlines what happens with the image, highlighting primarily how cultural memory is established and reinforced through the circulation of the image. This final illustration of the commemorative violence of war trophy photographs follows what moves with the image, but also what is changed in that circulation. This chapter suggests that soldiers not only want their photographs to be available to the public, but also that knowledge and memory of these experiences are fostered in that sharing and circulation through a mnemonic function. I further suggest that the networked circulation of digital photographs online escapes the simple intentionality of sharing within a specific group. When photographs circulate by email or via an 
online forum, they connect disparate points of meaning, establishing a general form of "cultural memory." Understanding and remembering an event is maintained across discrete viewing audiences and over subsequent generations only through ritual or common social practices, which cannot be presumed with online circulation. The sharing of digital images, then, is about communicating one's experience to others, now more quickly and easily than the analog ever allowed and to a larger public, but without predictable parameters of the meaning that will be received.

Chapter 4 situates the way that the Abu Ghraib images first circulated, as the story goes by email to friends and family (Hersh 2004), in a presumed limited, personal network. Digital circulation proved to be ripe for wider publication beyond an interpersonal scale. And of course, with the publication of the images, came the explosion of controversy and outrage. In this chapter, I analyse online "shock sites," websites primarily used by soldiers to share graphic photographic combat content - are considered: Now That's Fucked UP (NTFU), undermars.com, and LiveLeak. These forums have ceased to exist online and are deleted, but I proceed with the knowledge of their past existence alongside some available examples and descriptions to argue that these sites, as well as the original familial and friend circulation of the Abu Ghraib photos, are used to solidify group boundaries. Simply put, if you are sympathetic with what's featured in the images — or even simply believe that the images have a right to exist, be shared, and be discussed — then you are a part of the "in" group. Such networked circulation solidifies the communication of cultural memory, but only insofar as the online community is defined by its ascribed human usage, ignoring their marked possibilities as computer processes. Shared beyond the network, the images are dangerous; losing control over their circulation loses control over their meaning. 
Conclusions-Reflecting on "A Few Bad Apples" and Looking Forward: Are Drone War Photographs Objects of Commemorative Violence?

An emergent issue comes to the fore in a conclusion that considers the use of drone warfare and its corresponding photographic capture. Acting in a converse way from personal-use war trophy photography, and juxtaposed primarily against the Abu Ghraib images, I address how drone warfare photos are expressionless, absent of people and their gestures. I consider this briefly, for the impact on combat generally, and specifically regarding engagement with the enemy that can no longer include commemoration of its violence. Ultimately, humanity on all sides of the featured fight is ignored in drone warfare photography, complicating how these images might be used as trophies.

In these chapters, the commemorative violence of war trophy photography is sketched at the intersecting points of photography as a codifying practice, group formation, and cultural memory, specifically as they coalesce in soldiers' representations of war. I provide an understanding of why and how soldiers' war trophy photographs matter, not just to those directly involved in combat, but also to anyone who has knowledge and access to these images. With contemplation and analysis comes grappling with the importance of capturing images that depict enmity, thus perhaps opening a door to greater discussions concerning the valuation of group divisions. I have no illusions, however, that I have encapsulated the importance and impact of these images. Instead I provide a framework that situates Abu Ghraib in continuity with a specific practice of war photography that can fruitfully be defined as commemorative violence, in order to understand both why we are horrified and fascinated by the pictures, as well as why the images were made in the first place. 


\section{CHAPTER 1-THE CAMERA AT WAR}

In, With, And Behind the Photograph: The Visual Semiotics of the War Trophy PHOTOGRAPH

He wears latex gloves, while he gives a thumbs-up. She smiles, bent down in front of him. They stand above a pyramid of naked prisoners at Abu Ghraib. Canvas hoods cover the heads of the Iraqi prisoners, made to form a human pyramid as they awkwardly cling to each other's bodies. To perform such actions naked, and even more when not by one's own volition, they seem posed to be an expressly graphic display of physical vulnerability. Juxtaposed are fully clothed Specialist Charles Graner and Specialist Sabrina Harman. Standing behind the prisoners, Harman smiles broadly, crouched down in front of Graner while he stands behind her. Both look directly into the camera lens, which could equally be described as the making of eye contact with the photographer. Posed as physically close as possible to their spoils of war, Harman's squatting body is almost entirely hidden; behind the pyramid of naked bodies, only her face and top torso are in view. Graner, too, smiles widely. Both of Graner's hands wear medical latex gloves, while he gives a thumbs-up sign with his right. The photograph appears in what seems a sepia colour tone, though the image is unedited. Their surroundings appear to be a windowless basement that features prison bars. Clothing previously worn by the prisoners lines one of the walls, taking the shape of a haphazard pile. In this photograph, the detainees are rendered as possessed things, momentarily seized objects to be posed with.

\section{Background to the Abu Ghraib Photos}

To those following the news in 2004, the photos of Abu Ghraib are indelible. By retracing their formation, I have here uncovered the genre: the war trophy photo. Despite being horrific, these 
images of U.S. military abusing prisoners at Abu Ghraib are not one-of-a-kind. ${ }^{5}$ Let me begin by recounting the events leading to the public circulation of these photographs. Whistleblowing Sergeant Joseph Darby was handed the images after asking fellow enlisted member and known photographic enthusiast, Specialist Charles Graner, for photographs of their time in Iraq. Graner gave Darby two compact disks, one that contained conventional, tourist-like images of scenery from around Hilla and Baghdad, while the other was comprised of what Darby called suspicious content (Hylton 2006). Though three digital cameras were utilized at Abu Ghraib, Graner's camera was the device used by the roughly 8 military members who participated in the events; Graner was known to leave his camera with those on shift to ensure that a plethora of photos were taken. Many of these images feature naked and hooded Iraqi detainees in demeaning and sexually suggestive poses, while the participating U.S. military members often stand alongside, smiling and gesturing. These detainees were brought to the prison for a few different reasons. At the time of photographic capture, none had been officially charged, but they were suspected of "terrorist" involvement, had ties to known or suspected terror organizations, or had been suspected of committing a crime unrelated to terror-defined activities. ${ }^{6}$ Many of the photographed Iraqi detainees, even to this day, are still publicly unknown, though a few were given monikers at their time of imprisonment. For instance, the name "Gus" was assigned to the leashed man who was crawling on all fours, infamously photographed with Specialist Lynndie England. While many of these images circulated between military members, friends, and family beyond the base (Hersh 2004), including those who

\footnotetext{
${ }^{5}$ The official U.S. investigation report, written by U.S. Army legal expert Antonio Taguba, finds that "extremely disturbing incidents of detainee abuse [occurred] at the Abu Ghraib Prison" (Taguba 2004, 15). Though some declare that it is "torture," not "abuse," that occurred (Sontag 2004, 129), the term "abuse" will be used here. The abuse at Abu Ghraib occurred at the hands of untrained U.S. military police; they were enlisted army members, but many of them were only filling in because of a shortage of military police at the prison (Taguba 2004, 10).

${ }^{6}$ A clear definition of the term "terrorist" is needed. While the word has held similar meaning for decades, regarding generally the initiation of a type of combat that the other party disavows as too brutal or ruthless, the word has been used by the U.S. to refer to key enemies of a particular era (Puar 2007).
} 
were not directly involved in the photography itself, Darby had not previously seen these photos. Unfortunately no documentation exists outlining the content of these email chains, and so it is difficult to discern what those included thought about the photos. Believing that the photographs "crossed a line" - claiming that he was disturbed by the images because the content depicted acts aimed at humiliating the prisoners-Darby turned the disks over to the U.S. Army Criminal Investigation Command (Hylton 2006). On April 27, 2004, the news went public via a telecast of 60 Minutes II, stating that American military members took photographs of themselves using questionable force against Iraqi prisoners during their command at the Abu Ghraib prison (Leung 2004).

\section{Official U.S. Responses to the Abu Ghraib Photos}

The events at Abu Ghraib first became privately known in U.S. government and military circles from The Taguba Report (Taguba 2004). U.S. Army legal expert Antonio Taguba published this report on January 19, 2004, and it revealed a handful of troublesome situations at Abu Ghraib the previous year: a lack of training, a lack of military officials to effectively run the prison, and a disregard for international standards like the Geneva Conventions (Taguba 2004). As a result, the U.S. administration commented that they did not support what occurred at Abu Ghraib, that the behaviour was unsanctioned, and that only those who were stationed at the prison and participated in the events were to blame. "Disappointed by the actions of a few"-similar to the more common and colloquial phrase, "a few bad apples" — was a sentiment spoken by many U.S. military and government officials, including Brig Gen Mark Kimmitt (Rather and Leung 2004), but the American Civil Liberties Union stated that the abuse of prisoners of war by U.S. military was systemic and not limited to Abu Ghraib (ACLU 2009, 2). U.S. Senate Armed Services Committee questioned U.S. Secretary of Defence Donald Rumsfeld about the photographs and the incidents at Abu Ghraib on 7 May 2004. Rumsfeld centred on the problem of the photos: 
The photographic depictions of the U.S. military personnel that the public has seen have offended and outraged everyone in the Department of Defence. If you could have seen the anguished expressions on the faces of those in our department upon seeing those photos, you would know how we feel today... the photos give these incidents a vividness, indeed a horror, in the eyes of the world. (FDCH eMedia 2004)

Rumsfeld's words suggest that the actions carried out in the photos are less of a problem than what appears in the visuals. As he specifies, "the photos give these incidents a vividness." Sergeant MP Jarval Davis explains: "Somebody caught our administration with their pants down, that's it. They're pissed off at that. You can kill people off camera, you can shoot people, you can blow their heads off, as long as it's not on camera. But if it's on camera, you're done" (Morris 2008, 01:40:29). To restate, the embarrassment for the U.S. administration and military, then, seems to exist in the pictorial evidence.

Some reasons were given for what the military police did at Abu Ghraib. Sabrina Harmon, one of the military police charged, cites that military interrogators asked that they "loosen up the prisoners," to get them ready to talk (Hersh 2004). Jarval Davis admitted, "we were told "no pictures of prisoners.' I was asked to take it. I'm a nice guy, so I took it. I try not to have anybody mad at me. That's the way I've always been, but I guess being a nice guy doesn't always pay off' (Morris 2008, 01:09: 15). Even so, making the prisoners feel vulnerable is one notable thing that may prepare detainees, but what does taking pictures provide? This question will be at the centre of my analysis.

\section{Historical Relation of War Photography And the War Trophy}

War trophy photographs capture something worth remembering for the soldiers who take them; the images are themselves trophies, mementos of past rivalry at the moment of victory. Like other types of trophies, these objects are emblematic of the efforts taken to achieve a desired victory, which when captured, is reified by the framed image itself. The war trophy photograph, then, is imbued with shared memory and commemoration, which are powerful reminders of the struggles and 
successes soldiers have made together. Originating with the long history of trophy collection in war, of taking battlefield personal effects, weapons and even body parts of the enemy, the war trophy began to change shape with the emergence of the camera. No longer does a soldier have to steal and carry cumbersome objects as mementos of the enemy; they can now capture the likeness of moments of victory in images. Thus, staged war photos, taken by soldiers, become trophies.

My concept of war trophy photography combines the "war trophy" and the "use of photography in war," to become "the use of photography as a war trophy." This shift using photos as trophies is also marked by a historical shift in the conditions of media in wartime. Coincident with the ubiquity of personal cameras among soldiers, international and U.S. law had prohibited taking enemy objects as trophies of victory. I will detail the definitions and laws that inform the concept of the war trophy photograph, but it should be noted that, initially, visual and digital cultures will only be hinted at, to be further examined in later chapters. For now, let me first focus on the legal aspects surrounding the actions by U.S. forces at Abu Ghraib.

Generally with regard to war trophy photography, the two legal issues are soldiers' photography of detainees and the capture or possession of enemy effects. Occasionally these two elements fold into one, which is my overall argument: the war trophy photography is the visual capture of the enemy, in which the photographic object becomes the trophy, situating the enemy within the image as inanimate "enemy effects." However, prior to the emergence of affordable digital photographic technology, these two issues, soldiers' photography of detainees and the capture or possession of enemy effects, were usually distinct. Limits afforded by analog photography made the prevalence of soldiers' personal photography of detainees or their effects difficult though not impossible to obtain, and thus soldiers relied on the capture of material enemy possessions as trophy taking. Personal photography in war, then, was nearly a non-issue prior to the digital camera, and the internet for the easy circulation of images. With this, it has become clear in 
examining relevant mandates for international and U.S. operations that, prior to Abu Ghraib, photography and detainees were distinct aspects.

Rules of combat broadly govern this discussion. The U.S. Department of Defence defines the law of war as: "part of the international law that regulates the conduct of armed hostilities. It is often called the law of armed conflict. The law of war encompasses all international law for the conduct of hostilities binding on the United States or its individual citizens, including treaties and international agreements to which the United States is a party, and applicable customary international law" (U.S. DoD Law of War Program 1998, 2). This is a general definition of the law of war, which does not encompass specifics about breaking said laws. However, other documents address issues concerning trophy collection, which will first be considered here, followed by issues directly concerning photography.

With the Hague Conventions of 1899 and 1907, it became officially illegal to collect trophies or souvenirs of the enemy. Both peace meetings discussed a variety of topics regarding laws of war, war crimes, and international law. The central Convention of interest here is "Convention with respect to the Laws and Customs of War on Land," Convention (II) and (IV) in 1899 and 1907, respectively. Minor changes were applied in 1907, and thus the foci for each remained the same. Chiefly, this Convention drew upon the rules set out by the 1864 Geneva Convention, specifying five forbidden components for each signatory nation, to not: treat prisoners of war poorly, and must not kill enemy combatants who have surrendered; attack undefended regions; force inhabitants of occupied territories into military service; punish military or civilian groups collectively; and, finally, to not loot or pillage. This last element is the focus of study here.

Four articles of the Geneva Convention call upon the forbidden looting of a town or place. First, Chapter II "Prisoners of War," in Section I "Regulations Respecting the Laws and Customs of War on Land," states in article 4: "All their personal belongings, except arms, horses, and military 
papers, remain their property" (The Avalon Project, sec. I, art. 4). Secondly, Section II "Hostilities," Chapter 1 "Means of Injuring the Enemy, Sieges, and Bombardments," article 23 states "it is especially forbidden...to destroy or seize the enemy's property, unless such destruction or seizure be imperatively demanded by the necessities of war" (The Avalon Project, sec. II, art. 23). Section III "Military Authority Over the Territory of the Hostile State," finally, outlines that, "private property cannot be confiscated" (The Avalon Project, sec. III, art. 46) and "pillage is formally forbidden" (The Avalon Project, sec. III, art. 47). Here, international law for war on land suggests that each signatory nation has discretion for utilization and interpretation of the material, which is where some further parameters are required. I will first describe current criteria, which will be followed by a discussion of the parameters at the time of Abu Ghraib.

At the time of the incidents at Abu Ghraib, two key documents outline issues discussed here, made available to soldiers in 2003. The first, FM 27-10 Department of the Army Field Manual: The Law of Land Warfare, was published in 1956. Herein, the concept of pillage is the focus, in which it is specified that, "Pillage [is a] violation of military law. A member of the armed forces who before or in the presence of the enemy quits his place of duty to plunder or pillage is guilty of the offence of misbehaviour before the enemy" (U.S. Department of the Army 1956, 98). The document also outlines that "pillage or purposeless destruction" $(1956,118)$ constitutes a war crime. The second document made available to soldiers in 2003 was a General Order, titled Prohibited Activities for U.S. Department of Defence Personnel Present Within the United States Central Command. Sections $\mathrm{E}$ and $\mathrm{K}$ specifically address photography and trophy collection: the production of pornography is prohibited, which is outlined in Section E, and is the only mention of photography in the document. Section K states that the taking or retaining of individual souvenirs or trophies is forbidden except under specified circumstances: "anything collected must be returned to lawful owner, and failure to do so is a violation of Article 121, Uniform Code of Military Service. All 
public property seized becomes the property of the United States. Lawful acquisition of souvenirs can occur if sanctioned by military authority" (2000). The last point, that military authority might sanction one's retention of souvenirs, might work to further limit those inclined to collect enemy items since it would involve bureaucratic complications.

Prior to what occurred at Abu Ghraib, the U.S. Military Police Leaders' Handbook specified how to properly treat detainees. Relevant to those who were responsible for the torture at Abu Ghraib, as they were military police, the handbook notes in Chapter 7, Internment and Resettlement: "In any military operation involving U.S. forces, accountability and the safe and humane treatment of detainees are essential. U.S. policy demands that all persons who are captured, interned, evacuated, or held by U.S. forces are treated humanely" (Department of the Army 2002, sec. 7.1). Military police are to follow specific protocol when a detainee becomes the custody of the U.S., using the six principles of the "s.t.r.e.s.s." method: search (of physical body), tag (all information regarding capture), report (the number of captives), evacuate (from combat zone to detention facility), segregate (by nationality, ethnic group, gender), and safeguard (provide medical treatment, food and water, firm and humane treatment) (sec. 7.7-7.12). As for the use of photography, it is outlined as a necessary documenting tool of military police, and its specifications for use are particular, for instance, when investigating a crime scene (sec. 8.10). Finally, all other reference to photography occurs when military police are interacting with journalists, and are themselves being photographed (sec. B.2).

New orders have been documented since Abu Ghraib. The 2015 Department of Defence Law of War Manual sketches the parameters for the prohibition of collecting enemy property in a variety of forms. The entire document is nearly 1,200 pages, which may be difficult for anyone to read and absorb, including enlisted military who are nevertheless required to do so. Section 5.17 "Seizure and Destruction of Enemy Property" states that "pillage is prohibited" (U.S. General 
Counsel, Department of Defence 2015, 262). Section 5.17.4.1 further outlines, "pillage is the taking of private or public property (including enemy military equipment) for private or personal use.” Pillage is also referred to as "looting" and "plunder." Providing more than the previous definition, this document briefly outlines the history of pillage in 5.17.4.2, and indicates that it served as a form of compensation for private armies in the medieval era. However, compensation as such became illegal in the late Eighteenth Century (267). Specific examples of prohibited pillaging include: the wounded or dead, prisoners of war, persons in occupied territory, and cultural property (266-67, sec 5.17.4). Finally, an information paper from U.S. Central Command, dated 24 March 2011, translates various elements of both international and U.S. mandates into simple language:

War trophy personal retention by an individual soldier is restricted under U.S. domestic law. Confiscated enemy property is property of the United States. The Property becomes a war trophy, and legal retention by an individual soldier as a souvenir, only as authorized by higher authority. Pillage, that is, the unauthorized taking of private or personal property for personal gain or use, is expressly prohibited.” (U.S. Army: Fort Carson 2011)

Simply put, it is difficult to obtain and keep enemy effects in war.

Section 7.7 of the same manual covers Treatment and Handling of Enemy Military Dead. It states clearly: "the respectful treatment of the dead is one of the oldest rules in the law of war" (U.S. General Counsel Department of Defence 2015, 430). Section 7.71.1 instructs military personnel that the enemy dead must be protected from disrespectful or degrading acts, including mutilation, as well as posing with bodies for photographs (430-31; emphasis mine). Furthermore, provisions are in place to prevent the dead from being despoiled: personal effects cannot be taken off the enemy body or property without proper authorization from their military command, and specifically cites these effects as "booty" (431). Important to note, the italics added for emphasis indicate newly added criteria for the treatment and handling of enemies since Abu Ghraib.

Further to the point about photography in this 2015 manual, but adding an element of detainee protection, Section 8.2.2.3 specifies that the practice of taking photographs is prohibited: 
"In order to protect detainees against public curiosity, among other reasons, DoD [Department of Defence] policy has generally prohibited the taking of photographs of detainees except for authorized purposes" (U.S. General Counsel Department of Defence 2015, 493). Other protective provisions suggest that, "detainees must be protected against outrages upon personal dignity, in particular, humiliating and degrading treatment" (493). Additionally, threats to commit inhumane treatment are prohibited, and those of the detaining power also have a duty to protect detainees, from others within the detaining power, other detainees, or civilians (494). The document further outlines that POWs must be protected from acts of violence or intimidation and that it is strictly prohibited to kill a POW (524-25).

Linking together the collection of enemy personal effects and the protection of detainees, the Law of War Manual indicates that any articles that have a personal or sentimental value may not be taken from a POW, including photographs (U.S. General Counsel Department of Defence 2015, 531). Finally, and repetitious at times, the manual specifies the importance of protecting those in custody against insult and curiosity. The example given suggests that it is inappropriate to display these individuals in a humiliating manner on TV or via the internet. Thus, it is repeated: "for this reason and others, DoD policy has prohibited the taking of photographs of detainees" (656). A 2013 General Order makes greater specifications:

The purpose of this document, as outlined therein, is to identify and regulate prejudicial conduct, to bring order and discipline, as needed. Photography is prohibited, which includes uploading of content, and the Order specifically highlights problematic subject matter: detainees or former detainees; detention facilities; active combat operations; human casualties, defined as deceased, wounded, or injured, including separated body parts, organs or other bodily material. (DoD 2013)

As previously stated, these parameters have only been specified since Abu Ghraib.

The instance of Abu Ghraib changed how the U.S. defined many aspects of conduct in war. Interestingly, no further issuance of updates to pre-existing General Orders or Manuals occurred 
until well after various investigations of Abu Ghraib. The investigation by Taguba was the key source of the updates, generated from the consultation of 56 different manuals and orders that had direct reference to the activities at Abu Ghraib. The report outlines that, between October and December 2003 at the Abu Ghraib Confinement Facility, numerous incidents of sadistic, blatant, and wanton criminal abuses were inflicted on several detainees. Taguba notes that several members of the military police intentionally perpetrated systemic and illegal abuse of detainees (372nd Military Police Company, 320th Military Police Battalion, 800th MP Brigade). The discovery of extremely graphic photographic evidence (Taguba 2004, 16) and allegations of abuse were substantiated by detailed witness statements (Taguba 2004, annex 26). Taguba states that he employed the services of psychiatrist Dr. Henry Nelson to analyse the interviews of all those involved, who determined that the detainees suffered "horrific abuse" by dangerous soldiers in an unsupervised setting (Taguba 2004, 48-49). The overall goal of the report, Taguba writes, is to prevent future occurrences of detainee abuse (Taguba 2004, 50) and he recommends further training for those working in facilities like Abu Ghraib, as 320th MP Battalion and the 372nd MP Company had no prior training before being deployed to Iraq (Taguba 2004, 19). Thus, perhaps the eventsand photography — at Abu Ghraib may not have occurred if more training had been provided. In any case, photographs were captured, rendering the events into pictorial form.

\section{The COMmemorative Violence of War Trophy PhotographS}

"These photographs from Abu Ghraib have come to define the United States."

Scott Horton, New York Bar Association, Ghosts of Abu Ghraib (01:12:40)

"The goal is the same: to restore flagging moral confidence so that troops can continue to commit the atrocities and engage in the depravities on which an empire depends. The sign that such operations have succeeded is a cocky posture, a knowing smile, and a jubilant thumbs-up signal."

Bruce Lincoln, Religion, Empire, and Torture $(2007,107)$ 
What occurred at Abu Ghraib was no secret. According to Lynndie England, "everybody had a copy of the pictures. Everybody knew what was going on" (Morris 2008, 01:31:30). Within the circle of military insiders, "everybody" took the photos as an ordinary part of wartime. They became evidence of wrongdoing when circulated to "everybody" in the wider public. A notion of proof is foundational, then, because of how those stationed at the prison experienced their involvement, as well as, eventually, how onlookers the world over came to regard the events and their photos. For instance, Sabrina Harmon states, "the only reason I wanted to be there was to get the pictures to prove that the U.S. is not what they think...If I came up to you and told you what was going on, you probably wouldn't believe me unless I had something to show you. So if I say, 'Hey, this is going on, look I have proof', you can't deny it" (Morris 2008, 00:11:30). With this in mind, the images bring to light something problematic about U.S. military presence globally, and yet these photos are also emblematic of combat success. The pictures from Abu Ghraib presented above symbolically represent both the perpetuation of violence and its commemoration (Lynndie England and 'Gus'; Graner, Harman and a pyramid of prisoners). Looking at the elements in each frame, we can deduce the figure in power through semiotic abduction (Moriarty 2002). In these photographs, the U.S. military pose as powerful, centrally located in the frame to display their power, and the Iraqi detainees are posed as subordinates to enact their subordination. The compilation of characteristics, or inference chaining, within the semiotics of these images helps us to see this power dynamic, reinforced to extremes that verge on violence: the U.S. military are clothed, while the Iraqi detainees are naked; the U.S. military are free to gesture and use their bodies as they please, while the Iraqi detainees are confined by either a leash, or their heads fully covered. Taken all together, the obvious physical force behind the posed photos couples the existence of the torture depicted with the act of recording and documenting its perpetration, to share, for posterity. The image commemorates its violence. 
With concern for the value of graphic photographic evidence, Karen Engle suggests: "In the mainstream media, photography continues to enjoy the roles of evidence giver, reliable witness, and faithful recorder of history, despite an impressive body of critical work arguing otherwise" (2009, 44). The aspect of proof is complicated by whether or not it points to the photographs themselves, as material objects, or to the framed depictions. In her editorial "Regarding the Torture of Others," cultural critic Susan Sontag appears to be concerned with the notion of proof, as it pertains to the relation between the visual portrayal of the framed events and simply the existence of the photographs. For Sontag, "the horror of what is shown in the photographs cannot be separated from the horror that the photographs were taken" (2004). The horror, it seems, is twofold for Sontag: the mere existence of photos like these is integral to a discussion of the events, with the necessity of problematizing the camera and its products. The digital camera, for instance, is targeted by Sontag's criticism: "A digital camera is a common possession among soldiers. Where once photographing war was the province of photojournalists, now the soldiers themselves are all photographersrecording their war, their fun, their observations of what they find picturesque, their atrocities" (2004). Here, Sontag appears consumed by the potential of the camera; the digital capabilities seem to be complicit along with the soldier who photographs questionable and degrading content. This idea is concerning because it has the potential to remove or lessen the blame of the soldier, who pushes the capture button, by making the notion of proof the responsibility of the camera. Philosopher Judith Butler takes issue with Sontag's formulations, which seem to have been established in her 2001 [1977] publication, On Photography. Questioning Sontag's interpretation of the photographic visual, Butler suggests considering how Sontag frames the use of visual evidence. Sontag claims that the photograph is a device for providing proof. Paraphrasing Sontag, Butler writes, "Sontag argues that the contemporary notion of atrocity requires photographic evidence: if there is no photographic evidence, there is no atrocity" $(2005,824)$. With this, the photograph 
establishes a problem, and while the problem might exist with or without a photo, the framed contents define something that has happened. And so it becomes clearer that, while the issue might be the atrocity committed, the photo is what precipitates knowledge of it. The photo points to the problem; thus, the photo is the problem.

To be clear, mine is not a study of empire, war, or violence. Instead, my focus is on the representation and circulation of soldiers' wartime — sometimes but not always violent_poses in celebratory images. Although visual depictions of violence are rooted in person-to-person acts, a new and at times wholly disconnected form of violence emerges in a posed representation; images that categorically fit this description are themselves distinct forms of violence. These representations can be studied in and of themselves, for the very ways that they encompass a productive violence. I call this the commemorative violence of war trophy photography. Simply put, the photos do things for the soldiers who take them. The Abu Ghraib photos represent purposeful compositions that highlight the violence of victory over the enemy Other in war. The image is an artefact commemorating a celebration of justified, state-sanctioned killing, showing the hierarchical relations of combat and ideological relations with the enemy. Overall, I analyse the photographs from Abu Ghraib for their framed content, for what the visuals mean, and how these meanings are communicated. What follows from this focus is an exposition of the relationships between emotional and affective communication, photographic materiality, and the production of shared cultural memory. Moreover, this type of photography purposefully chooses the descriptor “trophy" over alternatives such as "memento," "keepsake," or "souvenir," precisely to convey the violent contest of competition, and the sport-like capture of the hunt. The trophy represents the moment of successfully capturing victory over rivals, opponents, enemies. A trophy is an iconic symbolic artefact, reifying the moment of when the balance of power tipped over to victory-a moment often photographed in a pose of celebration. 
Coupling the burden of proof with the quotes that opened this section, on the support for empire and the defining characteristics of the U.S., a question of value for these visual objects emerges. As already discussed, the photographs are the problem, not only for the U.S. military and administration, but also for the world over; these images provide enduring evidence of the horrors that took place during the U.S. occupation of Iraq. Even the convictions for the abuses that took place at Abu Ghraib occurred only because the photos existed. And, so, the photos do not simply point to a problem, they are the problem; no problem would have been recorded otherwise. The issue, however, is that the discussion then centres on the photos-and stops there-and only comments on the abuses that took place within the frames. The discussions then are primarily about the photos, only secondarily about what they show, although the two are difficult to separate.

In Abu Ghraib: Arguing Against Exceptionalism, Jasbir Puar states, "The torture of Iraqi prisoners at Abu Ghraib is neither exceptional nor singular" $(2004,522)$. Puar, a U.S.-based queer theorist, claims that contrary to U.S. government and military statements, the events at Abu Ghraib reflect an undercurrent of popular xenophobic American sentiment post 9/11. Puar adds that violence in combat practices is normative and is used to illustrate hierarchies of power: "these images not only represent these acts and allude to their ever-expanding audiences, but they also reproduce the power dynamics that made these acts possible in the first place" $(2004,531)$. I am following this argument, although with a caveat: the photographs of the events at Abu Ghraib are that which are neither exceptional nor singular. While not all trophied war photographs are as graphic as those from Abu Ghraib, certain shared features are visible regardless. I argue that a collected item from an enemy can substitute for the enemy's body, it becomes a symbolic token. Hence, similar compositional elements can be found throughout the history of war photography, particularly those taken by soldiers, and the relationship is revealed, the photograph being a visual object of this symbolic link. 
"Commemorative violence" is comprised of two words. Let me first consider them as separate ideas. "Commemoration" is a "sticky" practice, "saturated with affect, as sites of personal and social tension" (Ahmed 2004, 11). As ceremonial remembrance, commemoration is ritualistic and vacillates between varying degrees of homage and pensiveness. Commemorative practices give much to think about: what the tribute means, how it originated, if the representation is accurate, or what might be left out. Commemoration, then, questions just as much as it celebrates. "Violence," on the other hand, is transmissive rather than sticky, in the sense of having the ability to transfer its impact from one location to another (Girard 1979, 4). Violence has less to do with physical personto-person harm (though some of the photographs do depict such acts), and refers more to the abstract process of cruelty and brutality that exudes and is communicated and transmitted with the image. That contradictory combination of "sticky transmission" is the crux of commemorative violence - affective and emotional and yet also transferred and communicated. Pictorial hostility is its own violent act; to see it on the page or screen performs its own potent ferocity. To be sure, commemorative violence moves between people through the photographic object.

Framing the "camera eye" are the capabilities of photographic technology. The camera provides the ability to capture and store a mere moment in a visual, material object - a benefit for representing visual memories. There is negativity, too, in the way the camera "takes": the camera not only takes an image, in the form of photographic capture, but it also takes that visual memory from the object(s) of focus. Though not in the way that early cultures believed that this technology stole the soul, the camera does copy a likeness from the photographed. Whether or not what, or who, appears in the frame agreed to the photographic capture, this "taking" is inherently violent, in Girard's sense of having the capacity for transmission of power from one location to another (1979, 4). There is a transferral of force involved, whether analog processing techniques and the use of the flash and aperture, or digital processes that transform strings of 1's and 0's into pixels. 
Moving away from the technological to the social and cultural, force is still involved. Consider for instance the notion of "the sensible": the image is readable and relatable because it draws upon "common sense" or a "community of sensible data," which are shared ways of knowing (Rancière 2009). Thus, what has appeared in the "camera eye" becomes sensible. With specific regard to the photographs from Abu Ghraib, these images feature the collection of subjugated enemy bodies posed at the hands of dominant, smiling soldiers. Perhaps most significant when discussing the contents of the images, is the difference between posing and being posed. Consider the subject-object power relations within the frames, whereby the soldier is the posing subject of the photo, and the detainee is an object being posed. In order to conjure both suggestive sexuality and physical submission, the detainees are shown with clothing removed. Canvas sacs cover many of their heads; some have their necks leashed, and some are made to crawl on all fours. The military personnel, on the other hand, make eye contact with the lens. These individuals invoke an imaginary yet assumed audience, perhaps consisting of select family and friends, who were privy to the digital photos for months before the images went public. The detainee, while seemingly the centre of the photograph, is secondary to the soldier, whose gestures of pride, accomplishment, and prowess are centre stage, so to speak. The "camera eye" is there to capture these power dynamics.

Communicating itself through objects, violence has an infectious nature because of the spectacle it creates of itself, thus moving easily because of the attention it attracts (Girard 1979, 30). As a result, not only can the photograph convey the violent qualities it possesses, but also the violent imagery is stored within the photograph itself; war trophy photography not only illustrates violent acts, but these acts are visually coded — or stored — within the frame. Photography has been described as the best medium for portraying violence because it calls upon viewers to be active with their gaze (Wolf 2007, 68). Yet, interpretation is required for a message, containing violent content or not, to be understood. Linking these notions together, that violence is stored within the photo and 
decoding is used to understand what is featured, viewers can see the associations between the army personnel and the people or enemy artefacts they have claimed, by the act of posing within the photographs discussed here. The represented violence is an entirely different kind of violence from the acts themselves. To reiterate, this is not a study of violent acts, nor does it seek to define operations of physical violence. Instead, the focus is on the representation and circulation of these actions.

To understand the commemorative aspects of war trophy photography, as a medium representing violence in the service of remembering, one need not experience what is depicted firsthand; the commemorative process is recognizable in the representation by virtue of cultural practice, as outlined in the discussion of visual semiotics. For instance, poppy wearing symbolizes respect for veterans without the wearer necessarily being a veteran. Tying together representation, commemoration, and violence, cultural anthropologist Kenneth George describes the Pangnae practice of headhunting. He states that headhunting "begins in violence and ends in commemorative representation" $(1996,186)$, adding that a visual re-presentation is itself a form of violence because of the demands placed on the object as mnemonic device (1996, 304). George's conceptions are useful for the ways in which he conceives of commemorative acts as the solidification of both group dynamics and cultural memory. Most importantly, George states that a community enacts both commemoration and violence in order to resituate social divisions: the construction of Otherness is essential for constituting polarities. George writes: "a demonized figure whose subjugation and mortification are essential to the manufacture and hierarchical ordering of social difference...is intrinsic to the commemorative process" $(1996,193)$. In fact, the production of difference and humiliation — as seen in the Abu Ghraib photos—is key to the "trophied remnant of violence," which reaffirms that the purpose of the event (with Abu Ghraib, the photography) is to 
produce a representation that will continue to visually illustrate acrimony and Otherness throughout time $(1996,187)$.

Continuing with George's assessment, I propose that the photos analysed here are used to solidify group membership of the featured military personnel, as well as to illustrate their power. In broad terms, membership as such is premised on some form of belief in the military's agenda, which includes a tacit, if not overt, belief that "we" are better than "them." In so identifying, it becomes possible to imagine that the photographed events at Abu Ghraib took place for the purpose of producing artefacts of visual commemorative violence, ultimately highlighting the appropriation of an enemy; an artefact that makes visible these power dynamics has value as a shareable object because it affirms previously held beliefs and solidifies group boundaries. Yet, to be clear, with specific regard to the Abu Ghraib photographs, the camera is not at fault; the presence of the camera alone did not bring these photographs into existence. To be sure, it is not so much that the depicted events would have outright failed to occur, but rather that the purposeful staging of the photographs is called into question. Consider the manner in which the American military personnel at Abu Ghraib make obvious reference to the camera, by way of eye contact with the lens, invoking an imaginary yet assumed viewer of the photographs. With actions like these, it is safe to assume that the emotions written on their faces, which echo the bodily gestures of pride and success, were deliberate. Furthermore, if a photograph is taken during an act of violence, it is possible that this violence can be made static, stored, and can become emblematic with the force of the frame. The chemical processing or digitizing that occurs to create the photo arrests the movement of light in order to compose an image, which can be reproduced, and shared, again and again. The photograph, while not being the exact thing it depicts, is at once made to resemble the actions performed therein (Kittler 1987, 110). Whether an image featuring a crashed plane, an appropriated enemy item, or an appropriated enemy body, these photographs invariably show certain military personnel posing, if 
not smiling, for the camera. This juxtaposition is not only eerie, but also acknowledges these photographs as trophies, which are particularly concerned with communicating the idea that some have more authority and influence than Others in, as well as beyond, the image.

To be clear, commemorative violence is about the war trophy photo in particular, and is not a descriptor for all violence-based commemorative objects. While there may be similarities between the war trophy photo and other objects, for instance the red poppy worn on the lapel for Remembrance Day in Canada, there are differences in how they are used. The poppy, whether or not one agrees with the project of war, symbolizes the challenges and losses caused by war. Some, on the other hand, might see the war trophy photo this way, too; however, this photo type is mainly used to illustrate, and celebrate, the differences between warring sides and the victories declared over the conquered party. Rather than a prayerful reminder of suffering and loss, the war trophy photograph reifies victory in representation of the posed moment of celebration, often as domination over the enemy's captured or dead body. This difference with the poppy is key. Poppies, for instance, are about soldiers who fought and lost their lives - the celebration ends there. This celebration is one-way; it is only about "our" soldiers, not theirs. There is no Othering. The poppy conveys the idea of costs and sacrifice in war, but does not suggest that one side was wrong, but instead purports that the wearer acknowledges the loss and sadness inherent in combat. Conversely, and to reiterate, the war trophy photo intends to celebrate, if not gloat, about the insufficient and unequal enemy.

\section{Interpretation and "Like-Minded Community": Contexts of Abu Ghraib Photographs}

What are the photographs from Abu Ghraib capable of communicating? Many scholars have attempted to define the parameters of meaning of the Abu Ghraib photos, but no simple "take away" can be found in such complex imagery. Journalism scholar Kari Anden-Papadopoulos argues that the photos from Abu Ghraib function not only as a critical prism, but also as sites of protest 
(2008: 5). For me, her article, The Abu Ghraib Torture Photographs: News Frames, Visual Culture, and the Power of Images, finds the cohesion that brings critical scholars of Abu Ghraib together: after much research on the images and responses thereto, Anden-Papadopoulos ultimately affirms ambivalence when interpreting their frames.

There are multiple perspectives from which to orient when considering the images, though many have determined that the images represent empire-based violence. Concerning an historical and geopolitical point of view, political scientist and queer theorist Wendy Brown discusses the notions of power, group identity, and tolerance. Brown's chapter, “Subjects of Tolerance: Why We are Civilized and They are the Barbarians," in Regulating Aversion: Tolerance in the Age of Identity and Empire, focuses on the polarities highlighted in opposing groups. Specifically, Brown focuses on the dynamic of one group having power over another: "When political or civic conflict is explained as a cultural clash, whether in international or domestic politics, tolerance emerges...Some cultures are depicted as tolerant while others are not: that is, tolerance itself is culturalized insofar as it is understood to be available only to certain cultures" $(2006,150)$. Additionally commenting on this polarity, Brown isolates a key difference between the West and the Rest: "we [the West] have culture while they [the Rest] are a culture" $(2006,151)$. This discrepancy goes further with two sides: one that is civilized and one that is barbaric. The notion of Liberalism has cultural "tolerance" for the "civilized," while, conversely, barbarism is a description assigned to those perceived as failing to have tolerance $(2006,151)$. Organizing differences among groups in this way, as Brown ultimately argues, continues to build Western empire. Tying empire building to the symbolism thereof, Shereen Razack, a Canadian postcolonial feminist scholar, suggests that these photos are emblematic of violent processes. Razack takes issue with the contents of the photos in "If it Wasn't for the Sex and the Photos: The Torture of Prisoners at Abu Ghraib," a chapter in her book Casting Out: The Eviction of Muslims from Western Law and Politics. The 
main argument here centres on what can be learned from Abu Ghraib. By focusing on the use of violence, Razack sees an opportunity to criticize and ameliorate the ongoing legacies of empire building, as represented by the war in Iraq and the Abu Ghraib photos. For Razack, racism and positions of power result in violence $(2008,61)$. Echoing these sentiments, visual sociologist Eamonn Carrabine discusses the iconography of violent representation in the article Images of Torture: Culture, Politics and Power. Here, Carrabine concludes, "the photographs are compositions, containing motifs, which place them in a much larger field of representation-where the victorious pose with the vanquished to gratify the violence of the oppressor" $(2011,6)$. Empirebased violence depends on this distinction, between the victorious and the vanquished.

Though critical scholars of Abu Ghraib tend to agree that America is an empire-building nation, the notion of blame is complex and not easily attributable. The Abu Ghraib images give the impression that the featured U.S. military are solely responsible for the abusive and torturous acts. The focus on individual perpetrators fosters the narrative that only a "few bad apples" were responsible, thus enabling Americans as a whole to "exempt themselves from confronting race and the racialized violence that structures both the discourse and the practice of the so called 'war on terror"” (Tucker and Triantafyllos 2008, 83). Whether assigning or denying blame here, the aspect of shame can be considered.

In The Shame of Abu Ghraib, continental philosopher John Limon makes four key points: a) in order to feel shameless, one must have power; b) power enables one to disregard shame (2007, $568)$; c) to feel shame is to be overpowered, to have power removed, to be denied power (2007, $569)$; and d) nakedness is not inherently shameful $(2007,569)$. Feeling shame, because of nudity, is the result of knowing that others might see you naked. Specifically addressing shame and nudity, Limon further states that when these two concepts intersect, the body is instantly feminized, whether or not that body is female $(2007,569)$. The subject of the gaze is inherently feminized 
because of many (or most) cultural norms that make a binary distinction between masculinity and femininity: that masculinity is powerful and takes what it wants, while femininity is vulnerable and is ripe for the taking. Here, the feminized Muslim men are also made to participate in homoerotic acts, in an attempt to further degrade them, because some tenets of Islam denounce homosexual acts. Limon ties together what might be expected of the experience of the Iraqi detainees: there is shame written on the bodies of these men, who shield their nudity as best they can. These naked men were aware that anyone around —not hooded — could see them. The humiliation of the naked detainees is moot, for the participating U.S. military, because of the alleged instruction to weaken the detainees in order to make confessions more likely, and, ultimately, the U.S. military personnel are invited to feel shameless.

Just as the photos from Abu Ghraib circulated for months between soldiers, friends, and family, before someone saw them with concern, lynching photos, too, followed a similar trajectory. Linking the images from Abu Ghraib to those of lynching in the American South, art historian Dora Apel comments on the relevance of this comparison. Concentrating on "souvenir lynching photos" in Lynching Photographs and the Images of Abu Ghraib, Apel states that these images enable "white supremacists...[to] relive the erotic thrills of torture and mutilation produced under the guise of righteous civic actions" $(2005,89)$. Images of this type continue the social control of the Othered body and also protect whiteness $(2005,90)$. Apel notes, "like lynching photos, those from Abu Ghraib were meant to stay within a like-minded community" $(2005,91)$. The notion of community building, tied to group formation and objects of violence, is integral to the reading of war trophy photos. In Body Horror on the internet: U.S. Soldiers Recording the War in Iraq and Afghanistan, Anden-Papadopoulos highlights a link between group identity and artefacts of violence. Echoing Apel's notions, the publication of the Abu Ghraib images recreates a sense of cohesion for those who identify with the featured U.S. military $(2009,922)$. Herein emerges my own interpretation, 
branching off from this notion of Apel's, in which these photos build group solidarity, specifically drawing upon those who are of this "like-minded community."

\section{A Shared History and Practice: Photography Meets War in Example}

With its viewfinder, the camera brings visibility to the field of war (Virilio 1989, 64), and, in part, is used as a way to commemorate soldiers' efforts by creating visual "trophies" (Struk 2011, 18). Photography can be mapped according to common or cultural uses of the medium, in turn characterized by the contents of the image. With this in mind, the accomplishments depicted within this type of photograph are seemingly unproblematic when featuring the capture of non-human artefacts like dog tags, flags, weapons, or other accoutrements. Moreover, photographic trophies from war have become even more important with the passage of time. Already noted, the practice of collecting enemy items from the battlefield was mostly forbidden (Akinsha 2010, 258; Cashin 2011, 350), and, with the ubiquity of the digital camera in post $9 / 11$ wars, the soldier can effortlessly capture combat artefacts in pictorial form (Andén-Papadopoulos 2009; Kennedy 2009; Sontag 2003). Yet, these personal objects are not always innocuous: when the photograph is itself the trophy, whereby a combative enemy is captured within the frame, the body comes to reflect a conquerable, inanimate object. Three photographs appear in this section, discussed as an introductory comparative example of the larger task of this dissertation, one each from WWI, WWII, and Abu Ghraib 2003, the latter of which opened this chapter. Outlined here is the connection between each photo, specifically regarding compositional elements and the associated cultural practices of image capture.

Taken on August 13, 1918, at first glance "German plane brought down in Canadian lines" appears both common and striking. With shades of black, grey, and white, this analog photograph features roughly twenty-four uniformed servicemen, though some are more casual with only a shirt and without a jacket or visible weapons. A handful of these individuals look towards the camera; 
some appear to be smiling, though it is possible that the smirks are the result of avoiding glare from the sun. A few hold rifles and one in particular stands posing to the right of the frame. He fits all of the aforementioned descriptions: eye contact with the camera lens or photographer, uniformed, and standing at attention with weapon in hand. These attributes are the "common" features to which I alluded, while the striking feature is the destroyed plane that fills the centre of the frame. Appearing in shambles, the body of the plane holds together, although the material that frames the body looks as if it has melted, is collapsed in some parts, or has vanished entirely. The caption on the back of the image reads: "A Boche ${ }^{7}$ single seater photographed fifteen minutes after it landed, the pilot although badly injured, is expected to live. It was brought down in the Canadian lines." Overall, the symbolic here is mixed: while the soldiers stand at attention, acknowledging the camera, they surround the tragedy of a crashed plane. The compilation of visual characteristics suggests that, while disaster is highlighted, the posing for a picture emphasises normalcy.

A black and white analog photograph (though made available by digitization), "The British Army in Burma" illustrates a captured Japanese flag, taken near the end of a three-year military operation in Burma. The trophy is not simply a flag, but also features Japanese characters written across the white background that surrounds the centred red circle. It can be noted that, perhaps, the written inscription might be illustrative of personalization from the individual or individuals to whom the flag originally belonged. Some of the unnamed British soldiers hold the flag end-to-end for optimal display. Eight British soldiers fill three-quarters of the frame, while unfocussed forest outfits the background. All of the soldiers who pose for the photograph smile: five of them look directly at the camera lens, while two gaze at the flag, and another appears in the background seemingly caught off-guard and unposed. A centrally positioned soldier, one who holds the flag with both hands, stands with a cigarette casually dangling from his grinning mouth. Another soldier

\footnotetext{
${ }^{7}$ The term "Boche" is French slang, used during WWI, to refer to the stereotypic and assumed stubbornness of German soldiers.
} 
of note stands with a cigarette in one hand and a gun in the other. One might infer that, all visual elements considered, the capture and display of this flag suggests a prideful act.

Recall how the generation of symbolic meaning derives from the accumulation of gesture and the milieu in which the gesture arises. The three images introduced in this chapter are certainly different from each other. One features a crashed plane surrounded by military personnel who gaze at the camera, one features a flag as the prize, and the other illustrates bodies as captured things. While each image is different in composition, the subject-object relations are similar. The soldiers, who make eye contact with the lens, are active subjects who display their conquered, captured, and posed objects. The crashed plane is merely a thing that others surround. The flag is posed at the hands of the soldiers, clearly an object incapable of posing itself. These are lifeless things, plane and flag, and are in contradiction to the detainees' bodies; while capable of arranging themselves, they are nonetheless objectified as inanimate objects. Altogether, abduction allows for the interpretants to come together: this captured degradation, or even more simply a sense of command over an Other or Othered object, is juxtaposed with the actors with agency - a visible contradiction in many of the photos that comprise war trophy photographs. Once again, the existence of the photos suggests significance for those who took them. The three images presented in this chapter portray varying degrees of violence, at times perhaps resembling more of theft in the case of the flag, though even this might suggest that force was involved in the taking of this object. In any case, each photograph remembers and honours the possessive nature of the events pictured therein, and as I argue, signifies the commemorative violence of these war trophy photographs.

By way of further exemplifying, and focusing once again on Abu Ghraib, the human pyramid image is significant because of the viewable symbolism and the corresponding meanings. Generally, smiles and thumbs-up are culturally regarded as signs of happiness and pride, and, to provide further context, gestures discussed fully in Chapter 3. Continuing with Peircean visual 
semiotics, and to reiterate, Moriarty suggests that symbolic representations utilize arbitrary associations, whereby meaning is ascertained using social convention and practice $(2002,21)$. For instance, the thumbs-up gesture at a sports event, after a good play, might suggest that team members acknowledge and are excited about what just happened. However, compared to the photographs from Abu Ghraib, different meanings are generated because of the association between the gesture and the milieu in which the gesture arises; this gesture at a sports event is understandable if not banal, whereas the military personnel gesturing toward naked detainees is concerning, if not outright horrific, as outlined by critical scholars of Abu Ghraib. Finally, the conditions surrounding the photography at Abu Ghraib, while perplexing, are comprehensible by the process of inference chaining and subsequent symbolic associations. First, emotion and gesture are social (Ahmed 2004, 4), and when displayed, produce meaning (Kendon 2004, 14). Second, it is a noted social practice to emote in front of a camera (Rose 2010,7), whereby the photograph itself becomes a mnemonic object (George 1996, 304). Third, visual clues emerge from understanding the contexts surrounding the events: while the Abu Ghraib photographs of rogue American military members abusing Arab men could be interpreted through a myriad of sociopolitical lenses, certain descriptive characteristics of inequality can be noted regardless of the framework used (Razack 2008, 61; Puar 2004, 531); it is clearly visible that only one side in these images has any power.

This chapter introduced the overall structure of the dissertation, concentrating on the specific contexts readers should hold in mind. The background to the main arguments were framed, surrounding the context of Abu Ghraib and the war trophy more generally. From there, an overview of the theory of commemorative violence was given, which led next to an overview of the perspectives of critical scholars of Abu Ghraib. Finally, the war trophy photograph, as a type, was broadly sketched, and three examples were discussed. Now, let me turn to that which exists "behind" this image type, with an analysis of the symbolic genealogy of the war trophy photograph. 


\section{CHAPTER 2-“BEHIND” THE WAR TROPHY PHOTOGRAPH}

\section{Commemorative Violence in Historic ConteXt: A Symbolic Genealogy for the War TROPHY PHOTOGRAPH}

"There is no war... without representation."

Paul Virilio,

War and Cinema (1989 [1984], 8)

"The camera [is] a more civilized weapon than the gun."

Here they are again. Same smiles. Similar gestures. His photo and hers are comparable, if not interchangeable. This time posed over the dead body of a prisoner at Abu Ghraib. The photos feature the deceased al-Jamadi, who was killed during interrogation at the prison (Mayer 2005). The images do not show how he died. In both photos al-Jamadi appears the same: lying in an unzipped black body bag; the only visible portion of his body, the torso, is buried under bags of ice. His head, while visible, is turned slightly away from the camera, mouth eerily agape, with the only potentially visible eye bandaged with white gauze. There is a bloody sore next to his bandaged eye. Above him in each photo is either Charles Harman or Sabrina Graner; while Harman bends from the waist to be in the frame, Graner bends his knees and crouches down. Apart from the different postures, Graner and Harman appear the same: both smile showing teeth, and both give a thumbs-up with their right hands. The only other marked difference between the two is what they do with their left hands: Harman uses hers to prop herself up within the frame, placing it on the body bag for support; Graner holds his index finger upward, his thumb wrapped over the third finger. This gesture commonly indicates that a moment is needed before further action, or it can indicate success by way of claiming "first place" or a "number one" position. Mirroring championship sports photography, this latter explanation is more likely the case, as Graner appears ready for the shot with his 
accompanying hand posed in a thumbs-up. In this way, each of Graner's hands gestures toward the other, both marking success.

Why might a hunter place a hand on the carcass of his prey? What does it mean to stand in the foreground of the Eiffel Tower and to touch the tip, or seemingly do so in the image? What does a smiling crowd standing around a lynched Black body suggest? What can be made of the soldiers who stand posing alongside a crashed plane, or with an enemy's body? Answers to these questions are necessary to fully understand the social context behind the images taken as war trophies by soldiers. The relations featured in the war trophy photograph exist within a multitude of representations of social and cultural life, and though an explanation is possible for each unique type of photo-lynching, hunting, journalistic, or tourist-I propose they all together come to define the significance of the pictures from Abu Ghraib insofar as each is connotative within the denotation of commemorative violence in the war trophy photograph generally. While each photographic type is relevant in its own way, I will discuss each in order of my sense of its overt representation visually within the iconography of Abu Ghraib, as a foundation for a historical genealogy of the generic form of war trophy photographs.

This chapter considers the visual histories that are semiotically resonant with the practice of war trophy photography, specifically discussing the framed visuals and meanings that are invoked before or "behind" these photographs. From classification device to provider of evidentiary validation, the photograph is a codifying tool. The photograph has a frame, in which elements are featured, and though perhaps obvious, anything existing outside of this frame is not a part of the image. And yet, the meanings assigned to the image upon looking may, in part, derive from beyond its border, in the form of the social, cultural, and historical links to that which is featured. What occurs within the frame is further structured as types of photography are interpreted through their 
photographic subjects such as tourists, objects such as lynched Black bodies, and activities such as hunting, always in relation first of all to personal photos of soldiers at war. These categories stem from the decision of what to include within the frame, comparison becomes possible as I consider how the composition and juxtaposition of elements is posed. Photos of hunters posed with fresh kill; photos of tourists acting playful with foreign objects; the smiles of a crowd of white townsfolk around a lynched Black body, soldiers proudly posing with wrecked combat aircraft; I will argue that all of these are directly related to the war trophy photograph's soldiers commemorating victory over a demonized enemy Other. I will analyse all these examples to chart the symbolic genealogy of historical iconography "behind" the war trophy photograph, beginning with a close reading of several more photographs from Abu Ghraib itself, but quickly juxtaposed against pages from archived soldiers' scrapbooks of photos from their time at war.

I then take the typology outlined first as the semiotics of the war trophy photograph and seek its wider social and historical context by comparison against other types of images. I begin with lynching photos from the mid-twentieth century United States, as a type most directly parallel to Abu Ghraib and most clearly a similar form of commemorative violence. Closely related to lynching as a type is hunting photos, but here the aspect of trophy is more overt, essential to my characterization here. Each of these image types ultimately depicts the same event: the hunt and capture of prey. Whereas one highlights a racist history, illustrating how human prey can be from our same species, the other pits human against animal. Both photographic categories centre on the success of the hunters, juxtaposed with the humiliation and death for the prey; in this way, images of lynching are indeed hunting photos. So, too, is the human pyramid photo from Abu Ghraib discussed in the previous chapter. The army personnel who stand over a pile of human bodiesdead or not—conjure the hunting photo type because of the compositional similarity to hunting photos, where the hunter poses alongside weapons and subdued prey. These photos have a few 
things in common: they are not necessarily secret; they celebrate struggle and strife; and, while graphic, they nevertheless show a common bond is shared, if not normalized, among the featured parties who commemorate the violence of their kill.

The next images discussed in this chapter show suffering without including perpetrators of violence: photojournalism of atrocities inflicting distress, such as in famine, civilians affected by war, or environmental catastrophe. Typically, images of this kind socially alienate the privileged non-suffering position viewing the image from the depicted "distant" suffering —often persons from the developing world of the global East and South (Boltanski 1999). My final types of images depict significations at first glance more banal and not initially provocative: tourists posed cheekily in foreign lands; families posed to commemorate their common bonds. Despite their quotidian character or banality, each of these nonetheless displays a unique and necessary facet of war trophy photographs. Hannah Arendt reports on the "banality of evil" in Eichmann in Jerusalem, considering what causes someone to perpetrate horrific acts of human violence, while also being oblivious to the ramifications of their actions. The "strange interdependence of thoughtlessness and evil" (1963: 288) are banal, she argues, because the perpetrator's behaviour is neither diabolical nor vacuous. My purpose in relating each of these more ordinary image types to the genealogy of the war trophy photograph is to understand how the act of posed, performative torture could happen and then be shared in an ordinary and banal way, in an apparently cavalier fashion. The focus of this chapter is thus a robust charting of the emblematic patterns first outlined in Chapter 1 as defining the war trophy photograph as commemorative violence. Here, I related that definition to the wider, historical practice of photography and visual communication. The parameters marked by my typologies "behind" Abu Ghraib add to the imperial and colonial power dynamics already well established by the history of photography (Sontag 2003; Crary 1990). As I discuss fully in the next section, power is at the very heart of photography, which is a technology inaccessible to many, 
particularly when dehumanized or subjects of suffering. Historically, early cameras were used by anthropologists, by wealthy science enthusiasts, and employed in combat as a technology of war. In so doing, photography helped to shape colonial and imperial practices. Sharing and reading an image also asserts power dynamics. Looking at, considering, and examining are all acts allowed by and ascribed to authority; not everyone sees the same things, and not everyone is even allowed to look, where social inequalities like race and gender, or even humanity, are concerned.

The photos from Abu Ghraib are highly pixelated and their hue resembles a sepia-like tone. The quality of the photographs is actually the result of poor or fluorescent lighting in a windowless basement. These photos were taken in 2003, at which point digital cameras did not produce images with high levels of resolution. The resulting quality and colour tone, I suggest, reinforce the already geographical and political distance of this war by adding a kind of poor resolution-based temporal distance, one that hints toward the semblance of photographs from an earlier era. Similar colour and textural tones connote snapshot photographs from the 1970s and 1980s, or a deliberately nostalgic hipstamatic filter on a later cameraphone (Bartholeyns 2014). While not overt, these associations tacitly inscribe the Abu Ghraib images with an oddly old-fashioned, if not distant or remote quality, or-because we know when they were taken — of a digital instant filter. These issues in the background never stop the confrontation with the violence depicted.

"Charles Graner and Sabrina Harman with 7 Iraqi prisoners in human pyramid," is temporally similar to the image first mentioned, "Lynndie England and Charles Graner with 7 Iraqi prisoners in human pyramid (reverse view)," as the prisoners are shown in the same cumbersome, physically difficult to sustain manner. This image shows their nakedness, featuring exposed genitals, while the hands and arms of each detainee clumsily and arduously grasp the other nude bodies. Behind them stand Graner and England, who are fully clothed; arms wrapped around each other, their free hands make thumbs-up gestures. Large smiles appear on their faces. 
The setting of both of the human pyramid photographs resembles a windowless basement; one of the images features prison bars in the background, while the other features numerous doors. Additionally, both of these photos illustrate the authority of the U.S. military personnel, as well as their camaraderie. Graner and Harman smile with their bodies close, demonstrating a chummy account of their relationship. England and Graner embrace one another, positioned in unification. All three look directly into the camera without any scepticism, an act of confidence. Conversely, the Iraqi prisoners are stripped and shamed: clutched together yet isolated in their own nakedness, they are unable to facially emote, though their desperately awkward hand positions speak to their vulnerability. This type of communication is a disturbing feature of the photographs, particularly when contrasted with the overt smiles of the pictured U.S. military personnel.

The "Simulated fellatio" photo features four naked and hooded men. Three of them stand, two of them in the background, while one man kneels in front of another foregrounded standing man. The two men in the background appear as though they wish not to be present: the man on the left is made to simulate masturbation, his head only partially included in the frame, while his torso angles away from the foregrounded action. The head of the man on the right bends forward, his hands covering the sides of his face and ears, rendering him small and physically expressing pain. The man who kneels simulates fellatio on the foregrounded man, a hood appearing to cover the front of his face. The positions of the hands of these two men are noteworthy: while the man who stands rests his hands on the head of the man who kneels, the hands of the kneeling man rest limply on his own thighs, which mirror his slumping back. The physicality of the kneeling man is subdued, particularly with regard to his slack hands, which speaks in muted tones of the coercion used beyond the frame. 
Power and Photographic Visuality: Tracing Historical War Trophy Photographs

Photographing brutality against those labelled as enemies moves through a long history (Carrabine 2011, 7; Struk 2011). Historically, the focus of photographic capture in war is not random, but instead has often come as a result of careful construction (Bresheeth 2006, 57; Zelizer 1998, 32). How these types of photos are read across mass culture affects the way the events are remembered. Specifically, meaning is found in the formations of specific groups of people within the imagesrelying primarily upon the composition of emotion, gesture, and humour within the photographic frame-all of which are highlighted in the chapter that follows. Here, the solidification of photographic type and historical practice is the focus, primarily as a way to classify content for, ultimately, the reproduction and circulation of meaning in war trophy photography. There is a longstanding practice of collecting war trophies whereby the distinction between human and nonhuman, animate and inanimate compositional qualities are blurred (Harrison 2006; Weingartner 1992). While there is a rich history of relatively innocuous trophy collection in combat-usually taking the form of material items left behind, traded, or collected from the enemy after death—there nevertheless are some unethical forms to consider. And though it is difficult to say just how many military personnel participated or participate in these questionable activities, some trophies nevertheless come in the form of enemy body parts. However horrific this might seem, the notion worsens when one factors in that not all enemies are treated equally: only those deemed subhuman are subjected to the brutal practice of physical collection. An anthropologist of warfare, Simon Harrison notes that racial inequality is the backbone to this form of trophy hunting. Moreover, the bodies of those deemed racially unequal—often, people of colour-can be seen as nonhuman, animal, or even inanimate things. In this way, ultimately, the collection of these bodies is similar to the process of hunting; these bodies are treated no different from those of game animals $(2006,818)$. For Euro-American armed forces in the nineteenth and early twentieth centuries, this type of trophy 
collection occurred along geographic lines with marked social divisions of race (Harrison 2006, 819). It should be noted, however, that no known case of this sort of trophy collection has occurred between European and North American oppositional forces (Weingartner 1992, 67). Race, then, offers identifiable oppositions, and isolating enemies enables camaraderie to form amongst a single side of troops. Harrison suggests that this racial Othering stems from the combined practices of hunting and combat $(2006,821)$. American soldiers primarily come from rural and working class backgrounds, where rampant patriotism exists alongside ethnocentrism and strong feelings about white racial identity (Harrison 2006, 819-20; Weingartner 1992, 55-56). The associations here invariably have great consequence for the bodies of those who have been, or are, rendered as trophies in the nineteenth, twentieth, and now, twenty-first centuries.

The distinction between people and animals, nonhumans, or things seems to be sharply noticeable during the Second World War, with relations between the Allied forces and the Japanese. War historian James Weingartner declares that the dehumanization of the Japanese was, in part, due to Euro-American pop cultural pictorial depictions, which commonly rendered them as apes, monkeys, insects, reptiles, and even bats $(1992,54)$. If this were not enough to reframe the Japanese men who engaged in combat as subhuman, and thus conquerable like game animals, officiallooking "hunting licenses" were printed in numerous newspapers throughout the U.S., declaring that it was "open-season," that there was "no limit," and that "free ammunition and equipment" would be provided by the United States Marines to those who participated (Weingartner 1992, 55). In this way, if the Japanese were considered animals, they could be hunted. And if they could be hunted, trophies from the hunt could be collected for display to fellow troops or to those back home, which included gold teeth, "pickled" noses or ears $(1992,56)$, and whole cooked and cleaned skulls (1992, 57). The above examples require resources and commitment, saying nothing of the 
barbarism itself. The practice of photographic trophy collection, therefore, is simple and less gruesome, but nevertheless moves through a similar history steeped in unequal power dynamics.

The war trophy photograph is commemorative violence, but its transmission of affect is derived from the ascription of power to vision and visuality in general, and in particular to photography as a modern technology. Modernity and visuality are sociopolitical systems that coevolved whereby the modern subject claims authority. Ocularcentric, modernity fostered vision not as a function of the eye, but instead cultivated "visuality," a regime through which the politics of looking developed (Jay 1993; Levin 1997). Visuality is entwined in complex processes that cannot be simply defined as all that is visible (Mirzoeff 2011,2). In this way, seeing is not simply an action of the eyes. Asking how visuality affirms dominance and submission in subject-object relations, this chapter argues that the politics of looking are codified by the interplay between the ability to look and the denial thereof. With specific regard for this project, the military members who gaze into the lens of the camera assert dominance (i.e.: the U.S. military members in the photos at Abu Ghraib), as juxtaposed with visible others within the photographic frame, who are manipulated into submission (i.e.: the hooded detainees at Abu Ghraib). Here, dominance and submission are overarching themes that will be further developed and articulated.

In Techniques of the Observer, historian of visual culture Jonathan Crary (1990) outlines how social life was codified in new ways because of visual capture devices. He posits that prior to the derivation of meaning from a framed visual comes the capability of optical capture itself. In this way, an optical device guides how something is made visible; while there are multiple and intersecting points that influence what can be seen, parameters of visibility are no less constructive and prescriptive. Crary specifically notes that these tools provide sites of knowledge and power that operate on a person, as observer. Specifically, the observer is regulated by meanings that are codified and embedded within the visual, which are directly tied to practices of looking. Crary 
defines the observer as one who sees_-according to prescribed sets of rules, codes, regulations, and practices - and is limited to these specific conventions in terms of how the visible world is categorized and understood $(1990,6)$. This observer, while seeming to have agency because they can appraise information, nevertheless is constrained by these ingrained practices. The observer, in this way, is both a product and is constitutive of nineteenth-century modernity, where new events, social forces, and institutions shape the observer and the visible $(1990,9)$. Crary gives as example the state of the subject in a photograph: the subject is rendered permanently visible, captured within the frame. With this, the likeness of a subject is divorced from the spatiotemporal location at the time of photographic capture $(1990,136)$. To complicate these matters, Crary, as well as Benjamin — who will be discussed in a moment - claim that nineteenth-century modernity manifested the observer as a commodified subject, who is inseparable from the circulation of signs and other visual objects $(1990,11)$. At that time in the nineteenth-century, photography was a significant new field that allowed for the creation of serially produced objects (Crary 1990, 13). In addition, besides creating new commodities for the economy, photography reshaped the territory of signs and symbols, and consequently, value assigned in economic exchange. The identity of the observer was thus solidified according to visual appraisal, fostered by the capacity to see and then understand something from visual cues. Beyond this, Crary outlines that photography is a key component of modern techniques for the industrialization of image making. Citing Manuel De Landa in War in the Age of Intelligent Machines, Crary states, "the most important model for serial industrial production in the nineteenth-century was ammunition and military spare parts" (1990, 13). Here, relying upon mechanical reproduction enabled militarization: the manufacture of ammunition and spare parts allowed that each unit be made identically for ease of usability (1990, 13). Coming back to the visual and photography, Crary claims that the similarity between 
photography and mechanical reproduction derive not from the economic sector, but instead from the replication of warfare and bullet rounds.

Meanwhile, Benjamin states in "The Work of Art in the Age of Mechanical Reproduction" that mechanical reproduction centres not on military means but instead on the replication of visuals. The camera is a revolutionary device with its ability to reach mass publics, in addition to being relatively affordable as compared to the costs associated with portraiture painting. Prior to this, the visual or the work of art was only reproducible if it occurred under arduous circumstances requiring human coordination and precision (Benjamin 1968, 218). Photographic technology helped to change this human effort-intensive work into an attainable reproduction at the literal click of a button. Photography, via the process of pictorial reproduction, captured visual elements with such speed that it "could keep pace with speech" $(1968,219)$. Never before was there a profound, if not simple, way of seeing and knowing the world. Photography also brought an accuracy denied to the eye $(1968,220)$. For instance, processed reproduction allowed for once unattainable information to be brought into view: an aspect of a photo too dark to ascertain by the naked eye could be lightened mechanically, or an element once deemed too small in an image could be enlarged $(1968,251)$.

The pre-mechanical (or pre-camera) era also brought with it a particular association to the work of art, one that Benjamin calls the "aura." He describes the aura as an object with a transmissible history, capable of romancing its audience with socially-ascribed charm and charisma. In addition, this pre-mechanical era produced works containing an aura because of the notion of the "original" - at this time, reproduction was difficult — and with this, the aura was infused with authority and authenticity. These majestic qualities of the work of art produced a cult attitude, an unfettered following for the object based on the ritualistic associations that create an object of grand significance $(1968,224)$. Benjamin suggests that the aura made the visual sacred, attaching wonder and mystery. The aura, in this way, carries with it grandiose elements and associations. Consider for 
a moment the Mona Lisa. People travel from all over the world to see this tiny painting; it is supposed to be a grand and remarkable experience to be in the same room as this object. However, postcard production made this image common; copies could be obtained by anyone. The charm and larger than life qualities were thusly reduced. And yet, nevertheless painting's rich history continued to inspire and awe, and so, as Benjamin describes, the aura remains- because it happens to be an authentic original-however faint $(1968,222)$.

With this basis in a discussion of Benjamin's "aura," the central defining characteristic of the image is one of permanent crisis, since the emergence of reproductive technologies (Bolter and Grusin 2000,34). Benjamin claims that the aura disappears from the work of art when it becomes mechanically reproducible, and "politics" replace the sacred $(1968,224)$. With regard to film technology, the disappearance of the aura makes room for politics, for political use to emerge. As such, the once limited number of persons capable of viewing the image (e.g., a painting at an art gallery) opens up to an entirely new and wide-reaching audience; increased visibility is what marks this moment. No longer does the audience have to be in the same place and the same time as the image $(1968,220)$; the spatiotemporal divide is broken, allowing for new consumers, viewers, or participants to engage with the visual. This acutely detached, non-aura induced audience is capable of absorbing content, and thus is able to make non-sacred associations to the image. For Benjamin, it is here where change occurs, with the "decay" of the aura. As such, power is reconstituted in the social body when the work of art loses the ritualistic associations that once existed prior to mechanical reproduction. As noted already, Benjamin describes decay as the result of mechanical reproduction, but photo technology is a key example of this process. The camera offers the potential of an endless, massive audience. The camera allows for the awareness of the potential for infinite viewership, and, consequently, the reproducible image - this is the moment where the aura ceases to exist $(1968,231)$, and where the decay enables politics to emerge $(1968,224)$. Thus, the 
communicative potential of the camera and its properties of mechanical reproduction allow for the sharing of information between people who otherwise might not be able to communicate with each other. The aura disappears because access is granted to so many, and the once exclusivity of the original falls away $(1968,247)$. However, just as the aura fades to include the emergence of politics, the sacredness or some form of original etching can no less be seen, as is the case with war trophy photography; this is one way in which previous incarnations are linked to the present, further substantiated by symbolic, cultural associations.

The fading of the aura can be viewed as a precursor to Debordian notions of the spectacle: the reproduced image carries with it the potential to enlighten and even to change perspectives, according to Benjamin, while for Debord, the striking qualities of this kind of image render viewers immobile. Debord's conception of the spectacle, as with visuality, is implicated in capital. According to Debord in Society of the Spectacle, the spectacle is defined as "capital accumulated to the point where it becomes visible" (1994, 35). In the section, "Commodity as Spectacle," Debord explains that the commodity becomes such from the labour employed by the worker $(1994,35)$. This labour removes the worker altogether from the object, and only the transformed commodity is visible when looking at the object; it symbolizes nothing beyond the value added. Thus, to see anything beyond the product, one must peel away layers by noticing who did what to make the object into its finished thing. The photo, as example, has a photographer and sometimes a developer, which often do not exist within the photo itself (barring "selfies"). Moreover, Debord claims that the spectacle fosters a process of alienation comprised of power relations, of the spectacle alienating the spectator, who is held captive by fascination with the image. Debord describes: "The alienation of the spectator...works like this: The more he [sic] contemplates, the less he lives; the more he identifies with the dominant images of need, the less he understands his own life and his own desires" (1994, 23). Debord, a 60s French Situationalist Marxist, who in part made 
video art, understood all too well how to manipulate media, raising issues for power relations in the act of seeing someone in need. Compassion, empathy, and care might attract us to the spectacle, to fill us with the desire to look. With these acts, we will be forever blinded, plaguing ourselves with these images of horror and, thusly, never able to intervene or aid in the suffering of others. Debord's ideas, while foundational in any analysis of spectacle, fail to offer solutions because of tautological logic. Analyses of spectacles of suffering are premised on power relations held within the image and the idea that the spectator could seek to relieve the suffering, but cannot, because they are alienated from all intervention. Ultimately, according to Debord, when spectators care, they have limited agency.

Countering Debord's position, Jacques Rancière makes the claim that spectators $d o$ care when engaging with the spectacle. Rancière discusses these ideas in The Emancipated Spectator, outlining that we are participants when we witness suffering, thereby developing guilt, and a need to avert our gaze, which culminates in a desire for physical distance because of feeling implicated (2009, 85). For Rancière, this feeling of implication is necessary to foster a "disposition of care," albeit somehow a conflation of pity and compassion occurs - the opposite of Boltanski's distancing effects. Claiming that pity can lead to compassion, commitment, and social change, and similar to the ideas of Rancière though counter to Debord's claims, spectator agency is possible for Boltanski, however, justice for the sufferer fails to be sought by the spectator because compassion is lacking when the spectator feels pity (Boltanski 1999, 151). Here, Boltanski substitutes action for observation, when the spectator relates to the sufferer only through judgment - a desire to never be in the situation of the sufferer-and claims that modern humanitarian movements are marred by "mutual otherness" $(1999,189)$. He describes this condition as temporal and spatial distance that produces a lack of understanding and connection on each side of the spectacle. With this, for Boltanski, the problem is not getting spectators to care, but instead is getting spectators to critically 
engage with the politics present in images of suffering, so as to bring about the possibility of positive change. In answer, Rancière suggests that a spectator can engage by identifying with the sufferer, not by judging. To do so, Rancière suggests that meaning derives from the "community of sensible data," which he describes as perceivable and sharable in the simple act of seeing the suffering in the image $(2009,102)$. Rancière does not address the fact that boiling down all spectacles of suffering to the same point - that all human pain is equal, and similarly knowablemistakenly has the spectator appropriate the suffering of another as their own. And while it is optimistic to assume that spectacles of suffering can unite humanity under the ethics of helping others, this assumption places agency in the spectator alone, and removes the sufferer's situationspecific plight, by claiming commonality.

In sum, with Boltanski, the analysis exists in audience reception of the image, not with the image itself and what meanings it might carry. For this reason, his ideas are only relevant to my study here in so far as the symbolic associations are present within the frame, not beyond its borders. Visible suffering, then, is the focus of my discussions where Boltanski is concerned. The main differences between Boltanski, Debord, and Rancière are their conceptions of distance: Boltanski finds that distance between the spectator and the sufferer causes indifference for the spectator to aid the sufferer. Distance for Debord is what rescues the spectator from losing all agency, in being overtaken by the power of the spectacle, while for Rancière, physical distance enables a spectator to be critical of what they see comprised within the image of suffering. It is here where the link to transmissive violence emerges: seeing the framed violence allows us to know that the depicted violence has transferred beyond the moment of photographic capture, moving along with the image itself.

In Frames of War, Butler suggests that what is framed in a photograph can "break through" space and time: "The frame does not hold anything together in one place, but itself becomes a kind 
of perpetual breakage, subject to a temporal logic by which it moves from place to place. As the frame constantly breaks from its context, this self-breaking becomes part of the very definition" $(2009,10)$. Here, both time and space are implicated. As the image moves from one location to another, and through different points chronologically, the details within the photograph also move. Butler suggests that of course the image itself changes location, but also the very details represented in the frame, too, can change position, carrying with them different ideas that may or may not have been previously seen by other viewers. This "breaking through" is simple, in that it seems obvious that different people might see different things in the image, but it becomes complicated because of the contexts that help to shape the image. Specifically, contexts are both about the image itself, and those who engage with the image as an object. While the image does not alter what it portrays exactly, looking at the image in different eras, and with different cultural experiences, might bring about alternate perspectives. For instance, when lynching photos circulated as postcards, they were seen as normal and acceptable, as contrasted to today, when many people, regardless of race, would look at these as despicable, cruel, and completely unnecessary keepsakes. Time alters the original context because cultural norms shift. Thus, what is altered in this example is not the image itself, but instead what appears in the frame changes. This alteration is the "self-breakage" that Butler describes.

For Virilio, while the development of photography is certainly steeped in combat practices, time is also a factor in how media relay information. He discusses this concept in War and Cinema: The Logistics of Perception, describing how technologies of transportation, communication, and information intersect and have been developed particularly by militaries. According to Virilio, photographic technologies transcend time because they illustrate something that occurred in the past, though make something visible in the present $(1989,15)$, echoing what Butler describes above. Virilio suggests that the key dimension of these technologies is speed, whereby at any given point 
in time, military advancements of transport, communication, and information are always the fastest and best they have ever been. In particular, the development of digital means has allowed for "static warfare [to be] transferred to the technology of lightning-war" $(1989,74)$. In this way, rapid development is an asset for any army to surpass its enemy. Not only does the transfer of information occur at faster and faster rates, but also along with this comes the ability to assess that information at faster and faster rates, thus increasing the overall speed at which war is waged. Important to my task here, however, is that the images used to gain knowledge about enemy territory have not been the only function of camera technologies in war: photography also provides a way to remember and commemorate what has occurred, recalling Virilio above. As it became more affordable and common for soldiers to have their own cameras, rituals like the compilation of images in an album developed (Struk 2011, 51). And yet, practices like these had been occurring even before the introduction of cameras.

Kenneth George discusses a pre-camera ritual of remembering and commemoration, the practice of headhunting, in Showing Signs of Violence: The Cultural Politics of a TwentiethCentury Headhunting Ritual. He presents ideas about how this practice confirms group membership, and also discusses what occurs with the representation itself. While for George the representation is a detached human head, this object as a representation is no different from the representations I discuss here. Namely, the representation aims to communicate about the past incarnations of this ritual, thereby carrying with it a history that is called upon with every use, thus offering a commemorative function. Furthermore, commemoration involves traditions whereby the passing along of memories is highlighted; the notion of an "original" representation is a misnomer because each produced representation is itself a copy, where the origin is blurred by the rich and varied ways that the ritual materialized (George 1996, 187). Here, Benjamin's aura is irrelevant because there is no single origin. George goes on to describe commemorative traditions as "reenactments" 
$(1996,193)$, which further solidifies the notion of re-creation in representation and the invocation of the histories carried therein. George claims that these rituals occur in practices of headhunting, which I link to the practices of lynching, hunting, tourist, and journalistic photos, in addition to war trophy photography. For example, a lynching photo would not be a lynching photo if it depicted the lashing out and success of the victim escaping; the lynching photo is a lynching photo because it illustrates what happens when an Othered body fails to adhere to the (racist) protocols of the time.

Girard, too, discusses ritual violence, suggesting that it is a form of "good" violence, one that seeks to purify and cleanse a tarnished part of a culture $(1979,37)$. Often, this tarnishing has to do with group disagreements or challenges, and the damaged aspect of the group can be fixed if the group can be brought together again. The use of violence, here, rids the group of the mishap, by bonding the members to each other with the "unifying power of a common enemy" (Girard and Kennedy 2016, 00:29:00). And so, the act of violence is turned into an object that itself becomes a keepsake of this struggle. According to Girard, this object can be a human body, whereby the focus is on one person who represents all that the group aspires to eradicate or fix, thus "we are saved through violence that we all committed together" (Girard and Kennedy 2016, 00:33:30). The object onto which the violence is performed and affixed becomes a trophy, one that represents the ritualistic acts that occurred in its making. Once more, violence, or even simply the idea of it, is capable of transmission - from an object to something or somewhere else-in engagement with said object. However, these objects are not always seen as inherently violent. Recall for instance lynching postcards, whereby the positive aspects that bond the group outweigh the negative horrors the object might depict: "properties of violence - particularly the ability of violence to move from one object to another - is hidden from sight by the awesome machinery of ritual" (Girard 1979, 19). And so, not everyone will see the horror of lynching photos, and yet, the horror is nevertheless present; the knowledge of this is transferable. 


\section{A Symbolic Genealogy of War Trophy Photographs}

W.T.J. Mitchell states that the photographs from Abu Ghraib are the most spectacular and disturbing images from the war on terror $(2011,112)$. Positing that the most disturbing are those of the naked human pyramid, Mitchell proclaims that these images are so strikingly memorable that recalling them may only require a verbal reminder $(2011,113)$. What is perhaps most remarkable about the photographed events at Abu Ghraib is that, without visual evidence, the abuse would likely not have come under such scrutiny: the production of the photographs was itself the crime (Mitchell 2011, 126; Morris 2008, 15:55), or, as outlined in this dissertation Introduction, the photographs are the problem. What the images have to hide is a dark military secret: they not only illustrate the barbarity of those who posed the detainees, but also authenticate the abuse with documentation of the events themselves.

\section{Soldiers’ Scrapbooks from the Art Gallery of Ontario Photo Collection}

This section contains descriptions and analyses of six photographs or whole pages of soldiers' photo albums. The first features two images, each showing alternate sides of a downed plane, and a small newspaper clipping titled, "The Moods of War" (which will be written out in full and discussed in the analysis section that follows). The image on the top left shows the right side of a plane, forward facing. The plane, while crashed onto the ground, is not in complete disrepair: some of the siding is missing but the overall shape of the craft is still intact, nose on the ground and tail in the air. The craft name, E.2520, is legible on the right side of the tail. The nose of the plane is breached, as it appears to be the first point of contact with the ground. Finally, the front propeller is disconnected from the nose, though part of it is flat on the ground while the other part rests against the nose. Herein is the key difference between this photo and that of the bottom right: the part of the propeller that rested against the nose in the top left now appears flat on the ground in front of the other larger piece of the propeller. The top left, then, appears to have been taken first, as the second 
image might indicate that wind or gravity knocked the propeller piece, originally resting on the nose, to the ground. This second image, on the bottom right, shows the plane from the other front angle, the left, though no pertinent new information is presented. Surrounding the plane in each image is flat terrain, with grass and mud, while in the distance a few trees can be seen, and in the top image, a small portion of a building is visible just behind the plane in the middle of the photo. A Bristol is British plane, and the pilot himself also is also British.

There are two pages from a soldier's personal album. The first page has four photos, two of which are smaller and appear in the middle right and left. They show uniformed men "at rest," also known as "khaki portraits," with their arms linked between each other. The top photo shows two men, both uniformed but in relaxed positions, hands on hips or in pockets. Each of them looks at the camera, squinting or smiling slightly. The photo on the bottom of the page features a crashed plane turned upside-down. The caption indicates that the plane was just taking off, and that the pilot was one of their own. Four men appear in the shot, seemingly each preoccupied with appraising a component of the plane.

The second page has three photos. The top photo shows another plane that took a nosedive, though this one appears not to have crashed exactly, since much of the body of the plane is intact, though it is upside-down. The second image, on the bottom left, shows four men at a dining table. One of them is barely in the frame, while the other three gaze into the lens with varying degrees of smiles. Two of the men are seated, while one stands behind. Finally, the third image appears on the bottom right, and features a man in uniform holding a small white dog. The man stands outdoors, trees and grass around him, holding the animal up to his torso and face, as he looks toward the camera. Surrounding each page of this photo album are little airplane stickers, which add a personal touch and detail to the blank areas of the pages. 
Another album page features ten small photos, all the same size. Each of them is taken outdoors, with many of them in sandy locations. The top left shows grassland and a train track, while the centred top is an overly lit image of a rocky hill and bush. The image in the top right features three uniformed men seated on the sandy and rocky ground, surrounded by small shrubs. There is a group shot of uniformed men, the left image on the middle row, though they are seated restfully without weapons. The middle image of this row features many huts in the background, while foregrounded is sand in which many footprints can be seen. On the right of this mid row is an image of two men climbing up a rocky façade. Finally, the bottom row features photos of animals: the left image shows a uniformed man seated on what appears to be a bale of hay, holding a small white dog, while another man can be seen in the background along with other bales of hay. A lamb appears in the middle two images, one facing forward, while in the other, the animal is in profile. The image on the bottom right shows two dogs beside one another, one lying down and the other upright, with huts in the background.

"Devastation of war" show bodies in varying degrees of decomposition. On the first sheet are three photos, with the top image showing the skeleton of a soldier in the muck, skull inside a helmet. The middle image, too, shows the outline of a human body in the mud, though instead of bones, the figure can only be deciphered because of the clothes that have not yet decomposed. The image on the bottom shows more human bones, mostly a skull and ribcage, while two soldiers stand on either side. A small pool of water can be seen behind them. A caption on the top right of the page reads, "ce que decouvre 1'Yser en se retirent-1919." Translated from French to English, the caption states that the bodies were found at the Yser River, in the north of France entering Belgium, and suggests that these soldiers were retreating.

The second page also features three photographs. The top two are alternate viewpoints of the images on the previous page: skull, ribcage, other bones, and helmet sitting in mud, with the middle 
image showing the legs of one soldier, similar to the bottom image on the previous page. The bottom image here, however, is different from any of the others. This one shows a dead person, on overgrown grass, with two white chalky lines that appear in the top left frame. The body is naked and covered in dirt, with wounds and blood caked on the exposed flesh. Two captions are visible on this page; the top is the same inscription as on the previous page, while the other at the bottom left reads: "[unknown word] des boches en voulout passer la frontier." The caption suggests that these German men were attempting to cross the border, presumably into Belgium, from France.

Each of these above examples is meant to sketch an overview of the general composition of war trophy photos. Sometimes banal, and sometimes gruesome, these images intentionally blend everyday life and the horrors of combat. While the featured experiences may vary, the images all together suggest the solidification of groups - with happy posing, alongside either those with whom we identify or those Othered bodies that we seek to disassociate from - and the intended desire to remember these moments with the act of photographic capture.

The clipping, "The Moods of War," has no date, and appears in the top right corner of the album pages. Lance-Corporal C.F. Presley, of the $6^{\text {th }}$ Battalion Welsh Regiment, located in France, offers his viewpoints on wartime:

The more I am becoming acquainted with the phenomenon of war the less I understand it. It is like some fantastic monster that nobody knows but everybody likes to have a look at. Sometimes it swears at you, sometimes it growls and frightens you, sometimes it lifts its heavy fist unexpectedly and strikes - just missing. You will run for all you are worth, but when you look back at it, it will have a coquettish, smiling countenance for you, tempting and inviting you to come back. No one likes to die, neither is anyone indifferent to his fate. We all fear the cold and dark prospective domains of the Unknown [sic], but the power of brain thrusts everything aside, and even enables us to be happy. Man volunteers and deliberately takes the path leading to his own destruction and makes himself happy in it. The truest beauty in life we can see now when that life can hardly be called our own. We fight and work for our lives, but never grumble. Life is uncertain; it may be short, perhaps it is almost at its end, but the serene joy of it is quite an adequate compensation for all its hardships. (Art Gallery of Ontario Photographic Collection) 
While no indication in the album exists, proclaiming personal knowledge by Reynolds of Presley, it nevertheless appears that the words of Presley resonated with Reynolds. The juxtaposition of volunteering for duty and the horrors faced once there suggests masochism: Presley and Reynolds both know they are in awful situations, and yet they must partake. Placing these words alongside the images of crashed planes reinforces the presented ideas, that one must prepare for the worst, and that these fears may well come true. But if not now, the worst might happen another time. Either way, keep going; everything is awful and everything is great. These three items alongside one another suggests that Reynolds knew and understood a decent amount about his situation in life, and that making memory objects allowed him to both express and share these experiences.

The above example does well to preface the handful of dead body photos that followed, where the perils of war are obvious. What strikes me the most here is the lack of jovial "daily life" that appears in many of the other images. There is no posing alongside the carcasses and no photographic juxtaposition with said daily life back at camp; the carcasses are alone, their lack of life radiating from the frame.

\section{Prisoner of War Photos from the U.S. National Archives}

Each of these eight images is accompanied by a caption, which shed light on the depicted events. To analyse them, I begin with captions, if available, and then describe what occurs within the frames of the photos. This first image features one man, a German prisoner of war. He appears slightly dishevelled, dirt or stains on his coat, cap and headwear askew. The setting is uncertain, either indoors or out, but behind the man is a wood panelled wall with a window. He looks into the camera, seemingly caught off guard, perhaps irritated, indifferent, or questioning. His arms fall to his sides, though it is not known if they are somehow shackled. A piece of paper is affixed to his chest indicating that his back is injured and that he should be handled carefully. 
While numerous men can be seen in this image, only one stands out in particular. The caption to the photo indicates the men featured are American soldiers, captured by Germans on the Western front. The men appear to be walking in a line, on a wet, muddy road. The background left of the photo shows a building with a doorway, in which a man stands. The row of prisoners walk with heads downturned, their hands in the air depicting a familiar sign, "surrender." The man in the foreground does two things different: he clasps his hands behind his head, and looks directly at the camera.

Described as featuring communist guerrillas and their families in a Korean prisoner of war stockade in 1951, this image shows more than 30 men eating from small tin bowls. The men sit in three or four rows, tightly packed, with crossed legs that nearly touch the back of the man in front. Most of the heads of the eating men bend forward. To the background left stands a man who holds his left cupped hand up, though it is unclear what is in his hand, or what he is doing.

The caption of this next photo indicates that the man centred in the frame is a German general, convicted by an American tribunal and sentenced to death by firing squad, in Italy, 1945 . Five men in total appear in the photo, with the background consisting of a high wall. Two stand on either side of the German general, who are fastening him to a stake in the ground; one of the two men has his left hand on the abdomen of the general, presumably holding him in place. Two other men stand in the foreground, though off to the sides of the frame, seemingly in discussion and looking at each other. The one on the left holds a bible in his left hand. The man on the stake is the only one who faces the camera, looking into the lens or just off to the right, with a pensive expression and a stern jaw.

Another image features German prisoners in a French prison camp. Approximately ten men fit the frame, though numerous others are behind them. The men who stand and sit behind are at the front right edge of the frame. All of these men are behind a barbed wire fence, which is held up by 
wood poles, one of which appears left of centre in the frame. The men are wearing German war garb of the time, 1917-1919, of long button down coats and caps. One man, who stands right of centre, holds something pointy and looks off in the distance. A man stands behind him looking at the pointy object. Five men stand to the left of them, each looking at the camera, hands in pockets. All of these men have a tight-lipped look on their face, perhaps squinting because of the sun.

Similar to the barbed wire fence described above, though accompanied by a grass roof, an image features Japanese prisoners of war at Guam behind barbed wire. The caption indicates that Emperor Hirohito has just announced Japan's unconditional surrender, August 15, 1945. Dozens of men appear in the frame, and yet only about five faces are visible. Arms by their sides, hats in hand, these men stand in rows. The men wear light coloured, loose fitting clothing. Each man stands and casts his gaze downward; no eyes can be seen.

A photo shows numerous men who stand around watching two marines usher a blindfolded man across a narrow plank. The caption reads: "Marines unloading Japanese POW from a submarine returned from war patrol," in May 1945. Each of the two marines has a hand on the prisoner, one walking in front and the other behind. The marine in front holds the railing with his right hand, gazing slightly downward at the prisoner. The marine who stands behind the prisoner holds a rifle with his free hand. Another marine can just barely be seen on the right edge of the frame, also holding a rifle. The prisoner, who is centred in the frame, in profile, walks tentatively across the bridge, all eyes on him.

The caption that accompanies this next image indicates that a Viet Cong prisoner is awaiting interrogation by U.S. Special Forces, on January 23, 1967. The prisoner, who is centred in the frame, is the only figure in focus. Beyond him is rocky sand, two blurry small buildings or structures, and two U.S. military standing behind, visible only from the neck down. A third U.S. military shoulder is just barely in view in the top right of the frame. The prisoner, who crouches on 
the ground, knees tight into his chest, has his arms tied behind his back with a wooden stake between his back and elbows. Though blindfolded, it is clear that the man is shouting, as the skin of his cheeks is pulled tight around his jaw, his mouth open with corners turned downward.

These sets of images, from The Art Gallery of Ontario and The U.S. National Archives, show a very different type of photography from the Abu Ghraib photos. Professional photographers took these photos; the images are compositionally balanced, even if showing awful things. The images depict what I refer to as "white lynching": white people looking into the camera while marching to their death. They are enemies to those who have captured them, yet get to be proud, to walk with dignity, and can look into the camera - at the photographer-while they are alive. Their life-ness is capturable, not simply their subdued bodies, their undoing, their death. Each of these images seems to invite those photographed to look directly into the camera lens, to plead for their lives, to beg for forgiveness. All of these men appear to possess a great amount of stoicism, which might be deemed "manliness." As a contrast, the featured Japanese soldiers are portrayed quite differently: not only do their eyes fail to meet the camera, but even the eye line of the frame looks downward, depicting these men as small, defeatable. One can even be seen crying, what seems, for his life. It is not lost on me to compare these images to the practice of collecting Japanese skulls in WWII: those deemed subhuman need not be portrayed with dignity, either in a photograph or in death.

Trophy photos come in many forms, sometimes with ominous smiles from one's own side in war, other times merely remarking on the peril of the enemy by taking a photograph without one's self present in the frame. In either case, the war trophy photo affirms the soldiers' experiences and offers the potential of story sharing with these memory objects. 


\section{Types of Photography ANd Photographic Practices}

\section{Lynching Photography}

Seeing is also about "the right to look," and who has the authority to do so in a given context, a circumstance exemplified in lynching culture and photos from the American South. Mirzoeff describes the right to look as something counter to simply seeing, as a process motivated by colonial histories (2011). Mirzoeff describes a "single" look as inherently violent, because it is rife with authority and alienation when only one party is permitted the act, whereas a "mutual" look occurs when each person "invents" the other in their own vision process $(2011,1)$. Colonial histories have moved through the former incarnation, rather than the latter, in effect producing uneven and discriminatory types of looking. Many incarnations of the gaze in practice must be considered, from the dangers for a Black man to look at a white woman, to the complicated gaze of “colonial desire," whereby simultaneous repulsion and desire occurs by whites for the bodies of Blacks (Young 1994, 149). As a consequence, the right to look is not awarded equally: in certain instances, actual laws have been developed along these lines. Take for instance the Jim Crow laws in the Southern United States, spanning the late 1800s until the mid 1960s, which dictated that Black persons should not "recklessly eyeball" whites for fear of "rightful," or legal, retribution that varied from imprisonment to hanging (Berry 2008). In recent history, a farmer named Matt Ingram was charged and convicted under these offenses in North Carolina, in 1951, for the assault of a white woman; the woman stated that she simply did not approve of the manner in which he looked at her, from sixty-five feet away (Berry 2008). Another example occurred during WWII, in which Jewish people were questioned, detained, or worse, for making eye contact with Nazi officials, and more recently, prisoners at Abu Ghraib were told not to "eyeball" military officials (Mirzoeff 2011, 8). Thus, the act of seeing, as the right to look, is not available to everyone. Such histories invoke 
cultural memories that persist in the present and are not easily forgotten (Mirzoeff 2011, 6; Mbembé 2001, 14).

These intersections of visuality and the right to look are worth considering today in relation to war trophy photography, particularly considering the photographs from Abu Ghraib. The Abu Ghraib photos can be linked to lynching photos from the American South, where hangings of Black men occurred, to "correct" their wrongs by public murder. What is captured in the frames of many lynching images is staggering: white members of the audience can be seen smiling and pointing, making gestures of pleasure at the humiliation, pain, and death that occur in front of them. With this, the history of capture, detainment, and even the killing of Othered bodies are marked by the enjoyment of white audiences. The photos from Abu Ghraib present an eerie similarity, where the participating U.S. military knowingly pose, at times with glee, echoing former instances where it was legal to punish the racially Othered body. The similarity is clear in the next three examples of lynching photos, which lead into a comparison with the historical significance of photographs as souvenirs of this violent, racist practice.

Perhaps most striking about "The Lynching of Tomas Shipp and Abram Smith" are their aesthetic quality: though featuring two black men hanging from a tree, the foliage is well lit and shadowed, and the grey scale colour of the photo offers crisp distinction. The dead men's bodies hang limply, and each of them is covered in dirt, with torn clothing. The man on the right appears to have a sheet wrapped around his waist, for decency perhaps because his pants came off in the hunt. Below these bodies is a mass of people, all white. The people in the foreground are doing a variety of things, some looking at the hanging bodies, some looking aimlessly around. Four people are of particular note: three look directly at the camera, one of whom points to the body on the right with his left hand, and another man is seen smiling while holding the hand of a woman. The postcard version, while the same image, appears faded and washed out, in sepia tone. The crowd also 
appears smaller because the frame is tighter. The only new information is the location and date, found on the left of the frame, reading: "Marion, Ind. Aug. 7-1930."

Like the image above, "The Hanging of Elias Clayton, Elmer Jackson, and Isaac McGhie" shows numerous white people standing around the hanging of two black men. The two men centred in the frame, however, are hung from a post of some kind, instead of a tree. Their shirts are stripped off to their waists, still buttoned, arms still through the sleeves, chests exposed. The man on the left appears skinny with ribs protruding. The man on the right is bleeding from the neck or top torso; the top of his chest appears streaked with a darker colour. White men surround them, appearing in suits, overcoats, and hats. Nearly every one of them looks toward the camera; some even appear to have struggled to show their faces. On each side of the frame stands a man who smirks if not smiles: the one on the left has slightly upturned corners of his mouth, while the one on the right beams with teeth showing.

The stories these images tell are frightening. The torn clothes and dirtied bodies of the murdered Black men indicate that there was struggle beforehand. The body of the man who hangs from the tree, on the right, tells something more: for him to have a sheet wrapped around his waist, instead of pants on, indicates that he was either apprehended while in the privacy of his own home, perhaps asleep, or that his pants were lost in the process of capture, which seems suspiciously humiliating. The smiling and eye contact of the white faces are eerie, and call upon the unequal history of "the right to look." Such depictions mirror the photos from Abu Ghraib, which feature white, smiling bodies alongside brown bodies, whose heads are often covered, where the right to look is literally withheld.

Shawn Michelle Smith gives an account of U.S. lynching culture, from the late 1800 s to the early 1900s, with specific regard to the production of photographs at lynching sites. Describing these incidents as the production of "spectacles of whiteness," Smith discusses the visible aspects in 
the frame that are made to construct and verify white power, as achieved through the gaze, or as Mirzoeff says, "the right to look." Smith describes the spectacle of whiteness accordingly: "The representation and reproduction of the violated black body can function as a kind of fetish, obscuring from view the white torturers who also inhabit these images" $(2004,118)$. With focus on the construction of white audiences, people in these crowds often cluster their bodies around the lynching victim: their eyes brazenly meet the camera, seeming at times to even be cheerful (2004, 120). The white audience members appear surprisingly unafraid. In photographs of lynch mobs and victims, Smith states, "white spectators are, remarkably, not veiled or masked" (2004, 199). Omnipresent, yet diffuse, white power is homogenized among embodiments of white spectators, and, in so being, is not individually attributed. Richard Dyer describes blackness as bearing the burden of visibility, as strikingly noticeable in contrast to the diffuse invisibility of whiteness (1988, 44). Smith expands on this, pointing out that while the power of whiteness is everywhere and nowhere at the same time, it is nevertheless embodied in U.S. culture, reaffirmed by the production of lynching postcards; these objects became common, if not normal, in their distribution (2004, 139). In this way, the audience members or perpetrators become the focal point- the unifying purpose of the image - just as I argue with war trophy photographs, and particularly those from Abu Ghraib.

Smith further points out that these white audiences have been privy to the sights and sounds of torture, of a body undergoing such extreme duress that it has found eventual death $(2004,125)$. These scenes, as Smith describes, centre on the concept of control: "Control is the fantasy of whiteness constructed here. A look of distress [by the white spectator] might reveal the cracks and pressure points in this image" $(2004,125)$. It can never be known what individual white audience members might be thinking or feeling, but together they photographically make up an overall group of composed and resolute people: their eyes meet the camera, and many even smile. A 
transformation occurs when lynching photos become postcards, where a personal moment is commodified to reproduce and solidify group forms. Smith suggests that these postcards reproduce white purity, where the Black body has been corrected for coming too close to a white body. Finally, the convergence of public event — the act of a community lynching — and private momentthe mailing of a postcard to a friend or family member - solidifies the racist dominance of whites. The sending of a piece of cardboard from one county or state to another is significant because the act pictorially affirms and maintains unequal race relations. Smith points out that these postcards are prepared with forethought: "these photographers designed images not simply to document or depict but to memorialize; they created mementos for participants to share with family and friends (2004, 121), just as occurred with the email sharing of the Abu Ghraib photos with friends and family. Smith further describes the sociocultural role of lynching postcards: transcending both the public and the private spheres, there is an intimacy conveyed with these images. As with other types of postcards, these memorial souvenirs - as trophies - express sentiments of "I was here and I thought of you" $(2004,122)$. With this shared sentiment, an imagined community is fostered between sender and receiver. Smith describes this exchange as "individuals performing community" with the sending of the postcard, and affirms that these images "symbolically expand a community's claim on time and space by connecting static individuals with distant places. Postcards function as fantasy sites of desire for distant viewers; the sender weaves family and friends at home into a larger spatial territory by sending images from afar" $(2004,122)$. This is precisely a colonial act constructed from a piece of media rendered to symbolically normalize and order race relations in the U.S., during and after the practice of slavery. Citing Ashraf Rushdy, Smith adds that "one group of white people gathered around a burned black body, was communicating to another group in another county: they had done their part, asserted their place in the world" (2004, 70). The photograph here is the bridge between these two disparate groups, and with these photos, white 
power and pride are easily expressed in pictorial form; gaps between space and time are sutured via the acts of sending and receiving $(2004,125)$. The camera thus allows for the capture, and the subsequent processing and distribution of the image, enacting an emblem of white power and privilege $(2004,126)$. Finally, these images represent reproducible acts, which are reinforced when the images circulate widely $(2004,135)$. Here, media help to solidify group relations, and communicate what is at stake for racially Othered bodies.

\section{Hunting Photography}

Besides the lynching variety, hunting photography is the other most similar to war trophy photography: the trophy is ultimately about the hunter, and the image of the captor's game becomes the trophy, showing the skill of the hunter (Marvin 2005, 7). Thus, there is no trophy without the activity of the hunter. Visual anthropologist Matthew Brower describes the moment caught in a photograph that depicts an animal's capture as "camera hunting," calling these images trophies $(2005,14)$. The "game" is not only that which refers to the hunted prey, but also describes the quality of hunting itself: certainly known as a recreational activity involving challenge, skill, and dedication, hunting also at times consists of manipulation and questionable scruples, where the desire or pressure to "win" is paramount.

Trophy hunting photography began nearly as early as the inception of the camera itself, in the mid-1850s, with the connection of gun and camera technology. William Nesbit combines the two, writing about his "conversion from gun to camera" in How to Hunt with the Camera: A Complete Guide to All Forms of Outdoor Photography (1926, vii). Similarly, George Shiras notes, in Photographing Wild Game with Flashlight and Camera, "when the finger eagerly pulled the trigger and the eye anxiously sought to pierce the momentary veil of smoke between the gun and its intended victim, and then to that later period, when the simple pressing of a button captured, for all time, the graceful image of the hunted quarry, one becomes conscious of a peculiar mental 
evolution" (Shiras 1906, 367). Citing both the above, Finis Dunaway adds that the evolution described by Shiras is particularly interesting because of the "upward" movement described: "by claiming that photography represented a 'mental evolution', Shiras suggests that taking a picture was more refined than killing an animal, that the camera [is] a more civilized weapon than the gun" (2000, 216). Dunaway is careful to note that Shiras nevertheless sees that "hunting with the camera [is] not very different from hunting with a gun: photography offered similar pleasures, excitement, and thrills of the chase relished by hunters" $(2000,216)$. Moreover, Dunaway adds, "according to Shiras, the death of an animal was not absolutely essential to the hunting experience" $(2000,216)$, but instead the focus was on manliness and aggression (Shiras 1906, 368; emphasis mine). To be sure, while each tool—camera and gun—offers similar experiences, there are noteworthy differences. The gun can kill, whereas the camera can capture the experience of hunting without physical injury to the prey. To photograph from a position of "manliness and aggression" usurps the desire to take another creature's life. In this way, dominance is key.

Hunting photography in America is rooted in training for war and in expressing colonial power, but also had educational intentions. Early on, hunting photography had honourable dimensions: the Smithsonian and other scientific organizations hired hunters to capture images for scientific endeavour, used in both dioramic display and research (Herman 2003, 460). Moreover, there were prominent cultural and political individuals shaping how people saw hunting, centring on the idea of recapturing an "imagined past" (Herman 2003, 456). Connecting this point directly to war, Theodore Roosevelt wrote in 1910, in The Wilderness Hunter: "No form of labour is harder than the chase, and none is so fascinating or excellent as a training-school for war...the virility, clear-sighted common sense and resourcefulness of the American people is due to the fact that we have been a nation of hunters" (as cited by Herman 2003, 458; emphasis mine). Not only was hunting connected to training for war, but it was also an expression of colonial power. At this time, 
though later as well, photographs took a colonial shape, primarily recording white men with whole or parts of dead animals, ultimately illustrating prowess over both nature and racially Othered people who helped with the hunt because they "were closer to nature" (Ryan 2000). Said another way, "in demonstrating their imperial control over the world, hunters demonstrated their fear of a world out of control" (Herman 2003, 455). There was irony in that American men prized themselves in hunting, but saw the hunting done by American Indians as barbaric (Herman 2003, 461), a not uncommon double-standard often used by colonial powers regarding the Others with whom they come in contact. The overall point, however, is that white male hunters expressed their virility and readiness for war in the act of hunting, and photography offered proof.

Moving beyond photographic practice to the objects acquired therein, Linda Kalof and Amy Fitzgerald studied the display of trophy animals in hunting magazines. They conclude with two points: first, the animals featured are Othered, similar to people who are "minorities," and second, that the rare representations in which white women and men of colour pose alongside prey, as hunters themselves, adhere to gender $(2003,117)$ and racial $(2003,119)$ stereotypes. In this way, these hunters are abnormal, only reaffirming the true hunter as white, masculine, colonial settlers. Highlighting this iconic hunter and following the work of Haraway, who suggests that photographs of animals are "story-telling instruments" $(1989,41)$, Kalof and Fitzgerald find that hunting photography is nothing more than trophy collection: "Instead of love and respect for nature and wildlife, we found extreme objectification and marginalization of animal bodies" (Kalof and Fitzgerald 2003, 112). Here, the photo echoes and reinforces the success of subduing and catching the prey, and, where hunting magazines are concerned, Kalof and Fitzgerald note that the selection process demands high quality hunting photos and a good story $(2003,115)$. Quality hunting and a good story feature certain characteristics: "The most frequent visual image in the magazines was a photograph of a white male hunter smiling at the camera and kneeling on the ground next to his 
trophy...the hunter's weapon prominently displayed" $(2003,117)$. Kalof and Fitzgerald further address the physical contact between the human and the animal: "hunters commonly have their hands symbolically placed on the head of a huge bear, or clutching the antlers of large elk or moose, or just resting on the body of a dead animal. This human physical contact with the dead body serves no practical purpose other than to strike a pose that conveys messages of dominance and possession" $(2003,118)$. Eerily, these compositional elements echo what appears in a variety of war photographs, for instance the physical touch of certain things or people within the frame. Moreover, just as Kalof and Fitzgerald describe the featured animals as Othered, so too emerges the pictorial connection to Othered enemy bodies in war trophy photography: enemy bodies are already seen as less than human, which means they can be photographed like animal prey.

Elements of hunting, war, and lynching photography are outlined in what Jay Mechling calls "the vernacular of photography hunting" $(2004,54)$. Connecting hunting photographs to those depicting war and lynching, Mechling outlines how each photographic genre blends with the next because of the content featured therein: "The hunting photograph conjures all these associations once the viewer has seen a photograph of lynching. Again, without arguing a direct line of influence, it seems to me an emergence in vernacular photography of the early twentieth century a visual formula across these three realms of experience - hunting, war, and lynching" $(2004,54)$. Explaining how each are connected, Mechling outlines that:

It is not necessary to think that the photographers and their subjects in such hunting photographs consciously modelled their arrangements and poses in war photographs. Far more likely and interesting is the possibility that there was emerging simultaneously with war photos in the late nineteenth-century a visual formula for picturing the surviving hunters and their prey, and that this formula bled freely across the boundaries of the genres - the hunting snapshot and the war snapshot. $(2004,52-53)$ 
Discussing the work of James Allen and his book, Without Sanctuary, Mechling outlines how Allen connects a hunting photo, in which a proud father stands with (likely) his son and a deer corpse that hangs between them, to various lynching photographs. Mechling writes:

In some of these snapshots the deer is hanging from a tree, and in one memorable one I have seen (though not a snapshot I own) a child of no more than three or four years old poses with his father under a tree with four deer hanging from its limbs. The lynching photographs, a macabre photographic genre kept away from public scrutiny for decades until Allen organized the exhibition, had their origins in motives quite like the motives for taking the hunting photos. A lynching was a public event, sometimes with festival overtones, and people captured the event with photographs for remembering the moment of 'folk justice'. Some of the lynching photographs are of the victim(s) and a milling mob, but in some a member or two of the mob actually poses below or near the hanging body. Some of the most disturbing of these show parents posing with children. $(2004,53-54)$

It seems, then, that the histories of hunting, lynching, and war photography are linked by compositional likeness. Further connecting hunting practices to war trophy collection, Kalof and Fitzgerald discuss the similarity between captured arms or other spoils of war from the battlefield to animal trophy hunting $(2003,114)$. Commenting on the display of dead animals in hunting magazines, Kalof and Fitzgerald suggest that "animal bodies are the epitome of objectification" $(2003,119)$ and that the pictorial depictions of hunters and caught game reveal much about the relationship between those who are dominant and that which can be possessed, particularly when the hunter is pictured physically touching the trophy $(2003,118)$. Touch, beyond posing, is essential and noteworthy: to claim one's trophy, near immediate dismemberment and processing of the animal immediately follows the hunt $(2003,119)$, which can be compared to the previously discussed human-derived trophy collection in combat, with the extraction of teeth, pickling of body parts, or the boiling of heads to remove flesh shortly after battle. While none of these horrific practices occurred at Abu Ghraib, it is nevertheless important to compare the notion of "touch." Besides posing alongside the detainees, the U.S. military also touch the detainees at times, a comment on both the dominance of the participating U.S. military members, and the subdued and 
stilled detainee bodies. Four examples of hunting photos are described here, followed by a brief analysis.

Centred in the frame is a large black truck, parked on an angle, looking idyllic as if in an advertisement. Foregrounded in "Two men pose with 3 sets of antlers" are two white men, each with facial hair. One of the men appears in full camouflage, while the other wears a white T-shirt tucked into jeans. Both men look directly at the camera, a slight squint and smile reading across each face. The two men crouch on the ground, each holding buck antlers. The man more centred in the frame holds antlers that are still attached to a decapitated head of the animal, while beside him rests the full body, with antlers, of another buck. The man in the left of the frame, too, holds antlers in his hands, though these ones are scalped off of the head of an animal. This shot indicates that 3 buck in total were killed.

Three men appear in an image, two Black, one white, all crouching behind a large horned animal; much of the men's bodies are hidden from view with only top torsos visible. Surrounding them are trees and foliage, with branches and leaves strewn about the ground. A shotgun rests against the carcass of the animal, slightly off centre in the frame. The animal spans the entirety of the frame, from left to right, and fills half of the frame, top to bottom. At least one of each of the men's hands rests on the carcass, and all of them look into the camera lens. The two Black men, who appear on either side of the centred white man, appear to squint from the sun, mouths resting in a mostly relaxed state, though the man in the right of the frame appears to smirk slightly. The white man, in the frame's centre, has both hands on the carcass and a slight open smile on his face.

Though similar to the ones above, with a truck to the left of the frame, trees outfitting the background, and a male hunter in camouflage and a horned buck, the next photo differs slightly: it features two children. With the buck on the ground and the man kneeling to the left of the carcass, a genderless toddler sits atop the neck of the buck, while the older female child of about seven years 
stands behind. The toddler's mouth is open, perhaps smiling, eyes looking somewhere toward the right foreground. The older child smiles broadly: mouth stretched wide, as many teeth showing as possible. The man, perhaps the father of these two, also smiles broadly, as he leans into the heads of the children, holding the buck's right antlers upward. The buck's lifeless head also faces the camera.

The final hunting photo, older than the other ones, comes from the 1930s. This one features a large bear, who appears to be a brown or grizzly, and a man who sits atop the flattened carcass. The limbs of the bear are stretched out, front paws on either side of its head, which rests on the ground. A moustached man sits atop the bear, right hand on right hip, left hand clutching a rifle. Though the man looks directly at the lens and appears to be smiling slightly—-there is a light colour below his moustache, which appears to be his teeth-the image is too poor in quality to tell definitively. As with the other photos, foliage outfits the background, and sand or dirt fills the ground space. For each of these, the key element is posing with the captured prey, along with eye contact with the camera lens and some touching of the prey. The statures of all the hunters reflect pride and success, each taking up space in the frame, using their bodies to indicate that they were the ones who subdued the animal, either by touching the carcasses with their hands or holding them up, or by sitting atop an animal that would never allow such a thing were it alive.

Two major differences must be noted between animal-specific hunting photographs and the war trophy photos to which I compare them: the first, actual inanimate objects held in war trophy photos are physically touched, because they cannot pose themselves, whereas a number of the detainees go physically untouched by U.S. military. The second, the heads of the Iraqi detainees are a main feature of the photos from Abu Ghraib; instead of being touched by the torturers, their heads are covered. Perhaps so important are these heads that the living qualities of the detainees are unbearable to the torturers; to see them-alive, scared, responsive — might distract from the trophy 
photo posing. The canvas sacks that cover the heads imply a livingness that exists underneath but also suggest a kind of death, in the form of the head, a body part containing a vital life organ, being invisible.

Death, then, is not always the point of a trophy hunting shot. Instead, the focus is being able to relay that the hunter has successfully subdued and captured its prey. Ostensibly, the hunter could simply catch the prey, take a picture of this success, and then release it back to the wild. Such a thing would remove the necessity of the gun, as the subduing and capturing device, and instead suggests the camera as, arguably, the more humane way to partake in hunting. The outcome of securing the trophy is the same; the process is, however, slightly altered via technology.

Assuming this the case, the experience, for the hunter, might be similar. However, the experience for the prey might be the same whether or not a gun or camera is used; the prey has no idea whether or not the intent of the hunter is to kill, which means that the prey must fight for its life either way. With this, perhaps the more humane way to hunt might, oddly, be with the gun. The prey is then killed and put out of its misery; the suffering is short or shorter. Conversely, in hunting with the camera, the prey might only be slightly injured, but it also might be injured beyond the point of repair. The trauma — physical and psychological—possibly alters the prey indefinitely thereafter, such that being killed in the hunt would have been the better outcome. This project does not delve into either physical or psychological implications, though I do think, briefly tangential, this is the point at which the injury to the Iraqi detainees becomes clearer. I would be remiss not to acknowledge the rich compositional history that photographs, like those from Abu Ghraib, share with other types of images depicting championship or success over other beings. I am not suggesting that the detainees would have necessarily been better off if killed. I am, however, pointing toward the very real trauma experienced by the Iraqi detainees in the form of humiliation, which follows them beyond their imprisonment. And this knowledge, which the torturers were 
themselves aware of (i.e.: placing women's underwear on heads while hands are tied, and forcing detainees to mime sex with other detainees), couples the purpose of the photos as trophies for those who took them. The framed humiliation and pain, juxtaposed with camaraderie and victory, reinforces these images as trophies.

\section{Photojournalism of Atrocities}

Journalistic photography connects to war trophy photography because each can generally depict strife and atrocity, and, quite simply, the journalistic variety also at times features combat images. Because of this, let me revisit briefly in this section "spectacles of suffering." As outlined earlier in this chapter, Mitchell, Boltanski, Debord, and Rancière are each concerned with power and the philosophical meanings of the image, while others are interested in drama and sensationalism. To this end, journalism scholar Susan Moeller (1999), who recast the term "compassion fatigue" for media viewers, concludes that news audiences are indifferent toward distant suffering because of omnipresent distress in media. She articulates that people are tired of caring, not because of their own stresses in life, but because media bombard with the spectacular trauma of faraway Others. For Moeller, although spectators may wish to turn away, they still find it difficult not to look because they are compelled as much as horrified. As such, spectacles of suffering are of paramount importance in mass news media; stories of crisis are preferred if they feature controversy, novelty, and emotional appeal because bad news sells. Mass news do not simply relay necessary information to the public, but in recounting it, mass news becomes manufactured in similar ways as sensationalist Hollywood filmmaking. Moeller reflects upon this process in the interviews she conducted with American news producers, revealing that one specifically said, "reporters love the word "crisis" (1999, 17). Another producer likened the making of news to that of current Hollywood action film, that news competes with the explosions and humanitarian crises of the make-believe, ultimately to get the attention of an audience and to sell copy (Moeller 1999, 40). 
The sufferer might be a central figure to the news story, but the spectacle works to arouse and frighten the audience, not to simply inform.

Barbie Zelizer, author of the 2010 book About to Die: How News Images Move the Public, connects the obsession with the image to spectator action when viewing atrocities, specifically writing of circulated Holocaust photos during WWII:

Officials and politicians recognize the subjunctive value of news images in shaping public opinion and justifying policy...The use of images for political purposes relies on the recognition that abstract concepts and complicated events can become visible and understandable through certain kinds of depiction. Connected here has been an assumption that seeing photos is enough to promote action or responsiveness of some kind. Particularly following the Holocaust, the sentiment prevailed that had there been pictures available of the atrocities as they unfolded, the Holocaust might never have happened. Though that notion was laid to rest in later wars whose related atrocities were depicted but still received no sustained official attention, the presumed connection between public action and photographs persists nonetheless. $(2010,20)$

Here Zelizer illustrates the potential of spectator care - the theoretical response to the sufferer-as not enough to elicit compassion and subsequent action. The tension rests here: for Zelizer, as well as Butler, spectacles of suffering potentially engage a public to act, though uncertain as to how exactly, while for Debord, the spectacle necessarily depletes the spectator of all action to relieve crisis. For Zelizer the question centres on whether or not an audience understands what atrocities and disasters really are, besides knowing what to do about them. There is a tension, then, between providing relevant civic information, and entertaining a public. This tension permeates many, if not most or all, photos of similar likeness, including war trophy photos; this tension builds uncertainty about what to do with or about the images, in addition to what they mean. To exemplify this photographic type, let me consider two images as examples.

A vulture stands behind a small child who appears in the foreground. This child, bent over at the waist from folded knees, rests her head on the ground near her hands. Ribs can be seen on her naked body, though her face goes unseen. Surrounding her is a small amount of green grass, with 
much of the ground barren with dry dirt. The background of the photo has some greenery, while small structures appear to be made out of hay. The right eye of the vulture can be seen as it gazes toward the child, wings folded onto its back, neck crouched slightly, readying itself to attack its prey.

"Bosnian women cry during the $6^{\text {th }}$ anniversary of the Srebrenica Massacre," features three women. They appear side-by-side, though the woman on the left is alone in focus, the other two filling the centre and right of the slightly blurred frame. The woman on the left dabs her left eye with her head covering, while her right eye looks forward at something occurring out of frame. Her mouth is mid-cry, open with teeth showing, and furrowed eyebrows. The woman on the right looks at the woman in the middle, cradling her with her arms: one arm wrapped around her neck, one hand patting the woman's forehead. The woman in the middle covers her eyes with her left hand.

Both of these images depict catastrophic events, the likes of which are regularly relayed to a global public by news media. For me, the inclusion of this photo type has more to do with the content than the act of photography itself. The photographs are taken by professionals, thus appearing perhaps more visually pleasing than amateur photos, regardless of content. The content, however, depicts atrocity and strife, which are central components to war trophy photographs. And though not intended to entertain in the same way as something "fun," these images are meant to at least preoccupy, to prevent viewers from turning away, turning off the TV or phone, closing the computer, or throwing out the paper. Overall, while not as foundational as hunting and lynching images, journalistic photos of this kind inform the definition of war trophy photographs, for what they can tell about a situation, and for their subsequent ability to preoccupy or to fill the cultural mindscape. 


\section{Tourist Photography}

Different from journalistic, tourist photography is meant to depict vacation enjoyment along with the mastering of new environments, which can conjure imperial and colonial discourses (Struk 2011, 24). From a common pose of arms stretched out in the foreground of the Eiffel Tower, to the crouching down to meet the postures of local children abroad, the tourist photo is notable for the ways in which the spectator immediately understands that the highlighted individual(s) within the photo are from somewhere else, while possessing travellers' experience that enables them to appear confident in the photo's frame; they are masters of things that surround them. These photos are the equivalent of scrawling on a wall "I was here," and are meant to index this pastness whenever looking at them in the present. They are intended less for those depicted within the frame and more for those they will be shown to, and, as such, viewing illustrates the command of foreign environments and people in pictorial form. These photos, like lynching and hunting varieties, depict a private moment, though are meant for greater public consumption and appeal to a large audience because they are so widely recognizable. Three photos of this type are outlined and discussed below.

Depicting a common stance, with the Eiffel Tower in the background, the foreground features a woman in her 20s. Looking into the camera, smiling, she points with her right hand to the very top of the tower, seeming to touch the spire. She stands to the right of the frame, the tower stands just left of centre, and surrounding each are trees and unrecognizable figures of people on a cloudy day.

In much the same way as the woman described above, this tourist mirrors her stance: he to the left of the tower, which stands slightly right of centre frame. The same trees line either side of the frame, while unrecognizable figures outfit this image as well. The man's face, while not smiling, angles toward the camera, eyes looking at the lens; it appears to be a bright day, which may 
be why he squints more than smiles. Regardless of parody or not, the image is comparable to the online photographic trove from which it emerges.

The internet has an endless supply of people walking this stretch of street mimicking the Beatles on their distinctive Abbey Road album cover, including Gene Simmons and his family. This photo features four people, who each take the role of one of the Beatles, gregariously walking the crosswalk; all four of their right legs lag behind the left as they mime the famous walk.

The aim of tourist photos is not simply to capture the "I was there" moment. Of course this is foundational, and when showing the photos to others, this seems of upmost importance. However, the other motivation behind taking tourist photos is to reproduce what has come before, such that it is made clear that the featured individuals are on a trip - away from daily life and home. The cultural capital produced in this act reinforces not only the financial ability to take a vacation, but also confirms a type of (colonial) mastery in this foreign land. The 'I was here' is more than the engraving of initials; 'I was here' shares experience and adds to the history of other photos depicting similar things.

The tourist photo type, in this way, is also similar to those of war trophy photos because of the relationships contained therein. I argue that these images, while taken for those depicted in the photograph, gather importance, meaning, and value in a relational viewing; someone else must observe the photos for them to advertise the important narratives they captured. There is a specific kind of performance or staging that occurs in each of the photos - a narrative that translates when viewed - one that illustrates the capacity for the tourist depicted (or military personnel) to illustrate their prowess in the capturing of places, inanimate objects, or people as photographic things.

\section{CONCLUSIONS}

In this chapter, I explained the structured and typified aspects of war trophy photography and thus charted a symbolic genealogy for the pictures from Abu Ghraib. Similar themes and compositional 
elements were sketched within these varied photographic types, which generally reflect identifiable tropes of agonism and Othering, reinforced by the very idea that subjects can be divorced from photographic capture (Crary 1990, 196); the representation of this divorced subject, then, as a representation of Other, can be used to support an idea represented by the dominant group, or those who facilitated the photographic capture. Though sometimes not featuring opposing groups, the images nevertheless situate a type of belonging, in which Others are overtly excluded simply by not being within the frame. In the case of many of these photos, featuring those who pose of their own will, a visible cohesion is evident. Sometimes, however, the featured relationships are overtly oppositional, as depicted in lynching or hunting photos, where difference is not only highlighted but is also the very point of photographic capture. In any case, the camera eye helps see lines of division.

A concern arises for the purpose and value of such images generally, though with specific impact on the formation of soldiers' war trophy photographic type, which range from banal to graphically horrific. In any case, we are aware that there is commemoration in replication (George 1996, 193) and that "good violence" exists when structured around bringing groups together (Girard 1979, 37). With reference to some of the soldiers' photos that show crashed planes, I wonder if the existence of the image is to bear witness to the pilot's death, and to do so together as a group? If so, why not simply take a photograph of the pilot's body and the crashed plane, or even verbally relay the information to interested parties without pictorial representation? What is gained by the placement of the living soldiers within the frame? A tacit explanation may derive from the likes of tourist photography, claiming to "have been there," to provide visual proof. The image goes beyond simple portrayal of the captured moment, giving visual confirmation that those within the frame are a part of this moment in time-they are not merely aware of what happened but are also active participants in bringing this knowledge to light. The narrative becomes not just "I saw the body of a 
dead pilot," and instead is, "look at me, being there, when I discovered the dead pilot's body." Here, the value of the photograph increases because of one's own bodily placement within the frame, giving viewers confirmation of a story that otherwise might only be rumour.

The placement of one's own body within the frame enacts a similar confirmation as a fingerprint or a signature, fostering a personal link, moving away from possibility and instead toward proof. No longer can the photo be taken by just anyone; there is a direct necessity for those who captured the image. Additionally, by posing within the frame, these soldiers make the image equally, if not more so, about them, and less about the discovery of the dead pilot and crashed plane, as example. The image, then, is not merely about the dead pilot and crashed plane, because these soldiers have staked their own claim with their placement in the frame. Taken together, the combined interpretants of these images suggest that an overt claim of ownership exists over one's own experience, represented in each of these photographs. The image, then, is not simply a tourist picture, but also edges toward that of trophy, as a kind of pride for the moment depicted seeps from the frame and into our shared memories. Here knowingness and even pride can be linked to the faces of those who hunted and lynched prey; while featuring different events, the images each nevertheless conjure pride and success. It is these details - of the need to stand, posing, sometimes with pride, in the frame alongside something or someone captured, making the representation about one's own experience at the expense of the Othered - that precisely come to define these images as those depicting commemorative violence. As we will come to see in the following chapter, it is the display of pride and success, in the form of emoting and gesturing, that affirms social or group boundaries, with imitation that reproduces the very idea of the trophy. 


\section{CHAPTER 3-“IN" THE WAR TROPHY PHOTOGRAPH}

Gesture, Emotional Expression, and Camp Humour: The Case of 'Doing a Lynndie’

"The problem is that these photographs are not horrific to everyone.

They are not obviously anything."

Errol Morris, Believing Is Seeing $(2011,8)$.

A fully clothed woman in army-issued garb stands next to five or six naked men, whose only shelter-if it can be called that—are the canvas sacks atop their heads. Even with their faces covered, the shame and humiliation are written all over their bodies: their heads are downturned and many of their hands cover their genitals. Adding to this, the blurry quality of the image obfuscates much genital detail. The clothed woman, Sergeant Private Lynndie England, is starkly contrasted to the exposed bodies: not only does she point at a man's exposed genitals with one hand, the other hand gives a thumbs-up. Moreover, England casually yet affirmatively looks at the camera lens, smiling, with a cigarette dangling from the left corner of her mouth. This infamous image is now to commonly known as "doing a Lynndie." The gesture and the phrase have become ubiquitous and generic. In this chapter, I trace the legacies of "doing a Lynndie" in popular visual culture; it is tempting to denote the image in social media terms as DAL !, but in wanting to sustain the context of the original, I will restrain my shorthand to the acronym DAL.

The contents of the photo present an unsettling combination: there are attempts at humour, that resonate along with the smile on England's face, as she draws attention to the bodies of the detainees with her gestures. If looking only at the body of England, these gestures imply a comedic, almost slapstick, reference to whatever she might be referencing. Isolate what is referred to- the bare bodies of Iraqi detainees - and the oddness sets in. But the Abu Ghraib photos more generally also resonate with familiarity, however odd that might seem. Involving three types, hunting, 
lynching, and tourist, the DAL image transmits not only violence, but also numerous possible meanings.

The DAL image is polysemic. Though horrific, this image is highly ambiguous and, thus, contextual meanings need consideration. Many different things are happening all at once in this photo, and while opinions form quickly when one is looking at it-about what the photo means, to whom, and why - ultimately these ideas are competing. This does not mean that what one thinks when looking at the image is incorrect, in fact, the opposite might be the case; but with the different associations that exist simultaneously within the image, it would be near impossible to declare a singular meaning to it. One might be attracted to a single notion over another because of one's socialization or belief systems. The tendency might be to declare outright one way of reading the contents of the frame. My role here, however, is not simply to proclaim some permanently unknowable state of the image, but instead to point to, and explain, the associations and possible meanings that I see.

Following this line of thinking, it should be noted that the DAL image is named directly after what England does, not to whom she points. Though the pose obviously aims to make fun of someone who is objectified and downtrodden, the name refers to England, which can particularly be noted by the meme offshoot. The DAL meme reached peak popularity on the site "Bad Gas (2010)." England points and makes light of the horrible circumstances that occur within the frame; her gestures imply "funniness" even though this humour marks the detainees with humiliation and even despair. Nevertheless, it is her gestures and embodiment of pleasure that highlight what happens, between perpetrator and victim, in the performance of "doing a Lynndie." To complicate things, because England is the focus, identity with and even empathy is shared with her; whether or not a viewer actually sees themselves in her shoes, or experiences a shared sense of feeling associated with her, the composition or grammar of the image instructs us to see England as our 
"lead character." This is not simply because she gestures toward another, that our gaze follows and understands her hands, but is also because her eyes look at the camera lens. We make eye contact, as it were, as she "breaks the fourth wall." She tells us a horrible secret-about her despicable treatment of detainees — and whether we like it or not, we share this moment with her. The horror of this shared moment is acknowledged in the outrage noted by academics and cultural critics alike (Razack, Mitchell, Butler, to name only a few, detailed in previous chapters). This idea of outrage is based on a "to look or not to look" question; however, failing to look does not outright remove the existence of the image.

The actions of England call upon us as viewers, they draw us in, implicate us simply because we see, acknowledge, and, to some extent, understand what she is doing. Perhaps this image is so striking, in part, because we might know this: that we are somehow a part of what happens in that photo, and we are horrified. We are horrified not just with England, but also with ourselves and with a world in which an image like this can exist. Such a focus highlights the importance of humiliating the objectified in the photo. In so doing, the one who objectifies is highlighted, as are her actions. The gestures of this person are the focus of the photo, and the objectified could be anyone who "deserves" to be victimized.

Exactitude, in reading this and other Abu Ghraib images, cannot be achieved. The reader may wonder: we have focused on England, so what about the detainees who are featured? I, too, think of them. I don't want to follow in the footsteps of the U.S. military members who, by photography, erased the dignity of the Iraqi detainees. In fact, I see my role here as one that acknowledges this erasure in hopes of more fully articulating the value of these images, as media artefacts; this erasure has purpose. But even before these theoretical elements can be concretizedregarding what happens when the images circulate - the contents of the images require more analysis. These images are polysemic, and are thus ambiguous. These images are multi-layered 
because there are many ways to read them. The gestures, emotions, and even humour contained within make them what they are: visual objects that reaffirm group differences, as trophies of commemorative violence.

This chapter is organized around the commonly referred to "doing a Lynndie" photos from Abu Ghraib. In broad strokes, the chapter takes the following shape: the first section describes the images that are analysed. Section two, "Using Gesture: History and Theory of the Thumbs-Up and Index Finger Pointing," suggests some ways in which to read these images, and considers past use and communication possibilities of these gestures. The third section, "Expressions of Emotion and Humour," defines emotion as inherently social, linking to humour, which combine to help form the polysemic qualities of the DAL images. "Primary and Secondary Gesturing Bodies," section 4, combines the above and synthesizes subject-object relations in the photos, which strengthen the group formation as exemplified within the images. The conclusions that follow suggest how cultural memory is then formed, outlining the next chapter.

This chapter focuses specifically on what cannot be considered an isolated phenomenon, regarding the embodiments that comprise the DAL images; the gestures therein are similar to, and seep from, many of the war trophy photographs discussed here more generally. Moreover, there is a visual history that links the DAL images to other war trophy photos, via the use of gesture, emotional expression, and at times even humour.

\section{FRAMING "DOING A LYNNDIE"}

Because of the overt comedic attempt —at the expense of helpless people - these images feature the making of human subjects into objects. Objectifying these Othered bodies renders them as things to be made fun of, in the photos themselves, if not beyond. It should be noted that this chapter offers analysis of specific elements within the frame; this is not an analysis of everything contained within a photograph. To this end, I am reading the images for specific relations between subjects and 
objects, which are bound to each other via gesture, eye contact with the camera lens, and the space that exists between subjects and objects. As previously outlined, the image might depict a person, who is treated as an object, by the dominant subject within the photo. This relation will be further articulated in this chapter, which culminates in a discussion of the "primary gesturing body" and the "secondary gesturing body." Physical gestures are thus highlighted and expanded: index finger pointing and the thumbs-up extend the edges or limits of the body (the primary gesturing body) with the suggestion of where specifically to look (the secondary gesturing body). Moreover, gesture, emotion, and humour are implicated in the overall articulation of a photograph's meaning - the face, eyes, and hands are the focus of discussion regarding what is in the frame; these are the foci whereupon relational meanings, between people in association to other people and/or objects, can be conveyed. Restated and highlighted here are the visible and describable dynamics contained within the photos-which feature the juxtaposition of belonging and exclusion, or Othering - where the performance of gesture and emotion connote meaning. To this end, and methodologically, while nonverbal communication displays certainly are subjective, physical embodiments are symbolically understandable via semiotic analysis.

In the quote that opens this chapter, Errol Morris describes the difficulty of determining meaning in the photos from Abu Ghraib, stating that "the problem is that these photographs are not horrific to everyone. They are not obviously anything" $(2011,8)$. Morris believes, as do I, that people see different things in these images, noting that their meanings are ambivalent. And though meaning might be ambivalent, there are nevertheless specific elements to focus on in the frames. Via visual semiotics, I am considering how people and things in photos relate to one another, in addition to what these reflections might mean when viewed. Restating Moriarty's claims about images allows for the consideration of the codes, or signs, contained therein (Moriarty 2002, 24). I am seeking the 
symbolic, and to this end, other images related to the DAL photo from the opening of this chapter are described below, and synthesis and analysis will follow in a discussion at the end of Section 4, "Primary and Secondary Gesturing Bodies."

\section{Meme Circulations of “Doing a Lynndie” and Other Related Photos}

Meme culture was not quite in its prime in 2004 when the photo of Lynndie first circulated, and it took a few months before the DAL phenomenon took hold. The blog BoingBoing featured an article on August 18, 2004 entitled "Stealth Lynndie-ing," while a DAL photo competition thread began on August 30 (Democratic Underground). A Flickr photo group emerged on September 4, 2004, and it wasn't until September 28 that Urban Dictionary featured a definition (2004). A few years later, on November 10, 2006, a Facebook group was started, which featured DAL inspired photographs, although there were only 46 members on November 28, 2011 (knowyourmeme 2008), and the group was no longer online in June 2016.

The aim of copying DAL is to choose a victim who can be easily subordinated in order for the perpetrator to look more powerful, or to portray another seemingly positive quality. In the case of the DAL images themselves, not only does the nakedness of the detainees render them vulnerable, but also the detainees are perhaps rife for victimization by American troops simply for being Brown, Muslim, Iraqi, and, in this specific case, the enemy. In DAL meme copycat versions, inherent weaknesses of the victims become the butt of the joke. These tacit faults are sociocultural in scope, whereby assumptions are made based on Western ideals regarding poles of superiority and deficiency. Common discriminatory deficiencies are presumed, highlighted, and photographed with two key subjects: one who performs the superior DAL role, and one who is victimized and exposed for embodying deficiencies. Within the popular DAL meme images that circulated, some of the more striking victim tropes involved being: an unaware mum; arrested; drunk and/or passed out in public; homeless; and anesthetized prior to surgery. All of these images are interestingly odd, if not 
sad. Importantly, it will forever be uncertain as to the authenticity of these images; perhaps these DAL memes were staged for the purpose of photography, or maybe the victim had been happened upon, thus inspiring the photographic moment? Either way, the five images discussed here are: a) Boy with liquorice who points at unaware mum; b) Woman points and thumbs-up at a man on the ground being arrested; c) Man points at and gives thumbs up at scantily clad woman passed out on sidewalk; d) Man points and thumbs-up at homeless man on bench; and e) Doctor in surgical room points and thumbs-up at anesthetized patient on table prior to surgery.

"Boy with liquorice who points at unaware mum," might seem odd at first glance. Photographed in Texas, the setting is a family home with oak or oak-like furniture, including a bookshelf at the back of the image, which holds nondescript knickknacks. A young boy of about ten stands smiling with a piece of red liquorice dangling from the right corner of his mouth, as his eyes meet the camera. His left hand points, while his right gives a thumbs-up, each gesture reinforcing the other, as he indicates toward a woman in her late 30 s or early 40 s. The woman is seated at a table, perhaps in a kitchen, with her right hand on nondescript paper while her left holds a phone to her ear. The woman gazes toward the boy with an uncertain look on her face; she might be his mum. Whatever the relationship between the boy and woman, the manner in which they relate physically appears as that of parent and child: the boy is amusing himself by making fun of his authority figure, and the woman appears to judge and be irritated by the boy, as can be viewed in her gaze toward him.

The photo "Woman points and thumbs up at a man on ground being arrested," takes place outside of a busy marquee in Philadelphia, Pennsylvania. In the foreground is a shorthaired blond woman in a knee-length patterned iridescent dress - the hair and fashion are noted because while she has short hair, like the masculine woman Lynndie England, she nevertheless is contrastingly feminine in her dress, with visibly ample breasts. The woman points with her right hand toward a 
man on the ground, who is in the middle of the frame, and gives a thumbs-up with her left. Her right hand points palm-side down, as opposed to the more commonly used palm sideways in the DAL images. From the right side of her mouth hangs a cigarette, and her gaze looks toward the camera. The man is lying on his left side, facing away from the camera. Standing above him, and to the right of frame, is a cop who seems to have just handcuffed him. To his left are a few people, one of whom stands slightly bent at the waist, appraising the situation before him. The background of the photo features people lining up for a show.

"Man points at and thumbs up at scantily clad woman passed out on sidewalk," encompasses only two people, who are before what seems an outdoor wall, painted red, in Primrose Hill, London. One stands while the other is lying on the sidewalk. On the ground is a woman wearing short shorts or a short skirt, moccasin-type boots, a pink and black top, and a white and grey scarf. Her purse appears before her head, which seems to rest on her left arm. The woman lies on her back, eyes closed, mouth slightly agape, right hand across her exposed abdomen, with legs turned in and touching at the knees. Looking into the camera and standing on the left side of the frame is a casually dressed man who points toward the woman with his left hand, giving a thumbs up with his right, with a cigarette dangling from his mouth.

In tones of beige and dark blues, "Man points and thumbs-up at homeless man on bench," primarily features two men seated on a wooden bench, in London, England. The scene takes place outdoors: there is graffiti in the right back of the frame, and the ground appears to be cement. One of the men appears to be homeless: eyes closed and hunched over with long unkempt head and facial hair, in dirty, shabby clothing. The man holds a juice bottle. Beside him sits a casually dressed man in jeans, collared shirt, and sweater. This man points toward the hunched man with his left hand while giving a thumbs-up with his right. With a closed-mouth smirk and a cigarette hanging from the left of his mouth, the man looks at the camera lens. 
Photographed in Sydney, Australia, "Doctor in surgical room points and thumbs-up at anesthetized patient on table prior to surgery" takes place in a hospital surgical room. The image features five people, all outfitted in scrubs and surgical headwear. In the foreground and to the left of the frame stands the person doing a Lynndie: with his left hand pointing toward the man on the operating table and his right giving a thumbs-up, he looks toward the camera with a cigarette dangling from the right corner of his mouth. Behind him is the right arm of a person who is hidden from view. Two of the other three individuals are also hospital personnel: one is seated and holds the foreground centre of the frame, looking at nothing in particular. The other man stands adjusting his facemask, behind the man about to be operated on. The patient lies on his back, eyes closed, and seems to have been recently anesthetized. Surrounding them is medical equipment, including a chest $\mathrm{x}$-ray, intravenous fluids, and plasma drip.

Some gestures featured in my trove of soldiers' army photographs bear resemblance to the DAL images, beyond the Abu Ghraib or spinoff images like those above. Three additional images within my data are worth discussing, specifically because thumbs-up gestures or other popular gestural communications are made. These photos are from the site VetFriends, a forum for soldiers, friends, and family to post images of pride in combat. Beyond this, the site offers a platform to share stories with those who understand war efforts in multiple ways, though centred specifically on aspects of personal sacrifice and commitment to country.

"Children give thumbs-up and peace signs with US soldier," features a white wall and nine people within the frame: eight Iraqi children and one white U.S. military officer. Four faces cannot be seen, while four other faces of children are visible. Each of them either smiles, or looks toward the camera, or both. One of the children gives a thumbs-up as he looks toward the camera lens. Another two children give a peace sign, and one of them smiles and looks directly into the lens. The other peace sign is from a hand whose face cannot be seen within the photo. The military member, 
outfitted in military garb, is centred within the frame. He smiles and gazes toward the camera, surrounded by the children.

Different from the others, "U.S. Soldier in profile gives thumbs up," is highly stylized, and also perhaps professionally photographed. The contents appear in black and white, with the background out of focus, and the foreground clear. Though blurred, the background appears to encompass a street surrounded by buildings, in addition to the semblance of people and vehicles on the street. The contents of the foreground are positioned above the street below, and are crisp. Featured is a close-up of a person's top torso, wearing a camouflaged jacket and helmet, a watch, and the left hand in a fingerless glove. Facing away from the camera, this person looks toward the people on the street, giving a thumbs-up with the left hand.

The next photo features two U.S. troops, and three Iraqi children holding soda and chips. Set outdoors, the background features desert with a tank to the right of the frame. The two-army personnel are in full garb, complete with glasses or goggles, helmets, fatigues, and AK47s strung across their abdomens. Each of their right hands appears ready, holding the guns, as they look into the lens; one of them smiles. The children, who stand before the troops, look into the lens as well. One holds a bag of chips, and stands tentatively in the frame, seemingly ready to bolt if not for the hand of one of the troops on his shoulder. The boy in the middle holds a can of $7 \mathrm{up}$, chin angled downward, lips sucked into his mouth. The child on the left of the frame stands in dirty overalls, holding up his right hand, gesturing in thumbs-up. A can of Diet Coke appears on the roof of the tank, at the top right of the frame.

The images above tell a complicated narrative. The combination of facial expressions, physical gestures, and photographic contexts - i.e.: what can be seen within the frame, or settingcreates rich scenes that can elicit different meanings, intentions, or significance. While the settings of photographs certainly are important, I would like to draw special attention to the gestures used by 
the people in these images, specifically with comparison to the DAL and spinoff images. The thumbs-up is both highly noticeable and often discussed where Abu Ghraib is concerned, but I would like to equally highlight another gesture: index finger pointing or the 'lock and load' gesture. Within the context of these images, pointing references a subdued, objectified individual. Juxtaposed with the thumbs-up, gestures in general combine to reveal an awareness of the situation, of the one who poses and uses these gestures. The situational contexts of these images, which include setting and gesture - thumbs-up, index finger pointing, and peace sign — are explored next, and will be further discussed in the section that immediately follows.

\section{Using Gesture: Histories ANd THEORIES OF THE THUMBS-UP AND INDEX Finger Pointing}

The purpose of gesture, inherently, is to convey meaning (Kendon 2004, 10-15). Without the use of verbal language, the body moves in ways to exhibit a different kind of language, one that is physically expressive. And though, of course, these expressions may contain multiple meanings, especially across cultural divides, this is equally true for verbal language, to which dictionaries reveal multiple ways of using a single word. Although gestures-like words - carry multiple meanings, it is the context in which they are used that determines possible and specific meanings.

\section{The Thumbs-Up}

The history of the thumbs-up is perhaps coincidental, but it is nevertheless significant to the overall narrative sketched here about gesture and communication in combat. It should be noted, however, that there are numerous meanings attributed to this gesture, which have little to do with war itself. Additionally, it would be wonderful if I had more to offer regarding the history of this gesture, but little documentation, research, or commentary exists that is attuned to a cultural studies or communication perspective. Much research, however, exists from psychological and educational development perspectives, as well as in vast anthropological accounts. For instance, in some 
cultures, an upward extended thumb is a phallic insult. Here is a broad sketch of specific geographic places and times in which the thumbs-up has been used. In Southern Sardinia and Northern Greece during the 1970s, as example, the desire to hitchhike was expressed with the extension of the arm and flat palm (Morris et al., 1979, 189), contrary to North America, as well as other locations, whereas the thumbs-up is used to convey this desire. Beyond these general notes, a few direct associations relate to the act of combat. Anthropologist Desmond Morris notes one such association in their chapter "The Thumbs-Up," in Gestures. Outlined here, the thumbs-up is rooted in Roman gladiatorial battle: historians have suggested that a crowd would extend a thumb upward if the gladiator failed to win or woo his supporters, and thus should be executed by falling on his sword (1979, 186). Conversely, the crowd hiding their thumbs in the palms of their hands signalled acquittal $(1979,187)$. To substantiate this claim, Morris et al. further suggest, "there is something inherently optimistic, positive and dominant about upward movements, and something essentially pessimistic, negative and subordinate about downward movements" (1979, 191). Linking the thumbs-up to its use in the twentieth-century, Morris et al. further note that their research indicates, "many [southern] Italians were surprised to learn that Northerners thought of the gesture as having sprung originally from Rome. To them it was a 'new thing' imported by the American GIs during the [Second World] war," and this gesture had even been dubbed the "American OK" $(1979,193)$, an emphatic thumbs up.

The "American OK," or the "A-OK" as it commonly came to be known, was used by American or allied pilots and ground crew during WWII. The gesture is thought to be a short form communication for being ready to depart, or "all systems go," in addition to being used for a completed and/or successful mission. The latter use is thought to be less about communicating between one's squadron or mechanic team, and instead is more about photo ops, in which the image expresses success of missions to the public; a simple Google image search of "WWII pilot thumbs- 
up" appears to confirm this notion. Some important elements should be noted, drawn from a few iconic, highly circulated photos. Typically, soldiers are featured in the cockpit of a plane or on the ground below, and regardless of position each relays a thumbs-up along with eye contact to either the photographer (presumed audience) or to those below or above, and ultimately, each expresses "all is well." Generally, when the gesture is used by others than those enlisted, the thumbs-up typically expresses camaraderie, gratefulness, and support for the army by civilians (Morris et al. 1979, 186).

In Gesture: Visible Action as Utterance, anthropologist Adam Kendon uses semiotics to analyse human gestures, or "visible bodily action." Kendon, a leading authority on gesture studies, suggests that gesture is crucial to human communication. For him, nonverbal interaction conveys just as much information, if not more, as verbal; while communication between people relies upon gestures where various and many meanings might be attributed, there are often general understandings that can be derived (2004). In the chapter on "Gesture, Culture and the Communication Economy," Kendon discusses the thumbs-up as a "quotable gesture," as in, one that is suitable for replication because of how simply messages can be conveyed. According to Kendon, the thumbs-up gesture generally conveys positivity and support: "a meaning of 'good' or 'positive', and an interactional meaning by which the user of the gesture indicates that the social obligation he or she is under in a given interactional context has been (or will be or is being) met" (2004, 340-41). The thumbs-up, then, always relates from one person to another, and thus has social intentions. Kendon further notes seven contexts in which the thumbs-up gesture might be used:

1. To indicate that something is good (as when a fellow jazz musician gives the gesture after a colleague has just done an exceptional solo);

2. As a positive response to a question (a passenger boarding a bus asks the driver if the bus goes to a certain place, the driver responds with thumbs-up);

3. To demonstrate that one has grasped the point of something (a waiter asks a customer to remind him of what he ordered, makes the thumbs-up when the customer tells him); 
4. To acknowledge a remedy another has offered (as when A tells B she has left her car lights on, B says "thank you" and then does thumbs-up);

5. Used as a mutual greeting (a bus driver does the thumbs-up to another bus driver through the window of his bus, when both buses are stopped at a red light);

6. As an acknowledgement that one knows one has reached a certain step in an interactional sequence (a bus driver gives the thumbs-up to a passenger after he has told him he will announce when the bus reaches a certain destination); and,

7. As a request to do something (a customer uses the thumbs-up to a waiter when he enters a restaurant as a way of asking if a certain table is free for him).

8. In each of these situations a specific meaning could be given to the thumbs-up but in each there are meanings of "positiveness." However, in addition, the gesture is a move in a sequence, either simultaneously serving as a comment and a move that completes an expected move in an interactional sequence, or serving as a separate acknowledgment of the expected move. (2004, 340-41)

In the original DAL photos, England appears to be commenting on those who exist beyond the space implied by the gesture. Of the seven possible situations Kendon outlines in which the thumbsup gesture might be employed, I believe that two appropriately describe its use in the Abu Ghraib photos: the first one that appears to reflect England's gesture is the "indication of something good," and the second is "to acknowledge that a remedy has been offered." The "good" is about the tacit understanding that the detainees have been hunted, while the remedy is the capturing of the detainees. While this is the case, it might appear more strongly that the gesture expresses "good" or "positiveness" rather than "offering remedy." However, each of these implies a communication between those that use the gesture, and those who exist beyond the camera's lens, as opposed to a communication between the one who gestures and the objectified within the frame. The pointing, which couples with the thumbs-up, then, is a key element in this gestural puzzle and aids in articulating group forms.

\section{Index Finger Pointing}

As suggested above, index finger pointing is of equal importance to the DAL images, as well as the other photos discussed here. Pointing is used to relay specific pieces of information, between those 
that employ the gesture and those to whom the gesture is visible. For instance, I suggest that there are four key notions to take away from this section: a) that common understandings can be derived; b) the gesture indicates a specific target; c) there is a space or separation between the one who gestures and the target; and d) the gesturer indicates how the target should be regarded in the act of pointing.

Discussing the use of gesture in the communication of meaning, Kendon describes physical bodily movements as "utterances." As such, these are actions of expression in the social world, and are thus sharable and knowable moments of communication. Kendon offers a broad definition encompassing subject, object, and the space between, all of which are included in the act of pointing:

Pointing gestures are regarded as indicating an object, a location, or a direction, which is discovered by projecting a straight line from the furthest point of the body part that has been extended outward, into the space that extends beyond the speaker. This space may be treated... as the physical space that the participants share, in which case the object of the point is an actual object or location somewhere in the environment. (2004, 200; emphasis mine)

Here, the "speaker" is the one who gestures, who communicates in this intentional act, and the space between those featured is necessary for the communication of meaning. Besides the thumbsup gesture, Kendon also examines the act of pointing in his chapter "On Pointing." For instance, with the pointing gesture, while one may not know precisely why the pointing is occurring, it is nevertheless clear that something is being pointed to, and that there is a reason for this action. Kendon suggests that without pointing gestures, the meaning of "there"- that which is pointed tomight not be so clear. More to the point, "such gestures can play a fundamental role in establishing how an utterance is to be understood" $(2004,199)$. Kendon suggests multiple ways in which the human body can point, though most common is with the hands and head; eye, lip, elbow, or feet movements can also be used $(2004,199)$. Though differing according to different cultures, these: 
all have in common, however, a certain characteristic movement pattern in which the body part carrying out the pointing is moving in a well-defined path, and the dynamics of the movement are such that at least the final path of the movement is linear. Commonly, but not always, once the body part doing the pointing reaches its furthest extent, it is then held in position briefly. In pointing, except when a moving object is being followed, the movement by which the gesture is accomplished is thus a movement, which appears to be aimed in a clearly defined direction as if toward some specific target. $(2004,199-200)$

With this, Kendon remarks on the pointer's intentions:

The form of pointing adopted by a speaker is systematically related to the way the object being referred to is presented in the speaker's discourse. That is, if the speaker points to an object because it is to be an example of something, or because it illustrates a concept, then the form of pointing adopted will be different from the form adopted when the speaker points to an object because it is being identified as something distinct from other objects. It is as if the form of pointing adopted provides information about how the speaker wishes the object being indicated to be regarded. $(2004,201$; emphasis mine)

With both quotes above, Kendon explains that pointing indicates an example, and/or distinction, of something that is somehow different from other things. Thus, special consideration for that which receives the pointing is required. In this way, the meaning of the object being regarded is removed from the object itself, when considering what it means in relation to its surroundings. Meaning is now derived from how the subject regards the objectified: how does the pointing occur, and what do the associations between the subject and object, together, come to mean? The next section seeks to answer these questions.

\section{Gestural "Pointing" in Photography}

Tying gestural pointing and photography together, Tom Gunning suggests "the hand is an extension of the possibilities of the body and of its interactions with the world" (2015, 00:29:30). Pointing is indicative of "outwardness," or that which exists beyond the body; this gesture extends into the space beyond our reach, a notion already familiar because Kendon has expressed similar ideas. Though Gunning discusses, and subsequently conflates, the pointing of the camera with the general pointing of the hand and index finger - referring to each simply as "pointing"- -he nevertheless clearly states that, as the pointing finger extends outwards, it indicates a precise direction in which 
to look $(2015,00: 27: 15)$. Here, distance and separation between featured subjects and objects suggest possible discernment of meaning.

Gunning discusses pointing as something that is different from touch because no physical contact is made; a person who points does not hold nor even brush the thing that is directed to beyond the finger, and as such, a space exists between the gesturing hand and the indicated object. Gunning states: 'In contrast to 'the touch' or 'the grasp'—which aspires toward direct contact— the gesture of pointing expresses distance and, generally, separation. As such, its relation to the hand may seem more metaphorical and more distant. It instructs us to look away from the hand itself, toward something else.... As a gesture, it embeds the body in an act of communication, it opens us toward meaning" (2015, 00:24:50; emphasis mine). The distance or separation that Gunning describes is echoed in my descriptions of the relation between the "primary gesturing body" and the "secondary gesturing body." The space that exists between these is noteworthy. This link is where communication occurs, in the space between, which abuts the very edge of the subject's gesturing hand, and the objectified who is indicated by the specified gesture. While the space between separates, meanings nevertheless can be read within and beyond that space, with the subjects and objects themselves. Meanings of the gesture, thus, can be found in the distance or separation between what refers and what is referred to. This space, which might appear empty with first consideration, is where ideas and contexts are brewed. Expressions of emotion and humour also occur in this space.

\section{EXPRESSIONS OF EMOTION AND HUMOUR}

The humour depicted in the Abu Ghraib images is questionable. Yet, the corresponding memes show that, at least to some, the images are funny, in addition to uniting those who share the humour, thus solidifying group dynamics around these notions. Stefka Hristova asks, "how did torture become hilarious?" $(2013,430)$. It seems a complicated question to answer. For the images to be 
funny, certain features are highlighted, while others recede into the background or are altogether ignored. Specifically, and argued here, it is the emotional displays that express camp humour, which make the featured torture "hilarious." Following the work of feminist philosopher Sara Ahmed, external displays of emotion and gesture shape the surface of bodies and are thus social (2004, 4); external recognisability suggests that this kind information is communicable simply because it is visible. Adding to this notion, and building upon some of the sociohistorical elements outlined in the previous chapter, emotion and gestural displays are at the heart of photographing human subjects.

The act of smiling before a camera moves through tradition and ritual whereby the display of contentment — whether accurately depicting a felt emotion or not—is privileged. People perform in front of the camera for the very purpose of producing an emotive visual record (Rose 2010, 7). Such a focus intends to frame the composed subjects in a desirable manner, and in so doing constitutes a moment worth remembering. Typically, with the capture of photographic moments, people strive to present themselves as idyllic, with coiffed hair and made-up faces, wearing fine garments. While not all photographs entail such finely detailed primping and planning, it is nonetheless easy to recall the memories of previous photographic events in which these meticulous adjustments took place: grade school picture days, weddings, birthdays, graduations, or even more ordinary occasions like dinner with friends. We "say cheese" in order to manifest a smile because pronouncing the word "cheese" displays our open mouths in a flattering, friendly way. In these moments, we do not smile necessarily out of happiness, but rather because this is how we would like to be remembered. Subsequent viewers to a photograph, including us now, will see and recall this moment in this precise manner. Performances like these have become even easier to photograph with the emergence of the digital camera. 
But what does all this mean regarding the Abu Ghraib photos? Eamonn Carrabine discusses the Abu Ghraib images in terms of the faces that can be seen within the frame. The soldiers' faces are plainly visible - and smiling - the faces of the prisoners are often hidden; this distinction is paramount $(2011,15)$. Those who are fully visible relay information easily and mark the image as valuable with emotive display. Yet, it is equally important to acknowledge that emotions can be expressed elsewhere on the body, besides the face; even though the faces of the detainees cannot be seen, the composition of their nude, slack, and slumped bodies tells a story of subordination. These expressions of vulnerability are equally valuable for the reproduction of group identity. Emotions, in this way, enhance what is knowable by providing communicable, socially recognizable, visible evidence on the body itself (Ahmed 2004, 4). As a visual mnemonic aid, photographs make human emotions more recognizable. While a photograph is a two-dimensional object, it nevertheless enables emotional and gestural communication to be recognizable and recallable. Gillian Rose claims that the public sphere is constituted through the collective display and experience of feelings; participation in public occurs via mutual "performance of emotional display" $(2010,7)$. To be sure, emotional display is understandable because of the shared meanings that can be derived from the presented information (Berlant 2008, 41), and, for our case here, visible emotions and gestures offer a signalling mark for Peircean semiotic analysis.

I argue that emotional presentation and recognition is at the very heart of the cultural practice of photographing human subjects. Photography is particularly useful in the display of human emotion because of the indexical capabilities of the medium. In part, meaning is attributed to the photograph at the moment of capture and, once created, the photo is used to visually commemorate events with subsequent viewings (Barthes 2010; Sontag 1977). A myriad of interpretations exist when viewing a photograph, beyond the moment of capture, which include ones foreign to the photographer at that time, based on different associations made between the 
image and viewer (van House 2011, 132). The significance that can be derived from emotional expression within the frame is certainly interpretive — and is also context dependent-but emotional expression is nonetheless present. Whether noticed or not, the staging of emotion within these photographic frames is purposeful (Bresheeth 2006, 57; Mechling 2004, 73). As a result, the participating U.S. military members intend to be seen as content, if not gleeful, because of their overt portrayal of achievement. With this, let me reconsider the DAL images and the spinoffs now: are these photos "funny" in some way, and if so, what kind of humour is represented?

\section{"Doing a Lynndie" and Camp Humour}

While both comic and amusing, humour is also about taste and understanding the parameters of what is featured. Specifically, as Warren and McGraw describe in their survey of literature, humour finds its basis in incongruity, or that which is not in harmony with its surroundings. But Warren and McGraw are quick to point out that incongruity is not consistently defined, and that it can call upon four possible areas: surprise, juxtaposition, atypicality, and violation $(2016,407)$. This inconsistency, as argued by these authors, can be unified by situating humour as "a benign violation: something that threatens a person's well being, identity, or normative belief structure but that simultaneously seems okay" $(2016,407)$. This refined definition seems to accurately describe what is depicted in the DAL images.

On the face of things, if one is to sympathize with the American Army personnel, the DAL pictures are "a benign violation": they can read as simple fun, though clearly this fun is at the expense of others. The joke here, that it is okay to poke fun at those who are on an opposing side, makes difference the butt of the joke. After all, there were dozens upon dozens of people who viewed the images as relatively harmless - specifically, the friends, family, and colleagues who received the images by email, which circulated for four months before authorities were notified. More to the point, the DAL images do exactly as described above: they threaten the well-being of a 
person, their identity, and normative beliefs, all while showing a scenario in which things do seem okay overall, because England herself appears to be having a good time.

It is, however, hard to deny that the DAL images are tragic, however rich with textbook-like humour they might be. In another article, McGraw et al. discuss how distance and closeness relate to mishap and tragic humour. For them, "distance facilitates humour in the case of tragedies by reducing threat, but that closeness facilitates humour in the case of mishaps by maintaining some sense of threat" $(2012,1215)$. I would place the DAL photos in this category of distant tragedies (at least for some of the Western audience). On one hand are the original DAL photos, in which the geographic distance of what occurs is great, thus possibly illustrating the humorous aspects of the tragic acts portrayed because the physical distance reduces threat. On the other hand - and only briefly mentioned here, though more fully considered later in the chapter-are the DAL meme images, which are taken outside of combat zones and instead are photographed in the daily lives of civilian participants. Many of these photos depict mishaps, instead of outright tragic accounts, which are infused with the real sense of threat from the originals to which they refer. Yet, the images are funny because the closeness allows people to see themselves, as normal people, within the frames.

Camp humour has a "double sense": no single, precise meaning exists. Camp, just as with the DAL images, is polysemic. The DAL images were taken as a joke that completely failed to acknowledge the suffering and despair on which they are based. We are tricked into finding them funny, perhaps only until we notice that the humour is at the expense of a tortured person. And though it can be hard to acknowledge the humour in the photos, for fear that we, too, fail to see the suffering detainee, the humour (which we may personally not find funny) no less objectively exists as incongruous humour: the presentation of these images relies upon shared cultural notions that communicate previous instances or associations to this image, for instance with a cigarette or 
liquorice dangling from the side of a mouth. Whether we like it or not, the DAL images possess a "sense of humour."

Some other explanations of humour rely upon processes of complex interpretation. These notions are not altogether clear at first glance, and may not be known even if the image is deemed to be humorous; these ideas may be added when the image is viewed in creative ways. For instance, as Apter and Desselles suggest, the humour may end up being somehow warped: "In distortion humour, new characteristics are imaginatively added to the identity in a way that leads to absurdity" (2012, 417). Thinking specifically of the DAL original images, the absurdity rests in England's complex and contradictory gendered performance: a) the masculine drag of the dangling cigarette, of England performing the role of dominant army man; and b) the feminine drag of England who is cis-gendered ${ }^{8}$ female, but nevertheless physically embodies some idea of manliness, where her hips and breasts are delicately articulated beneath the odd juxtaposition of her masculine gestures and clothing. Oddly, there appears nothing natural about England's presentation. Instead, her portrayal appears to be in question. At this point, absurdity leads to camp: England may have no idea what kind of caricature and parody she presents, not only of herself (as a woman in the army more generally, who exists within a masculine space), but also parodies of the "idiot authority figure," war itself, homoerotic porn, the naked male form, and powerless women. Sontag discusses the camp of gender presentation in Notes on Camp". Here, she suggests that camp taste "consists [of]

\footnotetext{
${ }^{8}$ Identifies that the birth sex is the same as that which the person personally identifies with; for instance, a person assigned "female" at birth grows up to see herself as female.

${ }^{9}$ Camp is recognizable for its style, but Sontag makes a problematic assertion. Outlining various kinds of camp, from good and bad gay camp, to good and bad straight camp, LaBruce teases out the useful and faulty items offered in Sontag's Notes on Camp. For LaBruce, Sontag is correct in situating the stylized nature of camp as paramount, but finds fault in her claim that camp is apolitical (2009: 277). I, too, find the notion that camp is neutral to be preposterous. In that camp is inherently subversive, and perhaps even revolutionary, LaBruce claims that this makes camp highly political (ibid). Camp takes a political position in choosing to break with convention. Sontag even states that this apolitical attitude "goes without saying" (2009) in relation to camp, which appears precisely untrue. Camp, while not seeking to be or model "the normal," takes a position that acknowledges itself as a form, and particularly because it performs outside of the
} 
going against the grain of one's sex. What is most beautiful in virile men is something feminine; what is most beautiful in feminine women is something masculine...Allied to the camp taste for the androgynous is something that seems quite different but isn't: a relish for the exaggeration of sexual characteristics and personality mannerisms" $(2009,279)$. Though Sontag refers to "sex," she is describing the kind of characteristics that are commonly associated with a specific type of genitalia. For instance, a person with a uterus and breasts, who has a deep voice and commanding presence, might be presenting camp because of the unexpected masculinity she projects with her voice, and consequently she plays with her gender presentation.

The notion of camp relies heavily on absurdity: camp is foolish, unreasonable, illogical, and inappropriate; this is evident in the DAL images. Camp challenges what is commonly in the realm of the "normal" or the normative. It does so in its playfulness and exaggeration, which at first must be housed in the basics or fundamentals of a given genre, and then can be stylized accordingly to expand the form, to bring in irony, parody, or even kitsch. Camp is a chameleon, transforming itself as time passes and as a culture alters the meanings that can be read therein. Camp, then, is inherently queer because it takes what is assumed to be natural, expected, or inherent, and transforms it, works against it, and thus transcends the expected. According to Sontag, "camp sees everything in quotation marks" (2009), refuses to take itself so seriously, and is always already making fun of itself. With this, and as Sontag notes, camp "converts the serious into the frivolous" (2009: 276), and in so doing, form triumphs over content. Content is delivered by form, and this particular content would not be readable as such without its camp presentation.

That camp might ignore content is contentious. Sontag describes camp as being "neutral" with respect to content $(2009,277)$, "style at the expense of content" $(2009,278)$. Reading for style

expected, camp situates itself as a viable option, as its own thing, as something of significance and worth. Camp is something with power, drawn from its performance of parody and irony, and is granted status as something distinctly recognizable, which is thus highly politicized. 
encompasses reading for content. Even as Sontag writes that camp has certain predictable dimensions, which she calls "style," she is also describing some aspects of content: while camp makes fun of the idea of generic normality, it nevertheless inherently understands what is expected for a given genre, only then to parody what is featured. What is featured is the content, and perhaps Sontag has difficulty in determining the content of camp because it changes according to the generic conventions of that particular moment of exaggerated expression; its meanings are not fixed.

So the question becomes: why do the DAL images succeed at being camp humour? The answer, in part, is because they express ambition. Having ambition means that, according to Sontag, these images could not be described as "bad." For the images to be bad, they must be mediocre, in that they fail at attempting to be or do something, i.e.: to fail at having ambition $(2009,283)$. However horrible these images are, they are successful because of what they accomplish with their incongruity, polysemy, and tragic humour. The DAL images illustrate and solidify group distinction and opposing sides, and do so via humour, gesture, and emotional display. These representations simultaneously seem both nonchalant and heavy-handed. Are the DAL images transgressive and, by definition, camp? I think the answer is yes. However, it seems that camp is often a term used for progressive ideas and narratives, that push normative boundaries and force new ways of thinking and being in an ever-evolving world. The DAL images are not progressive or positive in the least, and so one might wonder if they are even capable of portraying camp. This hesitance makes sense, but I would suggest that perhaps camp itself has evolved to include new ideas; camp might be capable of possessing some attributes that are boundary-pushing and subversive, while also potentially carrying with it discriminatory and even boundary-affirming notions, thus going both with and against the grain. Camp, in this way, may also be conservative instead of being radically progressive. Perhaps where these two seemingly contradictory ideas meet is where camp has always 
had somewhat of a home: the capability, if not necessity, of offending some while entertaining others, with whatever expressions are communicated.

\section{PRIMARY AND SECONDARY GeSTURING BODIES}

The photographs from Abu Ghraib, and certainly the DAL images, feature offensive content. Inherent to this offensive content, I argue, is the positioning of bodies featured therein. Gunning and Kendon suggest that meaning in gestural displays form in the distance or space between the gesture itself and that which is gestured toward. Extending this notion, I suggest that this space or distance ties the opposing sides together. It is not simply what is expressed, but also what the parameters of expression are, where the capture of such dynamics is concerned. In war trophy photographs like those taken at Abu Ghraib, there exists a primary gesturing body (the one who orchestrates posing) and a secondary gesturing body (a person or persons made to pose at the hands of someone else, or who is simply gestured towards).

\section{Gesture as a Component of Commemorative Violence}

When one moves their body, the physical limits of that body are clear; others can not only see where that body ends but also where the gestural expression of that body ends. A gesture, however, is complicated when the parameters of expression are manipulated. Assuming that this discussion now focuses on two animate beings, as with the images discussed in this chapter, the relationship between these two bodies might not always be consensual because one of the two is treated as lifeless or inanimate; a body affixed to, held, moved by, or gestured toward might perhaps be manipulated using physical or verbal coercion, or might otherwise be taken advantage of in this relation. Equally important here is that the individual who manipulates another body for the act of photography need not physically touch the person or people. Instead, a signal toward the person or people is all that is required for the meaning of the gesture to be visually relayed. Thus, the 
manipulated body becomes an extension of the manipulating body because of the connection made within, and framed by, the photograph. A distinct relation may be drawn between the primary gesturing body, as the manipulating body, and the secondary gesturing body, as the manipulated body. Certainly the secondary gesturing body can be human, though it can also be an inanimate object; the possibilities for the secondary gesturing body are fluid because, often, the primary gesturing body is behaving as if the secondary is inanimate. The relation between the primary and secondary gesturing body is recorded in a photograph, thus creating a representation that can be viewed again and again. The dynamic between the two bodies necessarily relies upon the recording of the subdued secondary body at the hands of the primary. This recording assumes that the produced image is valuable because of what the image means beyond the moment of photography, chiefly, for the visual memories and symbolic associations that can be seen in the photo.

A question of personal autonomy arises when discussing the dominance of one body over another. While it is certainly the case that objects and bodies manipulated by others in photographs do possess their own sense of independence, and are thus not totally controlled, it is nevertheless important to note that the exploitative primary gesturing body intends for the secondary gesturing body to act in accordance with the manipulation; the prone body is prone to the gesture, subject to it as an extension of the primary, expanding the primary's communicative function. Moreover, the specific meaning conveyed, due to the manipulative acts carried out on a body or bodies, could not be portrayed without such a relation between photographic elements. Imagine the image of Lynndie holding "Gus's" leash. The possibility of a trainer-animal relation emerges, with the overt placement of Gus leashed within the photo. Gus may not have been physically handled and placed on his hands and knees, but the force is nevertheless implied, and his submissive body becomes an extension of England's dominant body. 
Though an iconic example of warring parties is certainly shown within this photo, it is also relevant to note that making a distinction between the primary and secondary gesturing bodies here aids in the definition of group formation, a key element in the articulation of commemorative violence. Furthermore, as an extension of the primary gesturing body, Gus is used to illustrate the power of these U.S. military members, if not the power of the U.S. military overall; the cowering and subdued body of Gus helps to visually communicate this notion. The autonomy of Gus as a person is not irrelevant exactly, but it is not visible within the image. Gus is used as a prop to express the dominance of Lynndie England (and America) and, as such, those who orchestrated the photographic event do not consider his autonomy. And though his personhood and autonomy are not entirely removed, the lack of consideration for his autonomy as a person is what gives the photograph its meaning as an object of commemorative violence. In effect, Gus as a person is all but removed from the photo. Gus is simply a symbol of unity and victory for those who look upon the image with pride.

\section{Lynndie England: Feminist Hero or Targeted Scapegoat?}

England's striking demeanour in these images makes her the figure representing the U.S. in Iraq during this time, and at the Abu Ghraib prison in particular. Holland writes that the manner in which she is framed "not only deflects attention away from the other soldiers involved in the scandal (particularly the men who were involved) but also diverted criticism away from more comprehensive discussions regarding the U.S. military's use of abuse and torture...and constructed feminism as the new villain" (2009: 246). Here Holland is outlining how England becomes the focus, as the key figure that perpetuates the abuse and torture, in addition to illustrating a combatspecific shattered "glass ceiling."

Unlike other glass ceiling shattering, which are generally considered positive for social progress, the shattering here is complicated, and not all that great. The featured objectification and 
humiliation, if not torture, is familiar within these images, but they can also ostensibly be described as progressive in terms of power and gender representation. In liberal (white) feminist terms: "Here, in these photos from Abu Ghraib, you have everything that the Islamic fundamentalists believe characterizes Western culture, all nicely arranged in one hideous image - imperial arrogance, sexual depravity...and gender equality (Ehrenreich 2004, emphasis mine). Without too much critical thought, it might be easy to say that women should have just as much a right as men to humiliate, abuse, and even torture detainees in combat. England embodies power, a "perverse dominatrix," who laughs and points at exposed male genitals, from the perspective of the military (Engle 2009, 110). It can then be argued: "premised on equality, the male remains normative, and patriarchy is undisturbed as the onus lies on women to enter structures of privilege. According to this theory, women who control male detainees have successfully reversed the power inequalities, at least for themselves" (Deb 2012, 2). Colonial, homophobic, and xenophobic the tone might be, England commands the frame from within, and moreover, is a (white) female who subordinates (Brown) males. Shawn Michelle Smith writes:

Much of the torture depicted in the Abu Ghraib images also focuses on male genitalia as a site of masculine power, and soldiers exert control over Iraqi men by forcing them to simulate sexual acts and to masturbate. As Lynndie England points at a penis and signals thumbs-up in a number of the photographs, she seems to revel in her power and control over the Iraqi male body, taking pleasure in her symbolic emasculation of Iraqi men. (2013, 207-08)

A preface should be noted here: prior to the U.S. invasion of Iraq, many images were popularly circulated depicting victimized and veiled Iraqi women, which echoed the recent initiatives of the "democratization" of Afghanistan, also a mission aimed, in part, to "rescue" and protect women (Holland 2009, 248-49). Not only did rhetoric surrounding this issue garner public sympathy for victimized women, but also anger toward the men who perpetrated the abuse grew. Dana Cloud notes that the primary discourse for the West became "the war of 'saving the brown women from the brown men"' $(2004,297)$. 
All things considered, however, equal opportunists may not want to rejoice too soon. As has been noted, the key question that circulated about this scandal changed from "who is ultimately responsible for the acts depicted?" to "how could a female soldier commit these violent acts?" (Holland 2009, 247; Hersh 2004, 42). Razack suggests that these images of Lynndie are striking not simply because of the torture and humiliation they depict, but also because they show a woman (white or not) overpowering Brown men and thus help to perpetuate the "narrative of rescue" beyond empire building. These men might come to symbolically represent a homogeneous figure of all Muslim men, who, factually or not, are believed to carry out institutional and religious-based subordination of women. It can be cathartic, then, to see Brown men subordinated. Razack identifies that, "against the hyper-visibility of the Muslim woman's body (customs officers, shop clerks, and restaurant workers now all presume to know how Muslim women are oppressed by their terrible men), it is virtually impossible to name and confront the violence that Muslim women (like all groups of women) experience at the hands of their men and families without providing ideological fuel to the "war on terror"' $(2008,107)$. With this, it could be argued that Brown women need help, but also that the homogenous group of all Brown men is guilty. While it would be naïve to claim that Islamic fundamentalism (and all forms of fundamentalism, for that matter) is no threat at all, the manner in which the claim is made often reflects problematic and misunderstood notions. Razack outlines: "The danger is made believable largely through appeal to racist narratives about intrinsically savage, pre-modern Muslims. Under this logic, it is possible to defend the idea that Muslim men must be detained indefinitely and denied due process on the grounds that they may carry within them the seeds of terrorism" $(2008,19)$. Justice may take many forms, then, as response, perhaps even coming in the form of humiliating photography.

While England is responsible for her own actions, she also has become the one to take most of the blame, even though nearly a dozen others participated. England is not only a part of the "few 
bad apples" trope, she is featured, the most visible, and the most closely connected to the Abu Ghraib photos because of the DAL images and the corresponding memes. Though a total of eleven military personnel participated in the Abu Ghraib torture images, England received the harshest punishment. Besides being dishonourably discharged from the U.S. Army, on September $26^{\text {th }}, 2005$, England was sentenced to three years in prison for conviction of one count of conspiracy, four counts of maltreating detainees, and one count of committing an indecent act. On March $25^{\text {th }}, 2007$, England was released on parole after only serving 521 days. In news reports, as well as a biographical account, England states that she struggles with depression, anxiety, and post-traumatic stress disorder, in response to the public disapproval of her actions caught on camera. In sum, England appears to be an odd and unfortunate mix of feminist hero and targeted scapegoat. These descriptors, however, are not that simple: as a feminist hero, she represents ideals gone awry; closing the gender gap with discriminatory practices is not an (intentional) attribute of any form of feminism (since the first wave, which outright excluded women of colour). As for the targeted scapegoat, the focus on England ignores that the Iraqi detainees are themselves the actual scapegoats - the detainees are vessels for ritualistic and group-affirming violence.

Simply put, the term "scapegoat" refers to one who is blamed for wrongdoings, while historically and biblically the term is used to discuss collective morality. The scapegoat is a "pharmakon" or a healing agent, one that transforms and renews the community by ridding it of evil, by assigning the evil to something or someone, which or who is then removed or killed (Perera 1986, 8). From the perspective of the military, England can be both hero and scapegoat; used like a surgical intervention by the military to simply pretend the disease can be isolated, cut out, and discarded. When this ritual is performed, the community is safe once again, until the next evil emerges and another sacrifice must be performed to restore order and peace to the community (Girard 1979, 37). Perera highlights that this can be helped with the use of a specific subject or 
object: "In ceremonies of riddance the evil is magically transferred to other persons, to animals, plants or inanimate objects. The evil is treated concretely, as if it were a contagion that could be drawn off into a material object which then becomes... an incarnated pollution that can be disposed of" $(1986,11)$. With this, once transferred to material subject or object, the pollution is placed in a vessel, which has boundaries that keep the "evil" or ostracized agent in, and thus, not only is the container holding these notions removable, but the community is also cleansed.

René Girard echoes Perera's statements, discussing scapegoating for its use of fostering and maintaining healthy communities, but also ties these ideas to the origin of culture. Girard states that the "saving power" of the scapegoat undergirds the formation of a culture and, specifically, that cultures produce order via hominization; culture and scapegoating teach how to "be" or act in the world (Girard and Kennedy ep1 33:50-34:10). Shared spaces provide social interaction with others who are decidedly like each other, and want to remain alike, scapegoating or isolating outcasts enables teachable moments; when someone fails to act in accordance, this behaviour is first highlighted and then ostracized. Moreover, as Girard notes, "when everyone opposes a single victim, order is created and maintained" (Girard and Kennedy ep2 3:50-4:00). While it is easy to see this in military cultures, where difference and Othering is integral to the project of war, notions of classifying and regulating people equally occur on the most mundane levels in societies and cultures; although some cultures are more intense and extreme, for instance with the military, these ideas are nevertheless a part of everyday life, as illustrated in the DAL copycat meme images. Whether on a mundane or powerfully important level, scapegoating seeks to eradicate or correct those who are somehow in the wrong, and thus, scapegoating seeks to keep a culture uniform, and to reaffirm a group. 


\section{CONCLUSIONS}

What can be made of the use of thumbs-up, index finger pointing, of humour? And what about the smiling soldiers, the juxtaposition of visible faces to those hidden, the composition of bodies within the frame? What happens when seemingly innocuous gestures carry with them ill intent, to discriminate, to dehumanize, to subjugate. What associations occur when the DAL and meme versions are viewed next to soldiers' snapshot photography from war, like those images posted on the VetFriends site?

The distinction made with these gestures is quotable and carries with it humorous meanings. The incongruity that exists in the often inappropriate dynamics expressed in the DAL and meme images creates the humorous tone, regardless of whether or not the images are, in fact, personally funny. Specifically, it is the gestures in the photos that imply humour. They also replicate messages in an easily conveyable format—so easily conveyable that their use in various cultures springs forth a myriad of meanings. And yet, common ground in reading these gestures can be found: we must continue to be distinct from them. Photos help in this endeavour, particularly when circulated en masse, because they help to form and solidify "cultural memory." This concept, occurring alongside images and narratives, is the focus of the next chapter.

Gestures help constitute the commemorative violence of the war trophy photograph - the thumbs-up, index finger pointing or lock-and-load, and peace signs. Gestures help form a narrative that conflates combat and everyday life. The gesture is used to simplify communication, while carrying with it complicated or dense meanings. The gesture, then, is a response: whether or not a question is literally asked, the gesture used in a social relation nevertheless offers comment, and possibly a solution. The suggested comment or solution of the thumbs-up, then, is not only that "good" and "remedy" are sought or impending, but also that use of this social gesture insists upon group formation. To be either on the receiving or sending end of the gesture implies a relationship: 
we are communicating. We understand each other. But when index finger pointing is coupled with the thumbs-up, as is the case with DAL, something altogether else happens-another person is singled out for not being one of $u s$, for not belonging. Pointing, thus, makes an example of something. Pointing can also imply a distinction from something. When used in the DAL and meme photos, the gesture is doing just that: it makes a distinction from the pointer to the pointee, that the pointee is symbolically different, somehow less-than, and in so gesturing, an example is made of the pointee. The implication is that the pointee has qualities that are not ideal, and that we are certainly on the better end of that comparison. Consequently, this gesture complements the thumbsup, and the division between "us" and "them" is confirmed. 


\section{CHAPTER 4-“WITH” THE WAR TROPHY PHOTOGRAPH}

Images, NARrative, And CUltural Memory: Circulation of THE WAR Trophy Photograph

"Distributing personal pictures over the internet or by cameraphone, which is now a common way of communication, intrinsically turns private pictures into public property."

Jose van Dijck,

"Digital Photography" (2008, 72).

Standing in celebration over a charred Iraqi in a photograph shared on a public website, the soldiers ask to be seen. The photograph appears in shades of black, grey, and white. The picture is the only accessible image from the infamous Nowthatsfuckedup.com (NTFU), a 2004 website for soldiers to exchange combat photographs for amateur porn. Seven people are in the frame, though the one at the bottom left looks burned beyond recognition. Behind this charred figure stand six men in army fatigues, a tank just off to the left. A torso at the right of the frame is cut from view, while five other men stand in various poses of excitement and triumph: looking off to the left, perhaps to a camera different from the one that captures this photo, they each smile and gesture. From left to right, the five men are described: 1) wearing an oversized coat, a man, appearing young with round cheeks, holds his right arm up (hand cut out of frame) while his left rests across his body; 2) the figure in the back row waves his right hand, mouth agape though without expression, the rest of his body hidden; 3) below him, a man in sunglasses crouches, index finger pointing to the charred figure in front, an elbow placed on each knee, a smile spread across his face; 4) in the centre of the frame, leaning over the crouched figure, stands a man with an open mouthed yet vague expression, his hands not visible; and 5) a man on the right also bends his body into frame, with the right hand in a horizontal thumbs up, indicating toward the charred figure, a severe expression on his face. Ultimately, two ideas emerge. The first, that the posing for this picture indicates a capturable moment of the experience of war, and, the second, while the image suggests individual experiences of those featured, the sharing of this image transforms a once private moment into a public incident. 
This idea was first outlined in the Introduction, that what once was a private matter with analog photography emerges as a public matter with the ease of circulation provided by the digital variety.

While this chapter begins with a description of an actual photo, it is actually about redacted or missing images. This chapter is different from the others because the image described above is the only one that currently exists from 2003-2004 when forum sites like NTFU featured such content. Consequently, this chapter does not feature nor discuss any images; thus, there is a different tone to the empiricism. In contrast to Chapter 2, which situates a robust genealogy from the plethora of available war trophy photographs, and Chapter 3, which isolates a single, infamous image for thorough analysis, this chapter discusses the elusive image. Here, the focus is centred on missing content. Specifically, I formulate that value and meaning are no less established with the removed content, and that the focus should not be on the missing content per se, but instead on the contexts that surround the once available and now redacted image. The narratives that circulate alongside the elusive image reveal these contexts.

It might appear strange to formulate a visual communication chapter on the absence of the image. However, this absence is what produces and reproduces the crux of the argument: denying access to soldiers' photos invalidates their experiences. While one photographic example exists, from NTFU, governments and mass news media have censored others with outright removal. The problem here is that censorship and removal do not eliminate what these images mean for the soldiers who take them. As stated at the end of the first paragraph, a once private moment becomes a public incident when a photo is shared online. Perhaps obvious, but also key: soldiers want these images made public. In fact, it is a necessity, one that ensures that people know about their lives in the battlefield. Shared war trophy photos in the digital age situate the graphic and at times questionable activities of soldiers' lives, and in so doing, the lives of soldiers are made present in the minds of civilians. Perhaps seeming like a small detail, soldiers want civilians to know about 
what they really do in war zones; they want civilians to share in the strife just as much as the success. With the help of mass news media, governments and militaries release only reviewed and sanctioned content. By contrast, forum sites bypass the roadblocks of official journalistic practice, and make available real (and sometimes problematic) events and experiences of soldiers, without them being sanitized. Soldiers' use of forum sites, like NTFU, offers the opportunity to emerge from the secrecy that often encompasses their lives.

Soldiers often feel left out of their own memory-making, or at least in the public sharing of it. The milieu in which these images are first released is significant: they emerge in an environment that renders them shared, cultural objects. When made publically available, these images are viewable to anyone, with many of the viewers likely unrelated to the featured private experience, like civilians. In so being, the images embark on a journey in which knowledge about the featured events accumulates and is also sharable. The very nature of soldiers' photos necessitates publicity because all things acquired by soldiers inherently belong to the State and its people, as previously noted in Chapter 1. Soldiers' lives are inherently lived in public, and are thus accessible to anyone with interest. Simply put, through the soldiers' lens, civilians can directly learn about the experience of war, without a sanitized filter. These online images, as a result, are a part of a public or shared existence, which broadly culminate conceptually as "cultural memory." Unless redacted (or unshared), what soldiers collect, civilians have access to, because soldiers are figures representing the State. As such, what soldiers collect, such as the photos they take, automatically builds cultural memory because these objects cannot remain personal keepsakes or memories. This notion of cultural memory, as it pertains to soldiers' use of digital photography, is considered at length in this final chapter.

Gestural and emotional displays are at the centre of the war trophy photo, as discussed in the previous chapter. Though at times gestural and emotional displays are subjective, they nevertheless 
often connote specific and commonly understandable meanings. As outlined in Chapter 3, many of the same gestures appear in war trophy photos, like the thumbs-up. These varied instantiations from disparate points in time are connected, suggesting not only the potential of copycat versions, but also that former instances are recognizable, understandable, and repeatable. With this repeatability, and bridging Chapters 3 and 4, digital photographs can be circulated and recirculated in ways that analog images never could. Specifically with digital platforms of email and forum sites, narrative couples with images to reach anyone within a given network; the larger the network, the more information that can be circulated, ultimately expanding the associated cultural memories of a given digital "moment" or "experience." With reference to the quote above, the digital pulls the war trophy photo from private property, in the analog era, to networked era public object.

Emerging as public objects, the images still belong to those who took them: copies are retained and personal memories of the depicted events endure. However, photos on the internet $-\mathrm{a}$ shared space-become part of the public domain. And while analog war trophy photographs, too, can be housed within a shared space, digitization and the web expand networks of circulation, in addition to amassing and distributing cultural memories that move along with the images. Moreover, as van Dijck suggests above, digital images are released from the shackles of singular physical object with the fostering of mass shareability and duplication. Captions or longer narratives often accompany online digital photos, on sites where people unrelated to the images can also offer their own, sometimes competing, viewpoints. Such a process thus expands and even complicates the original narrative or narratives; where the analog provides only brief captioning potential - typically on the reverse or below the image, and mainly only information on location and those featured - the digital completely alters this aspect. For instance, an online photo can be featured on numerous sites, with the same information as originally provided. Some of this information might be directly relevant to the image, as with news sites, while blogs and forums 
offer the opportunity to comment, thereby creating alternate stories. The potential to share in the knowledge of an event, particularly via online images, enables greater public participation. Digital photos seamlessly move between private and public settings, between those with intimate knowledge of the featured people and events, and those unrelated. Having seen the links between the Abu Ghraib photos and the history of analog and digital war trophy photography more generally, I can now move toward special consideration of war trophy photos as digital images that traverse the private-public divide.

I have already been engaging with cultural memory, as defined by Jan Assmann, who states, "cultural memory is a form of collective memory, in the sense that it is shared by a number of people and that it conveys to these people a collective, that is, cultural, identity" $(2008,110)$. To be certain, while there are multiple types of memory-ranging from what derives from the inner self, the social but singular self, to what is communal - cultural memory is something that belongs to groups of people who share the same space, time and/or material objects, and is rooted in both historical and mythical narratives (Assmann 2008). Assmann outlines numerous aspects that foster cultural memory, though for our purposes here I will be concentrating on a single element: the concretion of identity. Particularly concerning the normative formation of groups, identity is “characterized by sharp distinctions made between those who belong and those who do not" (1995, 130). I tie this notion back to a focus of this dissertation: belonging and exclusion are central to the Abu Ghraib images, and war trophy photography more generally. For example, group cohesion of the prideful U.S. military enables their posing alongside the Iraqi detainees, who are assigned the role of Other. Not unique, this difference is key to the creation of all war trophy photographs.

With specific regard to digital photography, cultural memory is easier to solidify now than previously before. Cultural memory, however, also existed with analog photography, which certainly did well to establish common understandings of events via pictorial representation. 
Consider for instance how images of suffering Vietnamese in the 1960s, at the hands of the U.S. military, helped to change the perspective of that war for the American people. Photographs provide something to think, speak, and write about. Photographs concretize a particular interaction in a particular place and time, but they are not solitary representations. Instead, photographs contain themes and symbols, readable via visual semiotics, which connect to other similar images. The photos discussed specifically here move through intersecting and rich histories, linked between cultures of combat, visual technologies, and rituals of commemoration. Here emerges the cultural memory I discuss.

The Range of Cultural Memory Potential for Analog and Digital Photographs (fig. 4.1) illustrates what can be known about different networks. Beginning with the top-down and highly organized network, "institutional" is defined as that which is beyond digital public access, and is aggregated by mass media, offering established and authoritative information. Corporate news, films, or documentaries, which can be quoted in parts or whole and have a "trustworthy" quality because of the associated producers; for instance, Sony Pictures Classics, who distributed a documentary about Abu Ghraib, Standard Operating Procedure, discussed later in this chapter. The institutional level is relevant, while not the singular focus of this chapter, because it helps to bring attention to something that otherwise would be unknowable to a majority of people. The mass publication of the photos from Abu Ghraib is an example of this, which enables consideration of the smaller networks through which they first emerged and circulated. 
INSTITUTIONAL Mass media, i.e.: established and corporate news, film, or documentary

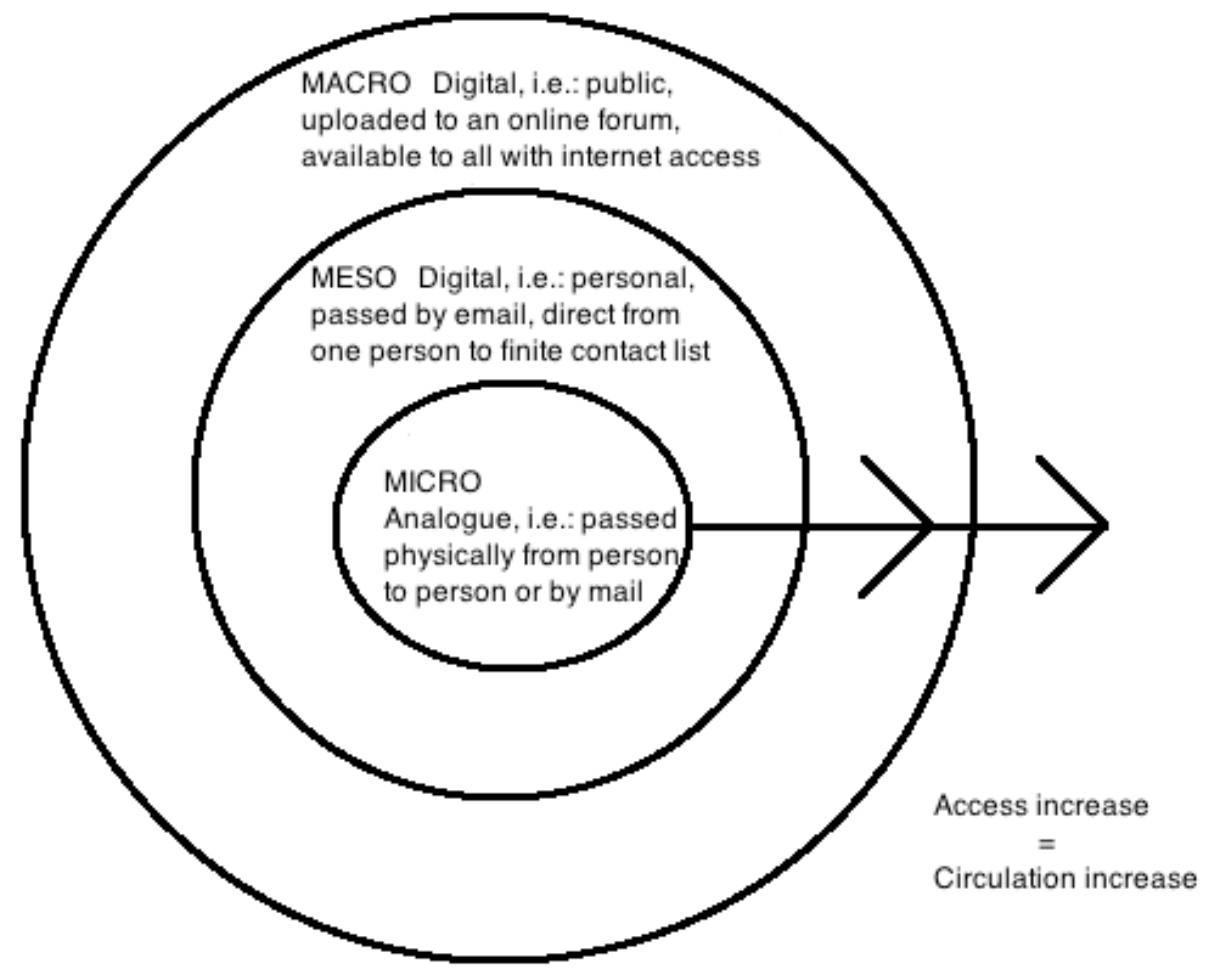

Figure 4.1 The Range of Cultural Memory Potential for Analog and Digital Photographs

These smaller networks have varying degrees of cultural memory potential. Following the work of Horst-Alfred Heinrich and Verena Weyland in their article, "Communicative and Cultural Memory as Micro-Meso-Macro Relation," I have created the above illustration to support the claims made in this chapter, specific to circulation of cultural memory. While the micro level consists of the personal, individual, or one-to-one communication, and macro encompasses social or large group communication, the meso level is where the transfer of information and knowledge considerably alters shape. Heinrich and Weyland explain: the meso level "refers to the intra-group interaction by which the individuals share their memories and come to an agreement in relation to the meaning of these...representations. This interaction has to be seen as a process that is a necessary mediator between individuals and society" (2016, 28-29). Here, at the meso level, the 
accumulation and outcome of possible macro understandings occur; the meso level is the bridge between the micro or individual and the macro or community. At this interaction point, dominant narratives have the opportunity to emerge and personal understandings become peripheral, replaced by an overarching theme which individuals agree - to some or varying degrees - is relevant to a particular representation. At the meso level, as Heinrich and Weyland further discuss, agreement on meaning occurs: "each single person does not reproduce her or his own notions. Rather, the members construct a group opinion within the exchange process...collected memories located at the micro level are transferred via the meso level into a collective or cultural memory at the macro level" $(2016,36)$. Said another way, a critical mass of sentiment regarding micro level individual memories emerges at the meso level, which then continues to accumulate and gain credibility when shared at the macro level. Cultural memory reaches its greatest grassroots potential at the macro level, moving beyond a single group to a larger group, where content is societally accessible (though not so highly organized as to be considered "institutional").

The above illustration broadly explains the range of cultural memory potential for analog and digital photographs. Here, circulation is "networked" only with digital photographs, encompassing the meso, macro, and institutional levels. The analog component, or "micro" level, conversely, is exemplified in Chapter 2 by lynching photographs, primarily when made into tradable postcards. Prior to digitization, photographs in this era were necessarily passed along in person or via mail. The potential range of cultural memory is small, limited to the number of physical prints or copies made. Moving beyond this example, the foci of this chapter are digital images, exemplified by the meso, macro, and institutional ranges outlined above. These three networks illustrate how rapidly digital photographs and accompanying verbal detail can be shared, expanding what people know about things featured therein. The photographic incidents analysed here, while all of the digital variety, come from three different camps of circulation potential. The 
first, like the Abu Ghraib photos, are passed in what I refer to as "meso" circulation networks, which begin with a single source that passes the images by email. Specifically with the Abu Ghraib photos, friends and family who received these images reportedly found the photographic contents funny and indicative of U.S. success in war (Struk 2011). The meso level is the point at which "group opinion" is formulated (Heinrich and Weyland 2016), and the narratives of "funny" and "success" begin to emerge. This circulation network is meso, and not macro, because limits exist in the form of contact lists; an email containing images can only be sent to a finite number of people. The Abu Ghraib instance illustrates the limitations associated with this type of range: until the photos are made more accessible, new viewers to an image can only be introduced by direct invite. However, the public becomes aware of the Abu Ghraib images when they are publicised via the institutional network. Finally, the macro range is exemplified as digital photos shared with an openaccess online forum. These images are shared with the general public, where the only imposed limit is internet access ${ }^{10}$. Now That's Fucked Up (NTFU), undermars.com, and LiveLeak are illustrations of online forums at the macro level.

Important to note is the focus on sharing. The sharing that characterizes micro, meso, macro, and sometimes institutional, levels is intentional, and specifically involves the choice to mail a postcard, pass content through email, or upload content to public sites. In this way, people move information on purpose, reaching out to known and unknown others, making participation open. Unintended sharing, conversely, is not discussed at length here, though it is relevant to indicate why: unintended sharing, I suggest, is likely the result of surveillance or hacking, both of which are practices of stealing. Knowing that information could be accessed does not condone its retrieval and use, and so, unintended circulation is always already about theft. Stated simply,

\footnotetext{
${ }^{10}$ While technically having limitless potential, access or viewers to images of this sort can be known by identifying how many people have access to the site — if open to anyone but free registration required—or by determining site or page visits for each photo per day.
} 
stealing is the opposite of sharing, which bars voluntary participation. Participation, specifically that of soldiers, is key in the use of digital photographs discussed here.

Three key areas will be examined in this chapter, one housed in the meso level, another in the macro, and one in the institutional. Briefly here, networked circulation, of any size, encompasses both image and accompanying narratives to contribute to the corresponding cultural memories. One example compares the circulated photos from Abu Ghraib-originally at the meso level though made public via the far-reaching, institutional network - to the verbal account made by Army Criminal Investigation Division Special Agent Brent Pack, in the documentary film Standard Operating Procedure (SOP). Few analyses exist of Pack's interpretations, and since he was hired by the U.S. military to assess what occurred in the photos, his account is perhaps the most influential in determining how these images are discussed and remembered. Pack's ideas greatly shaped the cultural memory of the photos from Abu Ghraib because, not only did his words help to determine the legal outcomes for the American military personnel involved, but his testimony was also echoed in news reportage worldwide; Pack's account shaped the narrative that accompanied these images in many widely read, institutional sources, ultimately contradicting many of the justifications expressed by the soldiers directly involved. Beyond Pack's narrative and SOP, three online forums are discussed: NTFU, undermars.com, and LiveLeak. Referred to as "shock sites," these forums do not censor violent or other graphic material in posted images. Because no known examples exist of the Abu Ghraib photos posted to a shock site, my discussion of these sites works to bridge the gap between meso and institutional networks. The discussion of shock sites, then, suggests how networked circulation informs the production of cultural memory at the macro level, drawing upon narratives accompanying images posted with similarity to the Abu Ghraib photos. Both NTFU and undermars.com were shut down after only operating for a few years, not surprisingly due to violent, graphic, and offensive content. This being the case, the available 
information is relevant here, helping to understand how people used the sites, and why, in addition to offering an explanation of their overall value. Still operational, LiveLeak is a participant-driven site that has morphed from simple provider of soldiers' graphic content, to a more general interest based image and video distributor and commenting forum. While horrific combat content can still be found there, other media content floods the site, featuring things like natural disasters or strange animal behaviour. Specifically with NTFU, while opinions regarding content differed among soldiers who participated in the forum, a common narrative nevertheless solidified regarding the necessity of the site, as a location for soldiers to share images and experiences of war that was otherwise unavailable. In this way, group bonding occurs with the use of these sites, similar to when agreement is reached over what images mean.

The arguments here take a particular shape: essential to the communication of group identity and the perpetuation of cultural memory is the role of digital photographic technology. First, I will define cultural memory. What follows is an overview of the similarities and differences of analog and digital photography, focusing specifically on durability and notions of privacy, as contrasted to impermanence and publishability, respectively. With impermanence and publishability in the digital era, group bonding via image circulation is prioritized, instead of images simply acting as mnemonic device. Considered next are the research sites. Finally, networked circulation solidifies the communication of cultural memory, whereby networked circulation is marked not as computer processes, but is instead described according to human use. In this way, digital photos are not only about the visual: with the digital comes networked circulation, and the ability to move not only pictures but also accompanying narratives, quickly and to large audiences. For soldiers, this sometimes means being removed from cultural memories of the events in which they directly participated. 


\section{Assigning CUltural Memory}

It is difficult to assign a singular definition to the term "cultural memory ${ }^{11}$." This section will give an overview of the concept, from its origins to its use today. First and briefly, I draw upon a definition from Heinrich and Weyland, who claim that "cultural memory refers to a canon of past events that are commemorated in a fixed manner and are defined as well as kept alive by history interpreters or other specialized institutions" $(2016,28)$. Focusing on the notion of interpreters and institutions, the concept steers firmly away from the understandings of memory as individual, moving instead toward the social: people would not have memories without society forming frames to recognize, recall, and locate ideas (Heinrich and Weyland 2016, 35; Halbwachs 1992, 38). Halbwachs, arguably the parent of "social" aspects of cultural memory, suggests a tourist walking in an unknown place as example. While this person may not speak with another nor share the experience with another, they nonetheless possess and use knowledge derived from others (friends, teachers, authors, cartographers) to comprehend and interpret surroundings (1992). Cultural memory is thus inherently experiential and communicative when ideas are intentionally shared with an associated group (Assmann 2008). Continuing with the tourist example, the accumulated knowledge of some tourists, of a particular era and location, become fodder for the experiences of other tourists for that particular era and location.

The simultaneous use and interchanging of the words "cultural," "social," and "collective," regarding memory, deserve some attention. Even top scholars in the area of shared memories use all references, often without explanation. For instance, Heinrich and Wayland's article, "Communicative and Cultural Memory as a Micro-Meso-Macro Relation," utilizes the term "cultural memory" in the title and throughout, though at various points the term "collective

\footnotetext{
${ }^{11}$ Though not implicitly stated, the foundations and canon of cultural memory are inherently West and Central European in scope (Hoskins 2009, 98). This might suggest that colonial or other defining practices of the West are bound up within its discussion, though this is also the case for many founding theories and readings of a particular canon.
} 
memory" is used without any indication of difference between the two. Even Google Scholar struggles to differentiate them, often grouping the terms and area scholars together; it appears that theorists and researchers have conflated the terms. Jan Assmann, however, has attempted to concretize the meaning of the words, although he does not completely differentiate them: collective memory concerns shared knowledge, which inherently possesses a cultural framework $(1995,125)$. To complicate matters, though, he also formulates another reference, "communicative memory," which he sees as social, formed in the playing out or interaction of social roles and responsibilities of individuals $(2008,109)$. Moreover, Assmann posits that cultural memory exists in myths, ritual, and symbolic production, all of which play out socially, as in, with other people $(2008,113)$. The distinction between cultural and communicative again appears to blur when Assmann suggests, "cultural memory is a form of collective memory" $(2008,110)$. A sociologist of collective memory, Jeffrey Olick, intervenes at this point, suggesting that "collective" might be better thought of as "collected," referring specifically to the results of collective behaviour: the accumulated memories of individuals become social when shared $(2007,23)$. For the reasons listed here, the terms, while not completely the same, nevertheless are flexible or interchangeable when no defining difference is presented. The term "cultural memory" is specifically used in this dissertation.

Some of the confusion regarding concept specificity can be found in the myriad ways to which social, collective, or cultural memory have been referred. "Collective memory has been used to refer to aggregated individual recollections, to official commemorations, to collective representations, and to disembodied constitutive features of shared identities; it is said to be located in dreamy reminiscence, personal testimony, oral history, tradition, myth, style, language, art, popular culture, and the built world" (Olick 2007, 21). For Olick, these vast descriptions can be summarized as the "two cultures": "one that sees culture as a subjective category of meanings contained in people's minds versus one that sees culture as patterns of publically available symbols 
objectified in society" $(2007,21)$. The difference here is between individual (people's minds) and social (shared sign systems). In assessing this difference, Olick, like others who ascribe cultural or collective memory to the social, suggests a way out of this binary conundrum: to focus on the shared nature of information is to engage with public discourse ${ }^{12}$, narratives and images of the past, which "speak in the name of collectives" $(2007,33)$. Social historian Michael Schudson affirms the collective nature of memory: "memory is social...located in institutions rather than in individual human minds in the form of rules, laws, standardised procedures and records, a whole set of cultural practices through which people recognize a debt to the past" (1993, 347). Finally, summarized by Roediger et al., "in short, individuals remember, but with much help from social and cultural aids including reports of memories from other people. Collective memories may ultimately reside in individual nervous systems, but complex social processes provide the basis for our memories" (2009, 141). All in all, whether referred to as "collective," "social," or "cultural," rather than isolated or "individual," this form of memory is rooted in shared or common ways of being in the world.

\section{History and Origin of "Group" Components to Cultural Memory}

Though conceptions of cultural memory begin with Halbwachs, Jan and Aleida Assmann further tease out some definitions. Where Halbwachs conceives of "social memory," rooted in notions of categories, norms, and evaluations $(1992,121)$, the Assmanns push the notions more towards collectively shared meanings and the preservation of group identity. Further discrepancies arise between formulations by each of the Assmanns: Aleida focuses on case studies of Holocaust

\footnotetext{
${ }^{12}$ Jurgen Habermas is in the background of the discussion of cultural memory. Described by Heinrich and Weyland, small group communication is located at the meso level, linked between the individuated micro and the mass macro levels, similar to the situating of Habermas' (1985) rational public discourse (Heinrich and Weyland 2016). Here, interconnected ideas of communication, groups, and nationhood are foregrounded, whereby shared memories are relevant to citizens of a particular nation (Lambert et al. 2009, 196).
} 
experiences, centering on political state strategies of forgetting (2012), while Jan centres on solidifying theoretical conceptions of group identity formed via myth, ritual, and symbols (1995; 2008). Jan's theories heavily inform this chapter, which will be explored in depth later in this section.

Olick traces the formulations of Halbwachs' theory of social memory to his teacher, Durkheim, and his corresponding concept of "collective conscience" $(2007,6)$, which addresses commemorative rituals of religious life (Durkheim 1995). Halbwachs incorporated these concepts by replacing the all-encompassing notion of "society" with the more nuanced and multi perspective oriented "groups" (Olick 2007, 18). Specifically, Halbwachs' notion of individual memory is ascribed a social framework, drawing directly from group-based remembrance as that which represents the collective. For Durkheimian Halbwachs, as Olick describes it, memory is not simply individual or that which binds groups; it is "cultural inheritance" $(2007,6)$. Cultural memory, in this way, seeks to affirm identities, which are not simply individual, but instead are informed by group parameters: "the narrative of one life is part of an interconnecting set of narratives; it is embedded in the story of those groups from which individuals derive their identity" (Connerton 1989, 21). Moreover, as Olick affirms, "Halbwachs argues that it is impossible for individuals to remember in any coherent and persistent fashion outside of their group contexts" $(2007,19)$. While this might be the case, garnering a collective response from a public or a group requires not only shared understanding but also a shared valuation of that reading. Heinrich and Weyland suggest how this occurs: "a collective understanding of meanings is established within the participants of the discourse. This kind of understanding provides the foundation of a common ascription of values" $(2016,35)$. While Heinrich and Weyland only describe the foundation to a shared association, I use the concepts of authority and social order to further flesh out the formation of group-based cultural memory. 
Authority, Social Order, and the Production of Cultural Memory

Cultural memory, useful in maintaining a shared understanding of the social world, also seeks to ensure order. According to particular criteria: "memory, as organized cultural practices, ensures the reproduction and cohesion of a given social and political order" (Misztal 2010, 28). Also significant is the notion that what is normative today moves through our understandings of the past: "we might say that our experiences of the present largely depend upon our knowledge of the past, and that our images of the past commonly serve to legitimate a present social order" (Connerton 1989, 3). Moreover, "accounts of the collective memory of any group or society are usually accounts of the memories of some subset of the group, particularly of those with access to the means of cultural production or whose opinions are more highly valued" (Olick 2007, 24). Here, cultural memory is not divided evenly amongst a group, let alone society as a whole. While this is certainly the case in the analog era, with the digital come new mechanisms for forming and maintaining alternate cultural memories.

The power afforded to information, and the compilation of cultural memories, is altered when moving from analog to digital networks. At issue are not only the generated ideas but also the mechanisms through which ideas are disseminated. Consider as example the narrative formed by Brent Pack about what occurred at Abu Ghraib. Pack's standing in the U.S. court system gave authority to the ideas he presented, which generated further credibility the more his ideas were shared via media. Historically, very few were given this kind of credibility, though this is changing in the digital era; while older notions of credibility still exist, centering on the belief of credentialism, access has altered this belief system. No longer are the highly educated or members of political or economic parties the only few who speak about an issue. "Regular" people (or U.S. presidents), too, with a twitter or other social media account are able to have their voices heard, an 
option once only offered to those who generated institutional or mass news media. With this, the concept of the "highly valued" opinion changes to accommodate those with internet access.

For now, I turn briefly to what the internet and digital technology affords to digital memory. Collective and digital memory theorist Andrew Hoskins suggests that "digital network memory" emphasizes the building of, and increasing access to, information. Hoskins suggests that the digital era offers people a "continuous networked present of the web and other digital media through which memory and technology co-evolve, including the co-existing of previously more distinct modes of cultural memory, for instance, the [separation of] the "private' and the 'public"' $(2009,101)$. Here, this separation challenges previously established notions of authority and social order in the collapsing of the private and public; digital access encourages the sharing of a plethora of ideas, some of which would have been previously unknowable. Thus, it is no longer as easy to ensure the continued and solitary existence of the singular (or minimal) authoritative accounts of the analog era.

\section{Working with Jan Assmann's Definition of Cultural Memory}

Cultural memory provides concrete collective identity, rooted in certain understandings shared by a group. A leading researcher of cultural memory, Jan Assmann defines this term as "a collective concept for all knowledge that directs behaviour and experience in the interactive framework of a society and one that obtains through generations in repeated societal practice and initiation" (2008, 126). As mentioned in the introduction to this chapter, Assmann claims that cultural memory can be housed in physical objects, is shared by a number of people, and that it "conveys to these people a collective, that is, cultural, identity" $(2008,110)$. As example, consider the Confederate flag of the American South. For some, it is a sign of freedom and commitment to the republic, while for others it signifies racism and the painful history of slavery; this symbolic object expresses how different groups experience the world. With its use, this one flag communicates these complex ideas, 
situating two (if not more) disparate positions, and ultimately establishes cultural memories along each narrative. To be certain, multiple types of memory exist. However, cultural memory specifically belongs to groups of people who share the same space, time, and/or material objects, and is rooted in historical and mythical narratives (like the racist and discriminatory ideas, encapsulated in the Confederate flag, for those who see it that way). Here, the concretion of identity is emphasized, fostered and formed via group belonging, whereby those who do not belong are "Othered."

According to Assmann, cultural memory hinges upon the reconstruction of specific events in specific ways. It is established at multiple points in time, never in singular moments. Colloquially, it forms like a snowball rolling down a hill, constantly gathering more snow, and ultimately growing and gaining mass. Cultural memory is communicative and thereby "offers no [one] fixed point which would bind it to the ever expanding past in the passing of time. Such fixity can only be achieved through a cultural formation and therefore lies outside of informal everyday memory" (1995, 127). Calling this process a "temporal horizon," Assmann further suggests that shared memory of past events is bound through cultural formation, like texts, rites, monuments, and institutional communication, like recitation, practice, and observance. As more time passes and people participate in the same activity, more information is shared or added to the overall experience. Such a process reinforces identity, for one within a group, in addition to the continued formation of the group itself. The repeating of the contemporized past in the present, via ritual or practice, affirms identity, and, moreover, this kind of "memory enables us to live in groups and communities, and living in groups and communities enables us to build memory" $(2008,109)$. Thus, the creation and maintenance of cultural memory reinforces identity and group association. The capacity to reconstruct past events in practical and contemporary situations is key because this reconstruction continues to add value: investing time to continually establish cultural memory 
reaffirms the shared values of a group, using authorized knowledge to reproduce symbolic objects $(1995,130)$. The items made by the group communicate inscribed symbolic notions when used and shared.

Cultural memory is complex, developing through rich social networks and symbolic associations that garner interest in preservation, but it is not a repository of all past experience (Olick 2007; Halbwachs 1992). The publically available narratives surrounding an event or group more generally are what solidify shared understandings (Olick 2007). Commenting further on the symbolic, Assmann defines the concept of cultural memory as "a kind of institution. It is exteriorized, objectified, and stored away in symbolic forms" (2008, 110). Importantly, cultural memory is reproduced in the sharing of material objects, which Assmann calls "figures of memory" $(1995,129)$ or "reminding objects" $(2008,111)$. These objects are readable texts that further reinforce social protocol and practices with the sharing thereof. Maintained through social convention, these memory objects represent specific moments or points in time, that resituate past inscriptions in the present when circulated. In so operating, the reminder of past events imbues the present with a valuable and dependable narrative. Citing images as one of these kind of textual objects, Assmann affirms: "things do not 'have' a memory of their own, but they may remind us, may trigger our memory, because they carry memories which we have invested into them" (2008, 111). The value of memory objects thus rests in how they are, continually, used, in addition to the narratives that are called upon and circulate alongside them, as "reminding objects." Taken together, verbal and visual narratives that accompany reminding objects, inscribed with symbols of group identity, gain traction and authority with continued use. Discussed here, the verbal account of Brent Pack, accompanying the Abu Ghraib photos, reinforces and reminds people of two greater narratives originally outlined in this dissertation Introduction: the images are the problem, and only "a few bad apples" are to blame. 
As I noted in Chapter 2, analog photographs of the personal variety were primarily used to illustrate social bonds and power dynamics. Whether discussing group photographs or those of hunting and torture, these images each offer information to viewers about those photographed. Here, the focus is on the "insiders" of a group, i.e.: those who are included in group images, those who make eye contact with the lens, or those who smile for the camera in the presence of a lynched body or dead animal. Regardless, these images often focus on group insiders, rather than outsiders or Others. To reaffirm membership in pictorial form, physical, paper objects are created, and are passible between people. However, though affirmations of group membership are still of utmost importance with digital photography, some things have nevertheless changed, particularly with the increased ease of circulation. Personal photos now can, metaphorically, pass between potentially endless numbers of hands, no longer bound by the limits of physical photographic printing. Empirical work in this area, in the form of interviews, has identified that this ease of communication has increased the willingness to share photos. In this way, digital photos and the internet have provided an effortless method of keeping friends and family pictorially informed about our lives, whether the featured moments or events are significant or the sharing of routine or mundane photos is used simply as a way to stay connected (Lampe, Ellison, and Steinfield 2008; Joinson 2008). And so with the boom of digital photography comes this increase of communication via online circulation, but there is an associated cost. Nancy Van House suggests that digital "personal photographs may be becoming more public and transitory, less private and durable" $(2011,133)$. The increased ease of communication brings forth tensions between private and highly publicized, and impermanence and durability, specifically regarding "personal photography."

Personal photography is the focus of this chapter. And while the phrase has gone unmentioned until now, I have nevertheless been referencing it, primarily as different from 
professional or journalistic varieties. Nancy Van House defines personal photography as a form of communication intended between those who took the photos and "friends and intimates." The form itself encompasses "multiple, overlapping technologies: of memory; relationships; self-presentation; and self-expression," which are increasing in circulation, or "publicness," and in volume, due to digitization (2011, 125). Van House further suggests that tourist and group photography are examples of this, though personal photography is not limited strictly to these two types $(2011,125)$. Personal photography in the analog age primarily afforded "autobiographical remembering," and paper prints were routinely housed in an album or kept in a box. Prior to the emergence of the digital, when photographers and theorists alike were unaware of the potential offered by technological advance, analog's function was primarily to offer a memory tool, as well as to communicate these memories to others (Barthes 2010; Sontag 2001). Analog photos connoted reliability, offering recall and proof of life events (van Dijck 2008; Stuhlmiller 1996). Conversely, with the digital, it has been suggested that the primary function is to communicate identity formation, over and above the use of recalling memories (Garry and Gerrie 2005; Harrison 2002; Schiano et al. 2002). While both digital and analog photography each has the same potential—as mnemonic device and as identity communication tool- the order of importance for each function varies according to era. The analog variety offers first, memory tool, and second, pictorial illustration of identity, while digital photography is the other way around, with identity formation coming first, followed by memory tool. In any case both types of photography provide communication of each aspect, though it is important to note the difference in use as a communication tool. Whereas personal analog photography was primarily a family tool for remembrance and reminiscence (van Dijck 2008, 60; van House 2011, 125), personal digital photography instead is used for conversation and peer-group building (van Dijck 2008, 61; van House 2011, 125). There has been "a significant shift from personal photography being bound up 
with memory and commemoration towards pictures as a form of identity formation; cameras are used less for the remembrance of family life and more for the affirmation of personhood and personal bonds" (van Dijck 2008, 60). This digital shift, since the early 2000s, situates the individual as the centre of pictorial life (van Dijck 2008; Rose 2010). In this way, self-presentation is the major function of digital photography, which connects the self to others using the image and accompanying narration (Harrison 2002, 107).

The sheer number of digitally available images, combined with the ability to circulate accompanying captions and stories, makes possible the formation of narratives through which to conveniently categorize content. van Dijck discusses, generally, the language of digital photographs, and comments on the increase in volume that comes with the digital era:

Pictures become more like spoken language as photographs are turning into the new currency for social interaction. Pixelated images, like spoken words, circulate between individuals and groups to establish and reconfirm bonds. Sometimes pictures are accompanied by captions that form the "missing voice" explaining the picture... The main difference between cameraphones and the single-purpose camera is the medium's "verbosity"- the inflation of images inscribed in the apparatus's script. $(2008,62)$

Here, the cameraphone or digital camera offers a new way to experience the world; no longer do people have to save film and wait for the perfect image before snapping the shutter. Instead, they can take numerous photos of a single event, which leads to the idea of capturing and especially the appreciation in viewing of mere moments as a snapshot of an overall experience. van House describes the verbosity as an increase in volume: "The volume of images available has exploded: people are making many more images, and they have access to images made by many, many more people, including family, friends, acquaintances and even strangers" $(2011,130)$. The verbose nature of the digital camera has shifted the cultural focus of both photography and the practice of looking at images. van Dijck explains, "when pictures become a visual language conveyed through the channel of a communication medium, the value of individual pictures decreases while the 
general significance of visual communication increases. A thousand pictures sent over the phone may now be worth a single word: see!" $(2008,62)$. The accumulation of information, as it boils down to this one word, further reinforces the value of an attached narrative to numerous images. In his article, "What People Do With Pictures," Alan Radley suggests that photos do not inherently make a single "voice" available, and instead, verbal narration is needed to understand the accompanying stories (2010). When so many photos depict the same place with the same people, and even roughly the same type of instances, a verbal narrative provides a theme through which to categorize the overwhelming visual content. Consider for instance common tourist images, like those discussed in Chapter 2. Without an attached personal narrative, one's image accompanies the mass of other similar photos to simply reinforce the iconic type. Impermanence is fostered here because other photos sharing a likeness will emerge.

I recognize the tension between what the digital provides and what it denies. While the digital has properties of remembering, as linked to analog photographic use and histories, it also fosters forgetfulness by way of producing throwaway moments; this is the verbosity van Dijck discusses. And so, digital photographs are situated at a nexus of remembering and forgetting; the image offers a visual account of something that happened, but with so many similar images or images describing similar experiences, the value as a memory tool is continually replaced by newly circulated images - the only thing that might maintain interest is a personal link to the featured person or group. What results is perhaps the knowledge that something is described within a photo, but this something is obscured by all the other digital photos, featuring similar things or not, that are also known to exist. Digital pictorial verbosity brings with it an overwhelming sense that there are endless images in the world. What could accumulate along with this sense are possible narratives explaining phenomenon, from what is depicted in a frame, to the manner in which the framed was captured. This being the case, other information surrounding the image might become of greater 
importance: captions or comments set apart one image from a myriad of others. Accompanying accounts, testimony, or comments help to reinforce a narrative that is contained within an image. Though it should be noted that multiple possible narratives exist for a single image, commonly known narratives come to the fore and are fostered via a specific perspective or authoritative account. I argue here that authority is granted in two ways: 1) by a person or people who have specified knowledge on a given topic; and 2) by the reproduction and circulation of certain ideas. Dominant narratives that circulate alongside digital images - because each circulation is combined with authoritative accounts, sanctioned by the sheer number or availability of certain viewpointsreinforce key viewpoints of the visual ideas contained therein. These dominant notions are reaffirmed and re-enacted when continuously shared, carrying along and solidifying recallable cultural memories in the process. Without accompanying verbal narratives, cultural memory might still exist and be fostered, but the publicized and popular notions regarding specific images are not easily known, and thus not easily recallable. Verbal accounts help to inform a common way of seeing something, sharable via our networks of communication.

As previously stated, an issue of permanence and durability arises when comparing analog to digital. The analog generation spent time and energy amassing collections of photos, with the knowledge that these images would exist with some permanence in material form. Conversely, and furthering the notion of identity communication tool, with the digital emerges a new kind of engagement with personal photography: there is "less interest in sharing photographs as objects than in sharing them as experiences" (van Dijck 2008, 61, as cited in Kindberg et al., 2005). Van Dijck further explains:

Whereas parents and/or children used to sit on the couch together flipping through photo albums, most teenagers [today] consider their pictures to be temporary reminders rather than permanent keepsakes. Cameraphone technology gives rise to a cultural form reminiscent of the old-fashioned postcard: snapshots with a few words attached that are mostly valued as ritual signs of (re)connection. Like postcards, cameraphone pictures are meant to be thrown 
away after they are received... Because of their abundance, these photographs gain value as "moments." (2008, 62; emphasis mine)

The practice of sharing digital photographs often relegates the pictures, once seen, to a diminished status, discarded once the content has been registered. More photographs will simply arise, taking the place of importance once held by the previously unseen image. This notion, however, is not true for all digital images. Some, like those from Abu Ghraib, haunt the minds of many beyond first viewing and require further consideration. Conversely, it is plausible that, while steeped in early digital photographic culture, the taking and sharing of the Abu Ghraib photos was reflective of "throw-away moments." It is possible those who orchestrated the photography at Abu Ghraib intended for the images to merely be considered as a moment, and these pictures should thus only be reflected upon for a single moment. Whatever was intended, the photos have been criticized for their enduringly haunting qualities, which distances if not altogether removes them from the category of throwaway moments.

Consider for instance the narratives that accompany the Abu Ghraib images, which will be a focus in the next section. Broadly, the surrounding narratives are complicated, and encompass, in part, the community of friends and family who received the images by email, and who, as previously suggested, reportedly found the photographic contents funny and indicative of success in war (Struk 2011). Another surrounding narrative, one that I subscribe to and is the backbone to the dissertation, is a critical perspective rooted in awareness of histories of racism, discrimination, and torture. These two narratives oppose each other, denying the possibility of a single perspective of cultural memory. In this way, and broadly speaking, differing viewpoints are what challenge and then cause changes to the cultural memory of a particular event. The next section considers how one viewpoint, that the images do not depict torture, helps to inform the greater narratives, or cultural memories, of Abu Ghraib. 
The cultural memories that come from the photographed military behaviour at Abu Ghraib ricochet between narratives of "a few bad apples," humour and combat success, and trophied memory objects. As previously detailed, while Sergeant Joseph Darby was upset by the images, describing them as "disturbing," not everyone saw the Abu Ghraib photographs in the same way. If you'll remember from the introduction of this dissertation, Specialist Charles Graner gave Darby a disk that contained the now infamous photographs. Darby notified authorities, and Brent Pack was brought onto the case. Pack is one of the people who does not find the photos particularly disturbing. In SOP, Pack states, "you can't bring emotion or politics into the court" (Morris 2008, 00:16:20). Pack is adept at leaving both emotion and politics out of judicature with this statement, though perhaps to a fault: he was hired to fully consider the images, and instead prefaces his analysis with a statement about what he blatantly disregards. How these photos are read across mass culture, coupled with Pack's authoritative testimony, affects the way in which the events will be remembered. The narrative that Pack forms is in contrast to what the images themselves reveal. If his words can be trusted — over our own eyes - the images might also be deemed to be nothing more than "standard operating procedure."

The person appointed to assess the contents of the Abu Ghraib photographs, one might assume, would be someone with a comprehensive knowledge and skill set regarding this role. Pack is not a photography expert, technically, aesthetically, or otherwise. Rather, he was hired for his expertise in forensic investigation. Specifically, he was charged with the task of crime detection, which Pack appraised by attributing a timeline to the events featured in the photographs (Morris 2008, 00:43:55). With Pack's account, the viewing public is told what to see, and what not to see, specifically in relation to the temporality of the photographed events. Though anyone is free to draw their own conclusions, Pack's analysis carries the weight of authority and legitimacy with the 
narrative he forms, particularly because of the mass accessibility afforded by the institutional network.

In SOP Pack concludes that although some of these images do in fact depict abuse ${ }^{2}$, he nevertheless dismisses many of them as nothing more than "standard operating procedure" (Morris 2008, 1:27:55). He admits that some of them depict abuse because of the overt connotations of sexuality and humiliation (Morris 2008, 1:15:50). He further explains:

It was important to separate those that were criminal acts and those things that were not criminal acts. And that's what the prosecution would have to focus on. If somebody was physically injured you know you have a criminal act. Putting somebody into sexually humiliating positions, you have a criminal act...they [the prisoners] weren't being tortured per se. They were going through discomfort to try and aid in attaining information. (Morris 2008, 1:27:10)

With this account, Pack at once both removes and affirms the ethical responsibilities of soldiers. It is surprising that Pack's assignment is to fully consider "what is in the picture." Yet, he overlooks the purposeful composition of these images, which is not only illustrated within the photographic frames, in the form of physical posing and props used, but also is indicative of the criminal acts he proclaims to see.

Beyond this, Pack seems more concerned simply with the existence of the photographs: "I'd say over half of all my cases were solved because the criminal did something stupid. Taking photographs of these things is that one something stupid" (Morris 2008, 00:15:55). Here again, as first outlined in the Introduction, the existence of the photos is the problem, not the actions depicted therein. A spectre of foolishness looms large; the U.S. military personnel get into trouble for having a lack of sense, because they took the photos. The contents of the images, however, do not seem to impel Pack beyond euphemistic finger wagging. Cursorily describing the images, Pack discusses what he sees: "You look in their [U.S. military] eyes and it looks like they're having fun. This scene is what sealed their fate... It's not so much that you're there committing these acts of abuse; if you 
were in the pictures while this stuff was going on, you were going to be in trouble" (Morris 2008, 1:15:50). In his own words, Pack affirms that the images were illustrative of the fun being had by the participating U.S. military members, largely due to the looks on their faces. This particular information about their demeanour is what "sealed their fate" for convictable offences (2008, 1:16:10). Adding insult to literal injury, Pack states outright that committing acts of abuse is not what would get these military personnel in trouble - the visual illustration provided by the photos is what is abhorrent, because the images remove deniability of said abuses. Simply put, for Pack, the criminality seems to rest with the taking of the images, not the criminality that occurred beyond the photographic frames. Again, the problem rests not with the abuse itself, but with proof that the abuse happened.

For some, the cultural memories that surround the photos from Abu Ghraib encompass the notion of "a few bad, stupid apples," which began with the circulation of the images within a likeminded community, in a meso network. Pack's account is disseminated through the documentary, establishing a narrative that suits those who participated in the events at Abu Ghraib: for legal reasons, it's better to be "stupid" than to have committed "torture." The words of Harvey Volzer, attorney to Specialist Megan Ambul, circulated in news, declaring that 'you don't ruin people's lives because they were stupid" by punishing them too firmly (Halloran 2009). Even Gary Winkler, author of Tortured: Lynndie England, Abu Ghraib and the Photographs That Shocked the World, suggests that, "all she [England] was guilty of is stupidity" (Jones 2009). This narrative of stupidity was substantiated by all the press surrounding the publication of the photographs in 2004, and then again was solidified in 2008 with the release of SOP. The associated cultural memories, here, are furthered with the various comments from concerned parties in the Introduction, which states that the main problem is the existence of the images, or, as Pack claims, "taking these pictures is stupid." Even with many years having passed, press coverage of the photographs and events are still 
described as "stupid": A 2012 Huffington Post UK headline reads, "When Will the Endless Military Defenders Confess to Their Stupidity," while the author describes being horrified by the torture and humiliation committed at Abu Ghraib, all in the name of Western freedom (Hill 2012). Another article, in Foreign Policy in 2014, "Obama's 'Don't Do Stupid Shit' Foreign Policy," outlines the diplomatic costs for America because of the atrocities committed at Abu Ghraib (Rothkopf 2014). Knowledge and circulation of "stupidity" runs far and wide through the institutional network.

More than mere personal souvenirs for the soldiers who captured them, these images have entered into the cultural memory of those familiar with the war on terror generally, and specifically with what occurred at Abu Ghraib. Marking the ten-year anniversary since the publication of the images, many major global newspapers revisited these events. It should be noted that all of this news content is available online, is linkable using social media, and can be sent via e-mail, thus further reinforcing and fostering cultural memories in a variety of networks. By way of example, Der Spiegel published a story titled "Iraq Anniversary: 10 Lessons from America's 'Dumb War"” (Fischer 2013), while Al Jazeera printed one titled "Abu Ghraib Closes, Bitter Memories of Torture Remain" (Tarabay 2014), and there was the story written by The New York Times Editorial Board, "Abu Ghraib, 10 Years Later" (2014). Each of these articles discusses the scandalous photos and how they have affected the remembrance of this U.S. invasion of Iraq. Mirroring these examples, it is the digital attributes of photography that reinforce the public remembrance of the Abu Ghraib images; while photography certainly pre-exists the introduction of the digital, ubiquitous online access to these images is precisely accounted for by digital technologies.

Striking digital photos, like those from Abu Ghraib, "may end up as a perpetual object of (collective) cultural memory" (van Dijck 2008, 71). As van Dijck suggests, the shared memory of what happened at Abu Ghraib is the result of the publication of the images, "reframed as evidence of the army's abhorrent behaviour as torturers posing triumphantly over their helpless captives" 
$(2008,69)$. As already discussed, the trophy represents success, and looking at the trophy might conjure pride in the viewer if they identify with those involved in the creation of the trophied object. Wendy Kozol describes this identification with the battlefield souvenirs from Abu Ghraib, referring to the photos as "memory-objects" $(2012,30)$, just as Assmann states that photos can themselves be "memory objects" or "figures of memory." Specifically, Kozol asserts that the images illustrate pride made visible within the frame: "The Abu Ghraib photographs function as trophies in which smiling American soldiers proudly display their prowess to the camera as they stand over the naked bodies and hooded or obscured faces of Iraqi prisoners" $(2012,30)$. With reference to visuality and colonial history, some refer to the photos as "trophies of accomplishment" (Sontag 2004, 4; Tucker and Triantafyllos 2008, 95). While this statement is redundant, as something that is a trophy clearly symbolizes accomplishment, it nevertheless reinforces the level of importance imbued by such a title. For a trophy to be a trophy, a particular meaning must be ascribed to the object itself. In this case, the photographs are the trophied objects in question. And, moreover, for a trophy to be a trophy, it must be won, which illustrates that a fight has taken place. The trophy, then, is also a memory object that pictorially resembles this match, which is itself a monument—as Assmann would attest—of the reciting of battle.

As mentioned previously, Pack seems uninterested in what motivated the photography. However, to consider the associations might allow for a better understanding of possible meaning attribution, and thus might allow for the consideration of why the photographs were captured at all. Pack also seems to proclaim the existence of a single meaning with regard to the photographs that could have multiple if not endless meanings. Adding to this sentiment, Pack regrets that the military personnel were foolish enough to take pictures, yet he justifies their behaviour by validating some of what appears in the photos, which might be heavily affected by the predominant sociocultural group to which one belongs, the military in this case. One could paraphrase Pack's account, that the 
criminality rests in the act of photographic capture, not the events themselves. To smile at the enemy's pain is perhaps customary for this group of people, and is possibly even an aspect of a soldier's job when "enhanced interrogation tactics" are used; but to take pictures of it is "stupid" (Morris 2008, 00:15:55). What Pack doesn't account for are the possible purposes of taking these photographs. Generally speaking, taking pictures offers the ability to commemorate the efforts of military personnel by way of producing pictorial representations, or trophies, whether featured military members are at rest in "khaki portraits" or are engaged in active combat. In any case, photographs make meanings visible. It could be argued that herein rests the motivation of photographic capture: the smiles and thumbs-up gestures at Abu Ghraib are not simply suggestive. Bringing Chapter 3 into 4, the meaning of these gestures is definitive, via social protocol and practice, whether or not Pack declares these embodiments to be factually relevant when assessing possible abuse. There is a reason why the individuals involved found the taking of and the images themselves valuable - they belong to a particular group who values the ideas represented therein: "we" are more powerful than "them," those Others. Pack's account misses this whole aspect, and instead reinforces the narrative of "a few bad apples"- a narrative that still circulates today for those who refuse to see the torture in the frames. Thus I offer a competing narrative to Pack's: perhaps the participating U.S. military members chose to be remembered the very way they presented themselves, and identified as such, as a prideful, powerful, and cohesive group. These soldiers were building memories of the events in which they directly participated. The corresponding images gain value as memory objects when shared. These notions are reinforced with macro network circulation of "shock sites."

Uses of OnLINE ForUms: Now That’s FUCKED Up (NTFU), UNDERMARS.COM, AND LiVELEAK "Unlike soldiers in other conflicts, who had kept their pictures private, it seemed that these soldiers were making them available to anyone who cared to look."

Janina Struk, Private Pictures $(2011,161)$ 
"Shock sites" are generally known to feature disturbing, provocative, and potentially offensive content, and are a cultural phenomenon that emerged in 2003 and 2004. The materials are often pornographic and extremely violent, often mixed together in some way. Also often displayed are degrading photos that challenge respect, dignity, and humanity more generally; Othering is central to many of these images. However graphic, as highlighted in the introduction to this Chapter, soldiers want their images shared. The texts here examine online forums, accessible to both soldiers and civilians. The first two, NTFU and undermars.com, are both defunct, banned for the graphic content featured. Access to these sites now prohibited, the content considered here comes in the form of descriptions, use, and opinions regarding the content that once existed. The third site, LiveLeak, is still active. LiveLeak has managed to stay operational after having morphed into a more general site, now primarily featuring information, news, and videos beyond war. Perhaps more important than the illustrated content, these sites are driven by participant interest. In part, this section also presents what might have happened if the Abu Ghraib photos were originally accessible on sites like these.

NTFU was an American-based online archive. While no longer available online (or anywhere), it is nevertheless relevant to the ways in which digital war trophy photography is examined. This website emerged in 2005, offering U.S. soldiers deployed to Iraq free online access to amateur porn in exchange for "war porn," photos of dead, mutilated, or humiliated Iraqi bodies, but it refused any depicting torture. The site's Webmaster, Chris Wilson, claimed that there were over 150,000 registered members, and at times it had 180,000 visitors daily (Struk 2011: 165). The U.S. government shut down NTFU in 2006. While the site itself can no longer be accessed, a few sources exist outlining and depicting the photos that circulated on this forum (AndenPapadopoulous 2009; Kennedy 2009; Struk 2011). Even though inaccessible, there are ways to 
analyse and discuss the absent photos based on the surrounding contexts (Cruz 2012), and I argue that this process has much to offer in understanding war for soldiers in the digital age.

With NTFU, Wilson saw an opportunity to trade content, between soldiers who had war photos and civilians who had amateur porn. Wilson, however, imposed a few conditions on the content generated by soldiers: uploaded war images had to come from serving soldiers, and could not be taken by professional photographers. Moreover, illegal behaviour, like that featured in the photos from Abu Ghraib, was forbidden. In return, Wilson said that he would refrain from editing the images (Struk 2011, 163). Even with these outlined parameters, he was surprised by the volume of graphic pictures that were uploaded to his site. As it was, he divided the content into two categories: "Pictures from Iraq and Afghanistan-General" and "Pictures from Iraq and Afghanistan-Gory."

Undermars.com ${ }^{13}$, another site that has since been shut down, featured similar content to that of NTFU. Like NTFU, little information remains of the site; in fact, there is less-no Wikipedia page for the site exists, an indication of just how little has been saved. A few pieces of information do remain, however; for instance, that the "site contain[ed] an archive of photos taken by soldiers serving in active duty. This site aims only to visually document their [soldiers'] experiences and is not a political site. The name "Under Mars" is an homage both to Mars, the Roman God of War, and to the otherworldly nature of the experience" (uruknet.info 2017). The tone of this comment seems to honour the efforts of war, highlighting by the notion that uploaded content intends to document soldiers' experiences, not to mention that the site namesake itself reflects combat efforts. Ultimately, in stating that it is not a political site, but instead is a forum for

\footnotetext{
${ }^{13}$ Undermars.com now reloads directly to another site, stormfront.org, a white pride site. It seems that after undermars.com became defunct, stormfront.org gained access to some of their content; however, all hyperlinks are deactivated as of February 22, 2017.
} 
soldiers to relay experience, the webmaster makes the observations and knowledge of the soldier the focus.

The LiveLeak site is organized in a formulaic manner, yet its layout is also overwhelming. The layout of the homepage is as follows: tabs on top; centred content with images, titles, and short descriptions; and, a sidebar on the right that offers "Current Events" and "Channel" options, both with images, titles, and short descriptions of their own. Generally, new content is featured first, with older content kept in searchable form. A number of features on the homepage are worth noting. The tagline of LiveLeak suggests the site's intentions: "Redefining the media." Besides this statement in the top left corner, a log-in or create account option appears just below, ultimately encouraging participation with the uploading of content and the commenting thereon. Facebook and Twitter icons also appear for the sharing of site material. Four tabs appear below: Home; Recent Items; Channels; and Forums, and the site automatically loads to the Home tab. Immediately to the right of the tabs is a Search box. Part of the Home tab includes subheadings, which appear to be standard headings, as well as current and relevant news topics: News \& Politics; Yoursay; Liveleakers; Must See; Ukraine; Syria; Entertainment; Staff Blog; More Blogs; and, Browse Channels. Below these titles are more tabs, still part of the overall Home tab, two of which are repeated: In the News; Yoursay; and, Must See. The Must See tab automatically opens, and on February 9, 2017, the three suggested titles are: Guy Gets Headbutted and KTFO; Blind Cat Gets Paid; and, Don't Crowd the Snowplow. Just below this are two "Featured Items": This Guy Does the Best Arnold Schwarzenegger Impression Ever, and, Man Ignites Fireworks Store. All five of these stories feature a small thumbnail from the related video. To the right, on the sidebar, is a LiveLeak on Facebook button, showing that 890,000 people "liked" LiveLeak on Facebook. Just below are thumbnails, titles, and short descriptions of three Current Events, as well as one Featured Channel just beneath, all of which centre on terrorism. From top to bottom they read: 2016 Nice Attack; 
2016 Brussels Bombings; November 2015 Paris Attacks; and, 2011 Norway Attacks. Though each of these events occurred over a year ago, the comments from site users suggest that they are still present in the minds of many.

Each featured element on the LiveLeak ${ }^{14}$ homepage seems to be driven by participant interest. Besides the reposting potential garnered by the Facebook and Twitter icons, the login button suggests that participation is welcome, particularly in the form of creating one's own channel on which to share and ultimately shape content. Concurrently, the forum area of the site allows members to directly access one another for conversation. The "Yoursay" tab reiterates the focus on participant interest by directly asking users to comment on anything related to the site. Participant interest is emphasised on this forum site, and is further discussed below.

As the name "shock sites" implies, these forums feature graphic content, although more important than simply providing "shock," at least to some, is the presentation of unbiased and unedited information about ongoing wars. With these sites, like-minded people can come together to share and discuss information. Independent scholar Janina Struk interviewed a number of shock site founders, and censorship is the central issue here. For many, these digital pictures have come "to epitomise a popular resistance to media censorship," because the lives of soldiers are visually knowable (Struk 2011, 161). According to Shannon Larrett of undermars.com, the images on this site are divisive, and yet provide access to otherwise unknown information: "People got angry on all sides because they couldn't figure out whether it was pro-or anti-war, but it was neither-just an attempt to give an accurate snapshot...I don't think that censoring soldiers' voices is a good thing.

\footnotetext{
${ }^{14}$ The LiveLeak forum has some interesting features regarding potentially disturbing content. On the top right of every page loaded is a button that reads: "Safe Mode: On," or "Safe Mode: Off." When the bottom is clicked, a pop-up window appears, which reads: "LiveLeak says: Turning the safe mode off will disable the current protection that prevents mature preview images and avatars from showing. By clicking OK you agree that you are 18 years and over and want to turn the safe mode OFF" (2017). If Safe Mode is on and the content is considered "Mature," the video thumbnails that accompany this content do not show an image, and instead reiterate simply read as "M," for mature.
} 
If the public doesn't know the truth of the experience of war, they can't make honest decisions on whether they want to be involved or not" $(2011,162)$. This sentiment, that seeing bad things doesn't negate the usefulness of seeing them, rings true for other site founders, like Hayden Hewitt, cofounder of liveleak.com. Describing how the beheading video of American contractor Nick Berg was downloaded fifteen million times, Hewitt states that the availability of material like this is valuable: "you will see things that offend you, but that is not necessarily a bad thing because it is really happening" $(2011,162)$. While access to information is something worth arguing for, a concern might nevertheless exist for what accompanies images and videos of this kind: are captions and commentary necessary to understand the inside scope of war, or can these documents stand alone to deliver all relevant details? This issue seems to go unaddressed by those interviewed by Struk. The focus seems instead to be first on making media available to the public, and second, for that media to be shareable.

Forum sites address an issue for soldiers, namely that media fail to show or discuss the specific experiences of soldiers. For those at war, this is not simply an issue of censorship, but is also about how their war efforts are knowable, accessible, and, ultimately, how their efforts are remembered. Ultimately, these soldiers want civilians to have access to their pictures. Uploaders and visitors to these sites can equally comment, and while descriptions and notes also accompany the "general" photos, they are often banal, reflecting more of the "tourist" type of information (I was here at this time, etc.). As for the "gory" variety, Struk is quick to note the sheer amount of content. Conversations occurred amongst site users of NTFU, about gory photos, about which a Gulf veteran angrily wrote:

War is death, destruction, and it looks that by the few photos I have seen we seem to be doing ok...War is not about respect, war is about surviving and winning... so if it bugs you that a soldier would kill an injured enemy, then you my friend have no concept of what war is...Years later when this war is over, the pics our guys have taken will turn from "trophy's" to memories...mine did. (Struk 2011, 164) 
Not everyone is so thrilled about the availability of the photos. Struk comments that some journalists declared that NTFU had "reduced the horrors of war to a 'spectator sport"” $(2011,165)$. George Zornick of The Nation coined the term "warnography" to describe this phenomenon (2011, 165-66). It is, perhaps, important to note that those who operated these forum sites and the soldiers who used them each saw the necessity of the content, however graphic, because it makes previously unknown situations knowable and sharable. Struk notes that, for the soldiers, access to and circulation of this kind of imagery allows them to reassert the value of their own experiences: "The resentment and defiance these soldiers showed towards the sanitization and censorship of their experiences of war-by governments, the media and the military brass-indicated that posting pictures was a kind of resistance" $(2011,166)$. Finally, soldiers can not only form their own narratives about their experiences, but also with these forums comes the opportunity to share these narratives with those beyond their immediate (micro and meso) social networks. Here, the digital arena affords a macro network opportunity through which to share and build cultural memory.

But not all soldiers agree over what the images have to say; some see nothing wrong with shocking photos, while others are concerned. One soldier responded to a critic of gory photos on NTFU, who claimed that the contents of the images appear to be similar to those of the "insurgent" enemy:

Get down out of your ivory tower moron how dare you equate these grave images of war with those we have seen from the other side on algizeera [sic]. I'm sick and tired of you lefties equating our troops to these terrorists and equating people like Lindy England [sic] who made a bunch of hadjis get down on their hands and knees in their underwear to the same bunch that cut the head off Nick Berg on video. Reality Check Lefty-It Ain't the Same Thing. (Struk 2011, 164)

Another veteran saw the gory images and was concerned:

As a career soldier and Vietnam veteran I have a different perspective on these photos. I have no sympathy for the crazy suicide bombers but pictures like this demean us all and appeal to our lowest instinct. Imagine if we were to see similar photos of our own men and women. I 
used to confiscate anything like this from my troops so they didn't fall into the wrong hands, e.g. the media. Having said that, I would gladly cut out the heart of Osama bin Laden and take a bite out of it. I just wouldn't take a picture of it. (Struk 2011, 164-65)

Even when site participants disagree, they nevertheless are engaging in conversations with likeminded individuals, where the similarity of opinion is not necessarily regarding impressions of the image, but instead is the result of shared use of the site-the site is what unites this group. Interested parties can come together, see photos and share narratives, and be made aware of soldiers' circumstances discussed nowhere else. Even with differing opinions of graphic images depicting enemy humiliation or torture, site participants share the opinion that soldiers work hard and often go unnoticed by civilians. Discussions like those above, over a macro network, offer visitors to these forum sites a variety of opinions, viewpoints, and experiences, which ultimately expand possible narratives and build cultural memories. Expanded notions of cultural memory, while perhaps at times unfortunately including xenophobic perspectives, ultimately offer a more participatory or democratic online media process; multiple and competing perspectives of an event are knowable and sharable, which, at the very least, means that a single perspective cannot reign as singularly true. This is important because war narratives have traditionally emerged from governments or militaries, which tend to have unfettered access to media, particularly in the predigital era. Excluding images of dead soldiers or other graphic content often sanitized these narratives. Rightly sanitized or not, the digital era provides a means through which soldiers themselves can share their own take on events ${ }^{15}$. Of course, there will be times when the content is highly questionable, like with the images from Abu Ghraib.

\footnotetext{
${ }^{15}$ Other groups have participated in a more democratic media, with blogs and other formats, since the internet first arose for public use; soldiers, while not civilians, are nevertheless citizens and it could be argued that they have a right to the same things. Although, perhaps this right is denied when one signs up for duty, as outlined in protocol for soldiers.
} 


\section{The Age of Digital Photography: Networked Circulation Meets Cultural Memory}

As previously outlined in this chapter, digital devices enable personal photography to be less private, to be more accessible, and to be more public (van House 2011). Mette Sandbye and Jonas Larsen describe the emergence of this phenomenon:

Photographs are now very widely produced, consumed and circulated on computers, mobile phones and via the internet, especially through social-networking sites. The digitization of images thus implies media convergence of new performances of sociality reflecting broader shifts towards real-time, collaborative, networked "sociality at a distance." In 2001 the first camera phone was put on the market, but they only really began to sell in high volumes in 2004... At that time, 68 million digital cameras and 246 million camera phones (mobile phones with inbuilt digital cameras) were sold worldwide. (2013, xvi)

Digital cameras thus allow for a greater capacity to capture and disseminate photos than the analog equivalent. As a result, this "sociality at a distance" is made nearer via the digital. Where the digital and the analog converge, however, is in the production of visual record; though digital technologies continue to grant greater access to these photographs, it is the contents of these images that foster cultural memory, and in particular, the concretion of groups. Online sharing of pictorial content, then, is collaborative, open, and participant-based because of networked circulation.

Instantly recallable, and with the number of exposures limited only to the size of the memory card, digital photography makes it easier to render an ideal pose. In Picture Perfect: Life in the Age of the Photo $O p$, Kiku Adatto states: "digital photography that makes pictures so easy to take and share has transformed how we use pictures in our daily lives. We increasingly experience the world as an occasion for posing. Never has the camera been more ubiquitous, the method of transmission so quick, the temptation to take pictures so great" $(2008,36)$. While perhaps this chapter situates an extreme phenomenon, an international scandal featuring the photographing of abuse at the hands of U.S. military members, the most basic functions and uses of photographic practices are nevertheless present. People take pictures of each other (or "selfies" of themselves) posing all the time, and do so in a manner that allows them a moment of personal composition prior 
to photographic capture. The result, as can be seen on many of the faces of the U.S. military personnel in the Abu Ghraib photos, often features subjects looking directly into the camera lens and smiling. Posing and composing, as such, brings awareness of the camera, which reinforces the intentionality of the photographic act as the maker of visual memory objects, which moreover, is intensified and distributed with networked circulation.

To make a moving thing remain still, as a photographic image does, suggests that the single depicted moment is coded as a visual impression, becoming something recallable with each subsequent viewing. As such, photographs are suffused with memory. With regard to temporality, explanations of visual cultural memory can be both backward and forward-looking. For Annette Kuhn, memory work is retrospective, involving an "active practice of remembering which takes an inquiring attitude toward the past" $(2000,186 ; 2008,284)$. van Dijck analyses cultural memory by considering what may be ahead of the moment of capture, claiming that visual cultural memories are created for future reference $(2008,59)$. Thus, photographs simultaneously provide a visible reminder of something that has previously occurred, in addition to rendering images with intentional existence in the future. It seems important to note the validity of both of these aspects: together these two theoretical accounts combine to illustrate the commemorative properties of these visuals. As such, photographs celebrate and build upon a captured moment in a two-dimensional form, with the intention of bringing this past moment into the present. One way in which photographs bring the past into the present is with circulation. With specific reference to digital photography and war, Susan Sontag states that:

The pictures taken by American soldiers in Abu Ghraib reflect a recent shift in the use made of pictures-less objects to be saved than messages to be disseminated, circulated. A digital camera is a common possession among soldiers. Where once photographing war was the province of photojournalists, now the soldiers themselves are all photographers - recording their war, their fun, their observations of what they find picturesque, their atrocities - and swapping images among themselves and emailing them around the globe. (Sontag 2004, 26; emphasis mine) 
Here, circulation combines with the reproduction of memory as key aspects of the photographs from Abu Ghraib. As Assmann has discussed, memory objects gain importance via the symbols comprised therein, which draw upon and resituate shared values of a group. The text, then, is of utmost importance, requiring reproducibility. Mitchell echoes this idea, suggesting that the digital medium aids in the production of shared, visual cultural memory:

The digital camera is a radically different technical apparatus from the analog camera: it is not just lightweight and easily concealed, but linked in unprecedented ways to a vast infrastructure of reproduction and circulation...[it can be] linked up to a computer to offload its images in mere seconds. We have to think of the digital camera, not only as an extension of the eyes and memory of an individual, but as linked very intimately to a global network of collective perception, memory, and imagining via e-mail and postings on the Internet. (2011, 123-24)

In so bringing the past into the present, the contents of the Abu Ghraib photographs are easily shared with a wide audience. No longer are the images a military secret, shared only between enlisted members, friends, and family, via email on a meso network. Once the photos leaked to news media, the scandalous images - and horror regarding them-could not be controlled; the images, or at least descriptions and explanations thereof, emerged on macro and institutional networks, producing and reproducing easily digestible notions of cultural memory.

To recap, the main elements involved in cultural memory are: the concretion of group identity and the creation of memory objects. "Group identity" encompasses all aspects that make a group cohesive, and relies upon sharing the same space, time, and/or material objects. These elements direct the group's behaviour and experience, and though occurring in the present, these ways of being are rooted in historical and mythical narratives. For instance, as outlined in Chapter 2 , the mythical narrative that the Japanese were subhuman, which made easier the removal of flesh to collect skulls during the Second World War. So, too, do the images from Abu Ghraib link up to 
historical and mythical narratives, as well as photographic instantiations, drawing and reflecting specifically upon lynching and hunting photos.

Connected here are also lynching photography postcards. While there is similarity between the content of these trophy photos and those from Abu Ghraib, there is a difference in how the pictorial memory is distributed and referenced. van Dijck describes the Abu Ghraib photographs:

Ironically, pictures that were casually mailed out as ephemeral "postcards," meant to be thrown away after reading the message, became permanently engraved on the consciousness of a generation; pictures sent with a communicative intent ended up in America's collective cultural memory as painful visual evidence of its military's hubris. The awareness that any picture let loose on the internet can be endlessly recycled may lead to a new attitude in taking pictures: anticipating future reuse, photographs are no longer innocent personal keepsakes, but potential liabilities in someone's personal life or professional career. The lesson learned from the Abu Ghraib pictures - beyond their horrendous political message - is that personal digital photography can hardly be confined to private grounds; embedded in networked systems, pictorial memory is forever distributed, perpetually stored in the endless maze of virtual life. $(2008,69-70)$

Pictorial memory is no longer simply "personal" because networked systems give way to inherent and perpetual distribution. Thus, if people know others can see photos, this might suggest that they want them to be seen, or at least they do not mind if the pictures might be seen. Considering the Abu Ghraib images, then, or equally those images uploaded to forum sites, it is worth remembering that these photos were not "dirty little secrets," hidden away like other horrific war photographs. They were instead shared. Originally only via email, the Abu Ghraib photos were nevertheless not a secret, even while passed to a finite contact list - these images were intentionally shared, over a meso network. This kind of sharing inherently calls upon what van Dijck describes above, regarding anticipated future use. If intended to be kept private, utilizing any form of the internetemail included - fails in this endeavour. And as van Dijck suggests, the digital pictorial moment demands to be shared before it expires. As more time passes and more photographs are taken, the older images fail to be as relevant as they once were at inception. Simply put, the digital photo is without value if not shared. With forum sites in particular, the graphic nature of an image couples 
with timely sharing, increasing the photo's currency. To share "fast and first" garners credibility, if not authority, on a given topic in pictorial form, particularly when occurring alongside a poignant and informative narrative. Moreover, to share fast and first means that the image cannot be intercepted, cannot be stolen. If stolen, someone else has the opportunity to attach the accompanying narrative, which might have a completely different intention. Consider the soldiers who use forum sites to upload their own images and narratives because, as they indicate, the news media — or those within the institutional network—are not including stories from their perspectives. Here, sharing fast and first makes one the authority, and any interception of content thereafter cannot be "fast and first"; media within the institutional network might access content via sharing, but the accompanying narratives may seem stolen if the intention appears altered, according to the soldiers' perspectives. This is an issue about coordinating (and controlling, to the degree that this is possible) networked circulation: to share with like-minded people is to increase the value of a photo and accompanying narrative because this garners more and more like-minded interest. Finally, digital sharing always involves a tacit understanding of anticipated future use - over and above the stealing of images, which may instead be used to hide images and silence attached narratives. The act of sharing, in a meso or macro network, inherently assumes future reuse. This is so not only because images here demand to be seen simply due to their ubiquity, first by the intended audience and followed by whomever might come along thereafter, but also because the digital builds within it metadata and other systems of instant recallability, like "tags" according to thematic contents. Known to the sharer or not, to share a digital photo is always to participate in categorizing data systems that inherently anticipate future reuse. Moreover, sharing with a like-minded community garners authority and following, whereby cultural memory is continually reconstituted and recirculated. Access to images and their narratives, then, comes easier and easier with the digital era, and so, too, do the associated narratives. 
Soldiers often feel left out of their own memory making, or at least in the public sharing of it. This chapter has highlighted a problem for soldiers generally in the post 9/11 era: sanitized media representations fail to illustrate what really happens in the lives of soldiers abroad. As a consequence, soldiers capture and share their own portrayals, which at times include questionable if not outright criminal behaviour. However horrific and striking the content, the information relayed in the images is fundamentally important to soldiers. This information conveys certain perspectives on the cultural memories produced about events in which soldiers participate, if not outright shape. Even some soldiers question their own and others' unlawful violence committed against the enemy, but sharing visuals and knowledge thereof nevertheless offers important insights on the hardships of combat life. These insights also transcend era specificity; they existed in war trophy photography of the analog era, though provide unsurpassed visual ubiquity in the digital era. Considered as a whole, the use of this violent imagery is called into question.

Outlined in Chapter 1 with my definition of "commemorative violence," and in Chapter 2 with the section on "transmissive violence," this section wraps up the discussion of the ritualistic relaying of information and meaning with the circulation of a pictorial object featuring violence. Wolf explains that photographs possess visual media-specific forms of power that reproduce difference $(2007,68)$, which are recallable via transmission. Following Girard's logic and tying in reproducible forms of power and difference, I assert that the characteristics contained within photographs may well move beyond them: if photographs can store visual information from the moment of capture, then it becomes possible that the images discussed here not only represent what they depict — enmity and Otherness — but that they can also commemorate these depictions via the medium. The violence is stored and recalled when the photographs are shared amongst people, instilling processes of remembering. Repeated compositional elements are seen in new photographs, 
like gestures depicting some form of enemy-conquering, continual reminders of similar images seen previously. Here, cultural memory emerges. Cultural memory, however shared, is nevertheless rooted at an individual level; when many individual viewers derive similar meanings, cultural memory is formed. In Mediated Memories, van Dijck defines what she calls "personal cultural memory" as "the acts and products of remembering in which individuals engage to make sense of their lives in relation to the lives of others and their surroundings, situating themselves in place and time" $(2007,6)$. A key aspect of memory is that, however personal it might be when it is stored in a material object, this memory is interpelated through human relations at its inception. When memories move between people through material use, the photographic object carries with it symbolic references that are ascertainable by subsequent viewers, regardless of these symbolic references being a part of the original etching. For instance, this is why many scholars see the history of lynching photography in the Abu Ghraib images, even though what occurred in Iraq is separate from lynching in the American South, or elsewhere.

Revisiting George's notions, coupled with my own, I propose that the photos analysed here are used to solidify group membership of the featured military personnel, as well as to illustrate their power. In broad terms, membership as such is premised on ideological identification with the military's agenda, which includes a tacit, if not overt, belief that "we" are better than "them." With such identification, it becomes possible to imagine that the photographed events took place for the purpose of producing artefacts of visual commemorative violence, ultimately highlighting either the appropriation of an enemy or of something belonging to them; a valuable artefact, one that makes this dynamic visible in a shareable object, these photos affirm previously held beliefs and solidify group boundaries. Yet, to be clear, with specific regard to the Abu Ghraib photographs, the camera is not at fault; the presence of the camera alone did not bring these photographs into existence. To be sure, it is not that the depicted events would have failed to occur, but rather that the purposeful 
staging of the photographs is called into question. Consider the manner in which the American military personnel at Abu Ghraib make obvious reference to the camera, by way of eye contact with the lens, invoking an imaginary yet assumed viewer of the photographs. With actions like these, it is safe to assume that the emotions written on their faces, which echo the bodily gestures of pride and success, were deliberate. As with other types of photography, moments like these solidify the medium as a visual storage apparatus.

Perhaps, however, too much credit is given to digital photographic technology. It is important to remember that photographs do more than act as mnemonic devices. Photographs conjure the past in the present, in addition to carrying symbolic meaning that is understandable through shared emotional and gestural communicative practices, as outlined in Chapter 3. Images visually represent something valuable, something that is worth remembering. To restate, the gestures of pride and accomplishment contrast starkly with the posed naked and limp detainee bodies, and, I argue, this combination ultimately assigns value to the photographs - for the group who took them, and for the group who later saw them via email. Cultural information is stored within those digital images and is subsequently circulated when shared amongst people, beyond the captured meta data. While the meta data contains identifiable visual markers, the data itself cannot interpret cultural symbols. In short, the data cannot say how to feel, or what to think, when looking at the photographs. On one hand, the photographs mean things to people; on the other hand, the data is a mark of computerized processes. Viewers of the photographs are meant to understand the images according to common photographic practices, not to see the digitized numeric codes that make up the contents of the digital frames.

The ease with which digital photographs can be produced couples with their contents and accompanying narratives. The capabilities of digital photography, not just the photographs themselves, are used to commemorate the acts captured therein. These images do not stand alone as 
representations without comment beyond the borders of their frames. While the tales they tell describe the moments depicted, as they are created by technologies that visually store cultural memory, these images also link to photographs that have come before, as well as to those that have yet to be made. Although different technological types allow for varying practices and processes, the cultural uses of photography and photographs are nevertheless similar: photos are meant to capture moments that, for one reason or another, are worth remembering. Ultimately, the worth of these memories are different for different groups. 


\section{CONCLUSIONS}

Reflecting on “A Few Bad Apples” and Looking Forward: Are Drone War Photographs OBJECTS OF COMMEMORATIVE VIOLENCE?

The U.S. drone bombing of Aleppo, Syria on March 16, 2017, appears impressionistic in image form: it takes a moment to decipher what the shades of grey indicate. An aerial view, of square buildings of various sizes and a scattering of cars, appears overall an innocuous image at first glance. With further consideration, the centre of the frame reveals that a bomb blast has just occurred, the marker of an artillery sight caught in the low centre left of the image. Three areas are redacted within the frame, appearing as blurred squares and rectangles. While no people can be seen from this view, the buildings and cars nevertheless indicate that human life is not too far away. From the accompanying Al Jazeera news report, "Deadly U.S. Air Strike in Syria Hit Peaceful Mosque," we learn that the al-Qaeda mark was a miss, killing thirty-eight people, while dozens more were injured (Collins 2017). Humanity is invisible within this frame: perhaps more accurate, at the point at which this photo was snapped, humans had recently been alive. But this picture does not show this. People are not the focus of this picture; there are no smiles, no gestures, and no eye contact with the camera lens. In effect, this is an expressionless photograph.

For me, questions emerge when looking at this image: do these images depict commemorative violence? Where, if at all, does one find triumph in a frame that does not show people? I would suggest that photos of drone strikes are nevertheless photos of people; these images are simply not zoomed in enough to notice. Further contemplation is needed. The idea of humanity, and fair fighting, needs to be questioned when the enemy is altogether absent from the image. This absence further Others the already Othered enemy because of denied physical identification in the combat strike. After everything written so far, this image speaks to where this project is headed. 
Drone warfare images highlight an issue: photos are still the problem, just as with the Abu Ghraib photographs.

Getting into trouble at Abu Ghraib was pretty easy for "a few bad apples." A group of U.S. military made Iraqi detainees their own personal entertainment, and with the influx of the personal digital camera, they pictorially captured their antics; the simple sign that appeared in the prison, "No Photography," was ignored. Many seem to agree-including those directly involved in the abuse and torture - that the taking of photos was the stupid part, tacitly suggesting that the behaviour was not altogether troublesome. This behaviour is what brings value to the images: the soldiers smiling and gesturing with pride makes these images important, commemorative objects.

Altogether the arguments here have culminated in a theory of commemorative violence, a group-based, ritualistic reproduction of celebratory imagery. Commemorative violence is described as the combination of three key elements: technological and cultural production of the visual record, emotive and gestural displays of dominance and submission, and, the circulation of cultural memory. At the centre of my analyses has been the question: what does the taking of pictures provide? I have explained the equally complicated and simplistic reasons in each of the chapters. To briefly resituate, the concept of "war trophy photography" was defined in Chapter 1, highlighting the value of images of combat for the soldiers who take them. Over time, this concept has gained importance since it is now illegal to collect enemy artefacts from the battlefield; the digital camera provides opportunity like never before because of the relatively innocuous (though not in the specific case of Abu Ghraib) nature of taking a snapshot. Each chapter discusses aspects in which the photographs' value is found in circulation with a like-minded community, from behind, in, and with the frame. As stated in Chapter 2, the photographs at Abu Ghraib are neither exceptional nor singular, but are instead a part of war trophy photography more generally, defined as photographs featuring the subdued enemy Other. This visual representation is specifically highlighted in Chapter 
3, where gestures and emotions are described as visual communication tactics concerned with meaning generation, and this chapter specifically focuses on smiles, eye contact, thumbs-up, and index finger pointing. Chapter 4 transitions from the contents of the image to its movement, thereby reinforcing the ideas presented therein with cultural memory, which is increasingly relevant in the digital era. The soldier can remember and share images from time in combat, thus validating individual experience at the societal level. Challenges to the valuation of individual soldier experience only come with the publication of nefarious photography, which brings to light the very problem at Abu Ghraib: the existence of the photos. Linking the images from Abu Ghraib to those of drone warfare, photos are still the problem. This problem, however, alters slightly when people are no longer the focus.

This project has had me consider who is implicated in the photos, suggesting that people are the focal point. Lynndie England, for instance, certainly is guilty of a few things, but so are "we," or civilians, as "we" make ourselves in her image, in Doing a Lynndie memes. Here, we play the role of incompetent yet hilarious soldier. We see ourselves in Lynndie so much that we figuratively place ourselves in her position. But this is not the case with aerial drone strike images. We cannot see anyone, let alone ourselves, in these photos; all we can see are rooftops of buildings and cars. But were we to zoom in, the image could tell a different story. In a story like this, we could see the faces of people, and we could confirm their existence as living and breathing humans. At least, of course, until the bombs are dropped and the enemy is killed. However, this is not the story that drone warfare photos tell; we do not see the ramifications of the explosion. These photos instead show an eerie setting, where death looms hidden underneath rooftops.

These images are undeniably violent. Certainly violence is visible within the frames, but commemoration is missing. To commemorate is to celebrate, to acknowledge that something important has occurred. While drone strike photos are important, and perhaps some even celebrate 
what is featured, these images do not show people; if anyone can be seen, their figure is so small that no expression is visible. Commemoration necessarily places people at the heart of the ritual, which is where these photos disconnect from any possibility of possessing properties of commemorative violence. Since people are not the focus of these images, of either warring party, these images cannot be commemorative. We cannot see any expression, any smiles or thumbs up from the bomb droppers, any looks of horror on the faces of those about to perish. The enemy is not even subdued; the enemy is unaware. Moreover, commemoration aims to acknowledge experience and effort, and with photos like these, no acknowledgments of any kind are made.

Drone images' disembodied perspectives betray that something is "off," although their use is increasingly normalized. Historically, combat literally occurs with the hands of different parties. In this way, people are forced to acknowledge the existence of the enemy Other. But with drone warfare comes the complete removal of human-to-human contact—one side fights from machines in the air, while the other party is unaware of an impending attack. We do not see people in images depicting this fight, thereby creating distance from visual human pain and suffering. In this way, war is fought without having to consider the hidden Other. As a result, these photos illustrate detachment from unseeable pain and suffering - no blood is drawn in these images. Failing to see the result makes war easier to fight because we do not have to consider our own discomfort, in seeing the pain and suffering of Others. I would argue that failing to see this strife is exactly the problem: drone war photography eliminates the possibility of empathy. Finally, to feel empathetic in looking at these images is to consider an abstraction, and yet to know that people are no less present, even if they cannot be seen.

I am arguing for seeing this abstraction, that people are nevertheless present in images of drone warfare. I am suggesting that we remember the history of war trophy photography presented here. I worry that failing to see these connections will drastically alter not only how warfare is 
conducted (this has already happened), but also how warfare is remembered. To remember war only in drone images is to think that people do not exist, that war is remembered only as images of things blown up. People wage war, not aircrafts and buttons. People, not machines, suffer from war. I argue that wars are generally all problematic, but the visual removal of people and suffering ups the ante, or, oddly, is a digression. For so long, activists and academics have fought to establish similarity to, and humanity of, the Other. Thinking back to the practice of taking skulls of Japanese soldiers as war trophies, we are reminded of the consequence of seeing the Other as different or inhuman. I worry that drone war photos repeat just this: these images offer war trophies removed from the humanity they nevertheless depict. Clicking buttons from the air, or from a comfortable chair in a war room continents away, reinvests the Other with inhuman qualities with the problematic ease of button clicking. To fail to acknowledge the grave consequence of that buttonclick is to remove the human qualities of the Other: now, button clicking kills dozens of people the same way dinner is ordered, or a photograph is captured. Ironically, at least with traditional war trophy images, the visual suffering of the Other is the reward. To be happy in seeing this, while horrific, is to acknowledge that the point of the trophy is to capture the suffering Other. Drone war photos not only remove the humanity of the Other, but also the humanity of those who inflict the suffering. At least with war trophy photography generally up to this point, and with Abu Ghraib specifically, we can see the notion that "we are better than them." As awful as these images are, we can nevertheless see why these images matter to the people directly involved: they place themselves centre frame, and smile at the capture and suppression of the enemy Other. In this way, and simply put, people are the point. Drone war photos altogether remove people to such a degree that dozens and dozens can be killed in a single shot, which we never see. We cannot confirm, only deny, the humanity featured therein. If the Other doesn't matter, maybe it doesn't matter if we cannot see them, making it easier to believe that they don't even exist. At least with traditional war trophy 
photography, we care enough to see the enemy suffer, because their pain is important. The pain of the Other, juxtaposed with another soldier's triumph, makes the photo valuable as a commemorative object. With drone war photography, however, we care so little for the Other that we imagine that they do not exist; we refuse to even see them. With drone war photography, people are no longer the focus; people are obfuscated even when bombs are dropped on them. These images become something else, other than war trophy photographs depicting commemorative violence, when people are no longer the focus. Though moving through the history presented here, this "something else" has yet to be fully explored. 


\section{BIBLIOGRAPHY}

Adatto, Kiku. 2008. Picture Perfect: Life in the Age of the Photo Op. Princeton, NJ: Princeton University Press.

"Afghanistan War Pictures \& Photos | Afghanistan War Pics by Veterans." 2017. Accessed February 17, 2017. https:/www.vetfriends.com/MilitaryPics/index.cfm?wars=Afghanistan.

Ahmed, Sara. 2000. Strange Encounters: Embodied Others in Post-Coloniality. New York: Routledge.

- 2004. The Cultural Politics of Emotion. New York: Routledge.

Akinsha, Konstantin. 2010. "Why Can’t Private Art 'Trophies' Go Home from the War?" International Journal of Cultural Property 17 (2): 257-90.

Allen, James. 2000. Without Sanctuary: Lynching Photography in America. Santa Fe, NM: Twin Palms Publishers.

American Civil Liberties Union. 2009. “The Truth About Torture.” Accessed April 9, 2016. https://www.aclu.org/sites/default/files/images/torture/asset_upload_file501_33165.pdf.

Andén-Papadopoulos, Kari. 2008. "The Abu Ghraib Torture Photographs News Frames, Visual Culture, and the Power of Images." Journalism 9 (1): 5-30.

- 2009. "Body Horror on the Internet: US Soldiers Recording the War in Iraq and Afghanistan." Media, Culture \& Society 31 (6): 921-38.

Apel, Dora. 2005. "Torture Culture: Lynching Photographs and the Images of Abu Ghraib." Art Journal 64 (2): 88.

Apter, Michael J., and Mitzi Desselles. 2012. "Disclosure Humor and Distortion Humor: A Reversal Theory Analysis." Humor 25 (4): 417-35.

Arendt, Hannah. 1963. Eichmann in Jerusalem: A Report on the Banality of Evil. New York: Viking Press.

Assmann, Aleida. 2012. “To Remember or to Forget: Which Way Out of a Shared History of Violence?" In Memory and Political Change, edited by Aleida Assmann and Linda Shortt, 53-71. London: Palgrave Macmillan.

Assmann, Jan. 1995. "Collective Memory and Cultural Identity.” New German Critique, 65: 12533.

- 2008. “Communicative and Cultural Memory." In Cultural Memory Studies, edited by Astrid Erll and Ansgar Nünning, 109-18. New York: De Gruyter. 
"The Avalon Prject - Laws of War: Laws and Customs of War on Land (Hague IV); October 18, 1907. Section I, Chapter 2, Article 4.” 2016. Text. Accessed October 4, 2016.

http://avalon.law.yale.edu/20th_century/hague04.asp\#art4.

"The Avalon Prject - Laws of War: Laws and Customs of War on Land (Hague IV); October 18, 1907. Section II, Chapter 1, Article 23.” 2016. Text. Accessed October 4, 2016. http://avalon.law.yale.edu/20th_century/hague04.asp\#art23.

"The Avalon Prject - Laws of War: Laws and Customs of War on Land (Hague IV); October 18, 1907. Section III, Article 46.” 2016. Text. Accessed October 4, 2016. http://avalon.law.yale.edu/20th_century/hague04.asp\#art46.

"The Avalon Prject - Laws of War: Laws and Customs of War on Land (Hague IV); October 18, 1907. Section III, Article 47.” 2016. Text. Accessed October 4, 2016. http://avalon.law.yale.edu/20th_century/hague04.asp\#art47.

"Bad Gas: Doing A Lynndie." 2010. Accessed April 28, 2016. http://web.archive.org/web/ 20100428050715/http://www.badgas.co.uk/lynndie.

Barthes, Roland. 2010. Camera Lucida: Reflections on Photography. Translated by Richard Howard. New York: Hill and Wang.

Bartholeyns, Gil. 2014. "The Instant Past: Nostalgia and Digital Retro Photography." In Katharina Niemeyer (ed), Media and Nostalgia: Yearning for the Past, Present, and Future. New York: Palgrave-Macmillan, pp. 51-69.

Belknap, Michal R. 2002. The Vietnam War on Trial: The My Lai Massacre and the Court-Martial of Lieutenant Calley. Lawrence, KS: University of Kansas.

Benjamin, Walter. 1968. Illuminations. New York: Schocken Books. 1972. “A Short History of Photography." Screen 13 (1): 5-26.

Berlant, Lauren. 2008. The Female Complaint: The Unfinished Business of Sentimentality in American Culture. Durham, NC: Duke University Press Books.

Berry, Mary Frances. 2008. “'Reckless Eyeballing”: The Matt Ingram Case and the Denial of African American Sexual Freedom.” Journal of African American History 93 (2): 223-34.

Boltanski, Luc. 1999. Distant Suffering: Morality, Media and Politics. Translated by Graham D. Burchell. New York: Cambridge University Press.

Bolter, Jay David, and Richard Grusin. 2000. Remediation: Understanding New Media. Cambridge, MA: The MIT Press.

Bresheeth, Haim. 2006. "Projecting Trauma." Third Text 20 (1): 57-71. 
Brower, Matthew. 2005. "Trophy Shots: Early North American Photographs of Nonhuman Animals and the Display of Masculine Prowess." Society and Animals 13 (1): 13-32.

Brown, Wendy. 2006. "Subjects of Tolerance: Why We Are Civilized and They Are the Barbarians." In Regulating Aversion: Tolerance in the Age of Identity and Empire, 149-75. Princeton, NJ: Princeton University Press.

Bush, George W. 2003. "President Discusses Beginning of Operation Iraqi Freedom.” Radio address. Office of the Press Secretary. https://georgewbush-whitehouse.archives.gov/ news/releases/2003/03/20030322.html.

Butler, Judith. 2005. "Photography, War, Outrage." PMLA: Publications of the Modern Language Association of America 120 (3): 822-27.

. 2009. Frames of War: When Is Life Grievable? New York: Verso.

Carrabine, Eamonn. 2011. "Images of Torture: Culture, Politics and Power." Crime, Media, Culture 7 (1): 5-30.

Cashin, Joan E. 2011. "Trophies of War: Material Culture in the Civil War Era." The Journal of the Civil War Era 1 (3): 339-67.

Cloud, Dana L. 2004. “"To Veil the Threat of Terror': Afghan Women and The 'Clash of Civilizations' in the Imagery of the US War on Terrorism." Quarterly Journal of Speech 90 (3): 285-306.

Collins, Dylan. 2017. "Deadly US Air Strike in Syria Hit Peaceful Mosque." Al Jazeera English, April 18. http://www.aljazeera.com/news/2017/04/air-strike-syria-hit-peaceful-mosque170418073446175.html.

Collins, Patricia Hill. 1993. "Toward a New Vision: Race, Class \& Gender as Categories of Analysis and Connection." Race, Sex \& Class 1 (1): 25-45.

Connerton, Paul. 1989. How Societies Remember. New York: Cambridge University Press.

Crary, Jonathan. 1990. Techniques of the Observer: On Vision and Modernity in the Nineteenth Century. Cambridge, MA: MIT Press.

Cruz, Ana Luisa. 2012. "Words Leaking from Objects: Thinking with Absent Photographs." Journal of Comparative Research in Anthropology and Sociology, Bucharest 3 (1): 101-16.

Deb, Basuli. 2012. "Transnational Feminism and Women Who Torture: Reimag(in)ing Abu Ghraib Prison Photography." Postcolonial Text 7 (1): 1-17.

Debord, Guy. 1994. The Society of the Spectacle. New York: Zone Books. 
Department of the Army. 2002. "US Military Police Leaders' Handbook.” Accessed April 4, 2016. http://usacac.army.mil/sites/default/files/misc/doctrine/CDG/cdg_resources/manuals/fm/fm3 - 19x4.pdf.

Dijck, José van. 2007. Mediated Memories in the Digital Age. Stanford, CA: Stanford University Press.

. 2008. "Digital Photography: Communication, Identity, Memory." Visual Communication 7 (1): $57-76$.

Dunaway, Finis. 2000. "Hunting with the Camera: Nature Photography, Manliness, and Modern Memory, 1890-1930.” Journal of American Studies 34 (2): 207-30.

Durkheim, Emile. 1995. The Elementary Forms of Religious Life. Trans. Karen E. Fields. New York: The Free Press.

Dyer, Richard. 1988. “White.” Screen 29 (4): 44-65.

Editorial. 2014. “Abu Ghraib, 10 Years Later.” The New York Times, Accessed April 22, 2016. http://www.nytimes.com/2014/04/23/opinion/abu-ghraib-10-years-later.html.

Ehrenreich, Barbara. 2004. "What Abu Ghraib Taught Me." Alternet, May 19. http://www.alternet.org/story/18740/what_abu_ghraib_taught_me

Ehrenreich, Nancy. 2005. "Disguising Empire: Racialized Masculinity and the Civilizing of Iraq." Cleveland State Law Review 52: 131-38.

Eisenman, Stephen. 2007. The Abu Ghraib Effect. London: Reaktion Books.

Engle, Karen. 2009. Seeing Ghosts: 9/11 and the Visual Imagination. Montreal: McGill-Queen's University Press.

FDCH eMedia. 2004. "Rumsfeld Testifies Before Senate Armed Services Committee." Washington Post. 07. Accessed April 4, 2016 http://www.washingtonpost.com/wp-dyn/articles/A85752004May7.html.

Fischer, Sebastian. 2013. “Ten Lessons America Learned from the 2003 Iraq War." Spiegel Online, Accessed March 20, 2016. http://www.spiegel.de/international/world/ten-lessons-americalearned-from-the-2003-iraq-war-a-890066.html.

Garry, Maryanne, and Matthew P. Gerrie. 2005. "When Photographs Create False Memories." Current Directions in Psychological Science 14 (6): 321-25.

George, Kenneth M. 1996. Showing Signs of Violence: The Cultural Politics of a TwentiethCentury Headhunting Ritual. Berekeley, CA: University of California Press. 
Girard, René and Kennedy, Paul. 2016. "The Scapegoat: The Ideas of René Girard”. Ideas. Episode 1 and 2. Accessed March 3, 2016. http://www.cbc.ca/radio/ideas/the-scapegoat-the-ideas-ofren\%C3\%A9-girard-part-1-1.3474195.

Girard, René. 1979. Violence and the Sacred. Baltimore, MD: Johns Hopkins University Press.

Gitelman, Lisa. 2006. Always Already New: Media, History and the Data of Culture. Cambridge, MA: MIT Press.

Goldie, Terry. 1993. Fear and Temptation: The Image of the Indigene in Canadian, Australian, and New Zealand Literatures. Montreal, QC: McGill-Queen's Press.

Goodman, Amy, and Seymour M. Hersh. 2004. Seymour Hersh: U.S. Knew of Rampant Abuse in Iraqi Prisons Months Ago. Democrocy Now! Accessed April 4, 2016. https://www.democracynow.org/2004/5/3/seymour_hersh_u_s_knew_of

Greiner, Bernd. 2009. War Without Fronts: the USA in Vietnam. New Haven, CT: Yale University Press.

Gunning, Tom. 2015. "Is Digital Cinema Out of Touch?: Elusive Touch, Evasive Grasp, Open Gesture." Lecture presented at the Ioan Davies Memorial Lecture, October 4, 2015. Toronto: York University.

Habermas, Juergen. 1985. The Theory of Communicative Action: Volume 1: Reason and the Rationalization of Society. Translated by Thomas McCarthy. Boston: Beacon Press.

Halbwachs, Maurice. 1992. On Collective Memory. Chicago: University Of Chicago Press.

Halloran, Liz. 2009. "Torture Memos Reveal Legal Double Standard.” NPR.org, Accessed April 28, 2016. http://www.npr.org/templates/story/story.php?storyId=103570033.

Hamm, Mark S. 2007. “'High Crimes and Misdemeanors': George W. Bush and the Sins of Abu Ghraib." Crime, Media, Culture 3 (3): 259-84.

Haraway, Donna J. 1989. Primate Visions: Gender, Race, and Nature in the World of Modern Science. New York: Routledge.

Harrison, Barabara. 2002. "Photographic Visions and Narrative Inquiry." Narrative Inquiry 12 (1): $87-111$.

Harrison, Simon. 2006. "Skull Trophies of the Pacific War: Transgressive Objects of Remembrance." The Journal of the Royal Anthropological Institute 12 (4): 817-36.

Heinrich, Horst-Alfred, and Verena Weyland. 2016. "Communicative and Cultural Memory as a Micro-Meso-Macro Relation.” International Journal of Media \& Cultural Politics 12 (1): $27-41$. 
Herman, Daniel Justin. 2003. "The Hunter's Aim: The Cultural Politics of American Sport Hunters, 1880-1910(1)." Journal of Leisure Research 35 (4): 455.

Hersh, Seymour M. 2004. “Torture at Abu Ghraib.” The New Yorker, Accessed May 10, 2016. http://www.newyorker.com/archive/2004/05/10/040510fa_fact?currentPage=all.

Hill, Scott. 2012. "When Will the Endless Military Defenders Confess to Their Stupidity?" The Huffington Post, Accessed January 13, 2016. http://www.huffingtonpost.co.uk/scotthill/military-defenders_b_1201893.html.

Hodge, Robert, Robert Ian Vere Hodge, and Gunther R. Kress. 1988. Social Semiotics. Cornell University Press.

Holland, Shannon L. 2009. "The Enigmatic Lynndie England: Gendered Explanations for the Crisis at Abu Ghraib." Communication and Critical/Cultural Studies 6 (3): 246-64.

Hoskins, A. 2009. "Digital Network Memory." In Mediation, Remediation, and the Dynamics of Cultural Memory, edited by Astrid Erll and Ann Rigney, 91-106. New York: De Gruyter.

House, Nancy A. Van. 2011. "Personal Photography, Digital Technologies and the Uses of the Visual." Visual Studies 26 (2): 125-34.

Hristova, Stefka. 2013. “'Doing a Lynndie’: Iconography of a Gesture.” Visual Anthropology 26 (5): 430-43.

Hylton, Wil S. 2006. "Prisoner of Conscience." GQ. Accessed August 1, 2016. http://www.gq.com/news-politics/newsmakers/200608/joe-darby-abu-ghraib.

Jan Mohamed, Abdul R. 1985. "The Economy of Manichean Allegory: The Function of Racial Difference in Colonialist Literature." Critical Inquiry 12 (1): 59.

Jay, Martin. Downcast Eyes: The Denigration of Vision in Twentieth-Century Thought. Berkeley: University of California Press, 1993.

Joinson, Adam N. 2008. "Looking At, Looking Up or Keeping Up with People?: Motives and Use of Facebook." In Proceedings of the SIGCHI Conference on Human Factors in Computing Systems, 1027-36. CHI '08. New York: Association for Computing Machinery.

Jones, David. 2009. "Why the Hell Should I Feel Sorry, Says Girl Soldier Who Abused Iraqi Prisoners at Abu Ghraib Prison." The Daily Mail, Accessed June 13, 2016. http://www.dailymail.co.uk/news/article-1192701/Why-hell-I-feel-sorry-says-girl-soldierabused-Iraqi-prisoners-Abu-Ghraib-prison.html.

Kalof, Linda, and Amy Fitzgerald. 2003. "Reading the Trophy: Exploring the Display of Dead Animals in Hunting Magazines.” Visual Studies 18 (2): 112-22.

Kendon, Adam. 2004. Gesture: Visible Action as Utterance. New York: Cambridge University Press. 
Kennedy, Liam. 2009. "Soldier Photography: Visualising the War in Iraq." Review of International Studies 35 (4): 817-33.

Kennedy, Rory. 2007. Ghosts of Abu Ghraib. HBO. https://www.youtube.com/watch?v=KC2fVXuR6o.

Kindberg, Tim, Mirjana Spasojevic, Rowanne Fleck, and Abigail Sellen. 2005. "I Saw This and Thought of You: Some Social Uses of Camera Phones." In CHI '05 Extended Abstracts on Human Factors in Computing Systems, 1545-48. CHI EA '05. New York: Association for Computing Machinery.

Kittler, Friedrich, Dorothea von Mücke, and Philippe L. Similon. 1987. "Gramophone, Film, Typewriter." October 41: 101-18.

Kozol, Wendy. 2012. "Battlefield Souvenirs and the Affective Politics of Recoil." Photography and Culture 5 (1): 21-36.

Kuhn, Annette. 2000. “A Journey Through Memory.” In Memory and Methodology, edited by Susannah Radstone, 179-96. New York: Berg.

Lambert, Alan J., Laura Nesse Scherer, Chad Rogers, and Larry Jacoby. 2009. "How Does Collective Memory Create a Sense of the Collective?" In Memory in Mind and Culture, 194-217. New York: Cambridge University Press.

Lampe, Cliff, Nicole B. Ellison, and Charles Steinfield. 2008. "Changes in Use and Perception of Facebook." In Proceedings of the 2008 ACM Conference on Computer Supported Cooperative Work, 721-30. CSCW '08. New York: Association for Computing Machinery.

Leeuwen, Theo van. 2004. Introducing Social Semiotics: An Introductory Textbook. 1 edition. London; New York: Routledge.

Leung, Rebecca. 2004. “Abuse At Abu Ghraib.” Accessed May 5, 2016. http://www.cbsnews.com/news/abuse-at-abu-ghraib/.

Levin, David Michael. 1997. ed. Sites of Vision: The Discursive Construction of Sight in the History of Philosophy. Cambridge, MA: MIT Press.

Lifton, Robert Jay. 2004. "Conditions of Atrocity.” The Nation. Accessed May 5, 2016. https://www.thenation.com/article/conditions-atrocity/.

Limon, John. 2007. “"The Shame of Abu Ghraib.” Critical Inquiry 33 (3): 543-72.

Lincoln, Bruce. 2007. Religion, Empire, and Torture: The Case of Achaemenian Persia, with a Postscipt on Abu Ghraib. Chicago: University Of Chicago Press. 
Lister, Martin (ed.) 1995. The Photographic Image in Digital Culture. New York: Routledge.

"LiveLeak.com - Redefining the Media." 2017. Accessed February 17, 2017. https://www.liveleak.com/.

“Lynndie England Pose | Know Your Meme.” 2008. Accessed May 5, 2016. http://knowyourmeme.com/memes/lynndie-england-pose.

Marvin, Garry. 2005. "Guest Editor’s Introduction: Seeing, Looking, Watching, Observing Nonhuman Animals (PDF Download Available).” Society and Animals 13 (1): 1-12.

Mayer, Jane. 2005. “A Deadly Interrogation: Can the CIA Legally Kill a Prisoner?” The New Yorker, Accessed November 14, 2016.

Mbembé, J.-A. 2001. On the Postcolony. Berkeley, CA: University of California Press.

McClintock, Anne. 2009. "Paranoid Empire: Specters from Guantánamo and Abu Ghraib." Small Axe 28 (March): 50-74, 232.

McGraw, A. Peter, Caleb Warren, Lawrence E. Williams, and Bridget Leonard. 2012. "Too Close for Comfort, or Too Far to Care? Finding Humor in Distant Tragedies and Close Mishaps." Psychological Science 23 (10): 1215-23.

Mechling, Jay. 2004. "Picturing Hunting." Western Folklore 63 (1/2): 51-78.

Mirzoeff, Nicholas. 2011. The Right to Look. Durham, NC.: Duke University Press.

Misztal, B. A. 2010. "Collective Memory in a Global Age: Learning How and What to Remember." Current Sociology 58 (1): 24-44.

Mitchell, W. J. T. 2002. "Showing Seeing: A Critique of Visual Culture." Journal of Visual Culture 1 (2): $165-81$.

- 2011. Cloning Terror: The War of Images, 9/11 to the Present. Chicago: University of Chicago Press.

Moeller, Susan. 1999. Compassion Fatigue: How the Media Sell Disease, Famine, War and Death. New York: Routledge.

“More Evidence US Ignored Abuse Warnings." 2004. Al Jazeera English. Accessed April 9, 2016. http://www.aljazeera.com/archive/2004/05/2008410142541312728.html.

Moriarty, Sandra E. 1996. "Abduction: A Theory of Visual Interpretation." Communication Theory 6 (2): $167-87$.

- 2002. "The Symbiotics of Semiotics and Visual Communication." Journal of Visual Literacy 22 (1): 19-28. 
Morris, Desmond, Peter Collett, Peter Marsh, and Marie O'Shaugnssey. 1979. Gestures, Their Origins and Distribution. London: Jonathan Cape.

Morris, Errol. 2008. Standard Operating Procedure. Sony Pictures Home Entertainment.

- 2011. Believing Is Seeing: Observations on the Mysteries of Photography. New York: Penguin Press.

Nesbit, William. 1926. How to Hunt with the Camera;: A Complete Guide to All Forms of Outdoor Photography,. New York: E.P. Dutton.

Olick, Jeffrey K. 2007. The Politics of Regret: On Collective Memory and Historical Responsibility. New York: Routledge.

Peirce, Charles Sanders. 1932. "The Elements of Logic," in The Collected Papers of Charles Sanders Peirce. Vol. 2. Charles Hartshorne and Paul Weiss, eds. Cambridge, MA: Harvard University Press.

Perera, Sylvia Brinton. 1986. The Scapegoat Complex: Toward a Mythology of Shadow and Guilt. Toronto: Inner City Books.

Philipose, Liz. 2007. "The Politics of Pain and the End of Empire.” International Feminist Journal of Politics 9 (1): 60-81.

Puar, Jasbir K. 2004. “Abu Ghraib: Arguing against Exceptionalism.” Feminist Studies 30 (2): 52234.

- 2007. Homoterrorisms. Durham, NC: Duke University Press.

Radley , Alan. 2010. “What People Do With Pictures.” Visual Studies 25 (3): 268-279.

Rancière, Jacques. 2009. The Emancipated Spectator. London: Verso.

Rather, Dan, and Rebecca Leung. 2004. "Abuse At Abu Ghraib.” CBS News. Accessed April 9, 2016. http://www.cbsnews.com/news/abuse-at-abu-ghraib/.

Razack, Sherene. 2008. "If It Wasn't For The Sex And The Photos: The Torture of Prisoners at Abu Ghraib." In Casting out: The Eviction of Muslims from Western Law and Politics, 59-80. Toronto: University of Toronto Press.

Red Cross, International Committee. 2005. "Evolution of Policy and Law Concerning the Role of Civilians and Civilian Contractors Accompanying the Armed Forces." Accessed April 5, 2016. https://www.icrc.org/eng/assets/files/other/2005-07-expert-paper-icrc.pdf.

Roediger, H. L., Franklin M. Zaromb, and Andrew Butler. 2009. "The Role of Repeated Retrieval in Shaping Collective Memory." In Memory in Mind and Culture, edited by Pascal Boyer and James Wertsch, 138-70. New York: Cambridge University Press. 
Rose, Gillian. 2010. Doing Family Photography: The Domestic, the Public and the Politics of Sentiment. Re-Materialising Cultural Geography. New York: Ashgate.

Rothkopf, David. 2014. “Obama's 'Don't Do Stupid Shit' Foreign Policy | Foreign Policy.” Foreign Policy, Accessed June 4, 2016. http://foreignpolicy.com/2014/06/04/obamas-dontdo-stupid-shit-foreign-policy/.

Ryan, J.R. 2000. "Hunting with the Camera: Photography, Wildlife and Colonialism in Africa." In Animal Spaces, Beastly Places, edited by Chris Philo and Chris Wilbert. New York: Routledge.

Sandbye, Mette, and Jonas Larsen. 2013. "Introduction: The New Face of Snapshot Photography." In Digital Snaps: The New Face of Photography, edited by Mette Sandbye and Jonas Larsen. New York: I.B.Tauris.

Sarvas, Risto, and David Frohlich. 2011. From Snapshots to Social Media - The Changing Picture of Domestic Photography. New York: Springer-Verlag.

Schiano, Diane, Coreena Chen, and Ellen Isaacs. 2002. "How Teens Take, View, Share, and Store Photos." In Proceedings of the Conference on Computer-Supported Co-Operative Work $(\mathrm{CSCW})$. New York: Association for Computing Machinery.

Schudson, Michael. 1993. Watergate In American Memory: How We Remember, Forget, And Reconstruct The Past. New York: Basic Books.

Sebeok, Thomas, and Jean Umiker-Sebeok. 1983. "You Know My Method." In The Sign of Three, edited by Umberto Eco and Thomas Sebeok. Bloomington, IN: Indiana University Press.

Shiras, George. 1906. "Photographing Wild Game With Flashlight and Camera." National Geographic 17 (7): 366-423.

Smith, Shawn Michelle. 2004. Photography on the Color Line: W. E. B. Du Bois, Race, and Visual Culture: Shawn Michelle. Durham, NC: Duke University Press.

Sontag, Susan. 2001. On Photography. New York: Farrar, Straus and Giroux.

—. 2003. Regarding the Pain of Others. New York: Farrar, Straus and Giroux.

—. 2004. "Regarding The Torture Of Others." New York Times Magazine. Accessed April 9, 2016. http://www.nytimes.com/2004/05/23/magazine/regarding-the-torture-ofothers.html?_r=1.

—. 2009. "Notes on Camp." In Against Interpretation and Other Essays, 275-92. Penguin Books. Accessed April 9, 2016. http://core.roehampton.ac.uk/repository2/content2/subs/ d.steedman/d.steedman1608/Sontag\%20(2009)\%20Notes\%20on\%20Camp.pdf.

Struk, Janina. 2011. Private Pictures: Soldiers' Inside View of War. New York: I.B.Tauris. 
Stuhlmiller, Cynthia M. 1996. "Narrative Picturing: Ushering Experiential Recall." Nursing Inquiry 3 (3): $183-84$.

Taguba, Antonio. 2004. “Article 15-6 Investigation of the $800^{\text {th }}$ Military Police Brigade." http://www.npr.org/iraq/2004/prison_abuse_report.pdf.

Tarabay, Jamie. 2014. “Abu Ghraib Closes, Bitter Memories of Torture Remain | A1 Jazeera America.” Accessed April 16, 2016. http://america.aljazeera.com/articles/2014/4/15/abughraib-s-infamousend.html.

Tardini, Stefano, and Lorenzo Cantoni. 2005. "A Semiotic Approach to Online Communities: Belonging, Interest and Identity in websites and videogames Communities." Proceedings of the IADIS International Conference. 371-378.

Tucker, Bruce, and Sia Triantafyllos. 2008. "Lynndie England, Abu Ghraib, and the New Imperialism.” Canadian Review of American Studies 38 (1): 83-100.

“Under Mars Gruesome Reality Iraq War Photos. - Stormfront.” 2017. Accessed February 23, 2016. https://www.stormfront.org/forum/t238077/.

“Urban Dictionary: Doing a Lynndie.” 2004. Accessed September 28, 2016. http://www.urbandictionary.com/define.php?term=Doing+a+Lynndie\&defid=3287991 .

US Army: Fort Carson. 2011. "War Trophies/Souvenirs Information Paper.” Accessed October 4, 2016. http://www.carson.army.mil/LEGAL/documents/war-trophies-2010-info-paper.pdf.

US Department of Defense. 1013. "Prohibited Activities for US Department of Defense Personnel Present Within the US Central Command Area of Responsiblity, General Order." Accessed October 4, 2016. http://www.christianfighterpilot.com/articles/files/golc.pdf.

. 1998. “DoD Law of War ProgramDirective 5100.77.” Accessed October 4, 2016. http://biotech.law.lsu.edu/blaw/dodd/corres/pdf2/d510077p.pdf.

- 2000. "Prohibited Activities for US Department of Defense Personnel Present Within the United States Central Command, General Order.” Accessed October 4, 2016. http://cdn.factcheck.org/UploadedFiles/2013/08/GeneralOrderGO-1A.pdf.

_. 2015. "Law of War Manual.” Accessed October 4, 2016. http://archive.defense.gov/pubs/law-of-war-manual-june-2015.pdf.

US Department of the Army. 1956. "FM 27-10 The Law of Land Warfare Field Manual." Accessed October 4, 2016. http://www.aschq.army.mil/gc/files/fm27-10.pdf.

US General Councel, Department of Defense. 2015. "Department of Defense - Law of War Manual (June 2015) - Law-of-War-Manual-June-2015.pdf.” Accessed October 4, 2016. http://archive.defense.gov/pubs/law-of-war-manual-june-2015.pdf. 
"VetFriends Military \& Veteran Search! Find Army Marines Navy USAF Veterans." 2016. Accessed September 26, 2016. https://www.vetfriends.com/.

Virilio, Paul. 1989. War and Cinema: The Logistics of Perception. New York: Verso.

Warren, Caleb, and A. Peter McGraw. 2016. "Differentiating What Is Humorous from What Is Not.” Journal of Personality and Social Psychology 110 (3): 407.

Weingartner, James J. 1992. "Trophies of War: U.S. Troops and the Mutilation of Japanese War Dead, 1941-1945." Pacific Historical Review; Berkeley 61 (1): 53.

Winkler, Gary S. 2009. Tortured: Lynndie England, Abu Ghraib and the Photographs That Shocked the World. Keyser, WV: Bad Apple Books.

Wolf, Herta. 2007. "The Tears of Photography." Grey Room 29: 66-89.

"www.uruknet.info: Informazione Dal Medio Oriente: Information from Middle East: [vs-1]." 2017. Accessed February 23, 2016. http://www.uruknet.info/?p=9225.

Young, Robert J. C. 1994. Colonial Desire: Hybridity in Theory, Culture, and Race. New York: Routledge.

Zelizer, Barbie. 1998. Remembering to Forget: Holocaust Memory through the Camera's Eye. Chicago: University of Chicago Press.

— 2010. About to Die: How News Images Move the Public. New York: Oxford University Press.

Zimbardo, Philip. 2007. The Lucifer Effect: Understanding How Good People Turn Evil. Reprint edition. New York: Random House Trade Paperbacks.

Zurbriggen, Eileen L. 2008. "Sexualized Torture and Abuse at Abu Ghraib Prison: Feminist Psychological Analyses." Feminism \& Psychology 18 (3): 301-20. 